\title{
NATIONAL SCIENTIFIC MEDICAL MEETING 1997
}

\section{Abstracts}

\section{PLENARY SESSION} GENETICS

\section{(O.1) FREQUENCY OF HLA-DR4 AND HLA-DQBI*0602 IN FAMILIAL SCHIZOPHRENICS AND CONTROLS \\ S. Gibson, Z. Hawi, R. Straub', K. Kendler', D. Walsh², M. Gill.}

Department of Psychiatry and Genetics, Trinity College Dublin. 'Department of Psychiatry, University of Virginia, Richmond. ${ }^{2}$ Health Research Board, Dublin

An autoimmune pathogeneses, at least in part, has been postulated for schizophrenia. Susceptibility to autoimmunity is strongly influenced by the genes clustered in the HLA region on chromosome 6 , and linkage in a proportion of pedigrees has been reported in nearby markers. There is a negative association between schizophrenia and rheumatoid arthritis (RA), an autoimmune disease positively associated with HLA-DR4. Wright et al. (1996) postulated that there should therefore be a negative association between the DR4 allele and schizophrenia. In addition, a negative association between schizophrenia and DQB $1 * 0602$ has been reported in American blacks (Nimgaonkar et al. 1993), and Chinese males (Zhang et al. 1994). We attempted to re-examine these findings in 229 familial schizophrenic probands and 248 unrelated controls at the DRB region, and 241 familial schizophrenic probands and 257 unrelated controls at the DQB region using the PCR-SSOP technique. The frequencies of DR4 in patients and controls was respectively 35.8 per cent vs. 35.8 per cent, and the frequencies of DQBI*0602 in patients and controls was respectively 29.5 per cent vs. 27.6 per cent. These findings do not support the initial hypotheses. Some of the discrepancy may be due to study design in that the control frequencies in the Wright et al study were higher than in other samples from the region. It is also possible that the HLA association with schizophrenia is due to linkage disequilibrium with unidentified gene(s) within the HLA region which is less strong in the Irish population, particularly in the case of DQB $1^{*} 0602$ as significant results were found.

\section{GERONTOLOGY \\ (O.2) THE DRIVING HABITS OF OLDER PEOPLE \\ I. Bruce, A. Radic, B. Lawlor, *D. O'Neill. Mercer's Institute for Research on Ageing, St. James's Hospital, and ${ }^{*}$ Centre for Mobility Enhancement, Meath Hospital, Dublin 8.}

Older people rate transportation as the third most important issue in their lives after health and income'. Little is known about driving patterns and transportation use of older Irish adults: we report a community survey. The mean age was $72 \pm$ 5.4 (range $65-88 \mathrm{yr}$ ). Of 134 interviewed: 56 still drove (mean age $71.2 \pm 4.8), 59$ had never driven $(72.4 \pm 5.4)$ and 19 had stopped driving $(72.7 \pm 6.8)$. The main reasons given for stopping driving included: Health 32 per cent; expense 26 per cent; traffic 11 per cent. Of the 56 drivers, $12(21$ per cent) were on psychoactive medication. The mean Mini-Mental State Examination (MMSE) of those driving was 28.2 (range 20-30). Only 1 current driver had a MMSE of less than 23 . There were 3 patients with depression ( 5 per cent) among current drivers, but 16 per cent of former drivers were affected with depression. The number of accidents in 118 driver yrs which were reported was 5 -none of which involved any injury. Current drivers made much less use of public transport. Our results show that the self reported accident rate is low among the elderly. Driving is an important everyday function and health concerns are the major cause of driving cessation in one third of cases: Older drivers who continue to drive make less demands on public transport and appear to suffer from less depression. Health care interventions should therefore be aimed at supporting the older driver ${ }^{2}$.

References

1. Carp, F. M. et al. Gerontologist 1980; 12:11-16.

2. O’Neill, D. Rev. Clin. Gerontol. 1996; 6: 295-302.

\section{HAEMATOLOGY}

(O.3) TREATMENT OF MENINGOCCAL INDUCED PROTEIN C DEFICIENCY / PURPURA FULMINANS IN CHILDREN WITH PROTEIN C CONCENTRATE

\section{B. White, O. P. Smith.}

Department of Paediatric Haematology, National Children`s Hospital, Dublin 2.

Coagulation disturbance is an early event in the clinical course of meningoccal sepsis and low functional levels of the natural anticoagulants usually reflect disease severity. The acquired protein $\mathrm{C}(\mathrm{PC})$ deficiency seen in meningococcal infections is usually associated with purpura fulminans/septic shock - the lower its level at presentation the greater the likelihood severe morbidity and mortality. Early replacement of PC may not only limit haemostatic activation, interrupt DIC, and ultimately restore the microcirculation with improvement in organ function but it also is most likely acting as a potent antiinflammatory agent We report 10 children with purpura fulminans related to meningococcemia in whom PC concentrate together with low dose heparin was successfully used early in the course of their disease. No adverse reaction was observed during infusion or afterwards. In one patient heparin therapy was delayed by $24 \mathrm{hr}$. Haemofiltration and respiratory support was required in 9 patients during the early phase of their illness All 10 children are alive with only 1 having had limb amputation We believe that PC concentrate is safe to use in children with purpura fulminans secondary to acquired PC deficiency. Its true efficacy and safety can only be assessed via a double-blind. randomised, controlled multicentre trial. 


\section{MICROBIOLOGY}

\section{(O.4) INFECTIVE ENDOCARDITIS: EVALUATION OF THE DUKE CRITERIA AND TRANSOESOPHAGEAL ECHOCARDIOGRAPHY FOR THE DIAGNOSIS OF ENDOCARDITIS}

A. Gilleece, A. Buckley, P. Quigley, L. Fenelon. St. Vincent's Hospital, Elm Park, Dublin 4.

The purpose was (1) to review all cases of Infective Endocarditis (E) in St. Vincent's Hospital from 1991-1996, (2) to compare the Von Reyn with the Duke criteria for the diagnosis of E, (3) to compare Transthoracic echocardiography (TTE) versus Transoesophageal echocardiography (TOE) for the diagnosis of endocarditis.

Patients with a diagnosis of $\mathrm{E}$ were identified using the hospital enquiry and laboratory records. Demographic and clinical features, microbial aetiology, valve(s) infected, echocardiographic results, complications and outcome were recorded.

Twenty-five patients were identified. Demographic features were similar to previous reported series. Microbial aetiology was remarkable for the high incidence ( 28 per cent), of Staphylococcus aureus endocarditis. Six patients required surgery. The overall mortality rate was 24 per cent.

Twenty patients ( 80 per cent), had TTE performed, 6 patients, (30 per cent), had findings suggestive of E. Thirteen patients, (52 per cent), had TOE performed, 11 patients, ( 85 per cent), had findings consistent with IE.

Table I: Comparison of Von Reyn V's Duke Diagnostic criteria Diagnostic category

$\begin{array}{lll}\text { Diagnostic category } & \begin{array}{l}\text { Von Reyn } \\ \text { No. patients (\%) }\end{array} & \begin{array}{l}\text { Duke } \\ \text { No. patients (\%) }\end{array} \\ \text { Definite } & 9(36 \%) & 21(84 \%) \\ \text { Probable } & 7(28 \%) & 0(0 \%) \\ \text { Possible } & 10(40 \%) & 4(16 \%) \\ \text { Rejected } & 0(0 \%) & 0(0 \%)\end{array}$

Conclusions: The Duke criteria are more useful than the Von Reyn criteria for the diagnosis of endocarditis. TOE is far superior to TTE for the detection of IE and should be carried out in all patients in whom this diagnosis is suspected.

\section{PAEDIATRICS/PERINATOLOGY}

\section{(O.5) THE EFFECT QF SALBUTAMOL ON PEAK FLOW RATE AND OXYGEN SATURATION IN THE ACUTE ASTHMATIC ATTACK}

M. R, H. Taylor, M. McKay, C. Carrig, M. McDonald. National Children's Hospital, Harcourt Street, Dublin 2 and Trinity College Dublin.

To study the effect of salbutamol on Peak Expiratory Flow Rate (PEFR) and Oxygen Saturation (SaO2) these parameters were measured in children presenting to the Accident and Emergency Department with acute asthmatic attacks.

The children studied were all 4.75 yr or older. Measurements were made before and after $5 \mathrm{mg}$. Salbutamol administered by oxygen driven nebuliser. PEFR was measured by mini Wright peak flow meter in 2187 children, $\mathrm{SaO} 2$ was measured by pulse oximetry in 576 children.

PEFR rose by a median of 17.2 per cent of the expected value for the child's age. 2.4 per cent of attenders recorded a fall in PEFR (median-5.1 per cent, max-36 per cent, min-1.1 per cent), 7.3 per cent no change and 90.3 per cent a rise in PEFR.

$\mathrm{SaO} 2$ rose by a median of 1 per cent. 11.1 per cent of attenders recorded a fall in $\mathrm{SaO} 2$, (median-1 per cent, max-8 per cent, min -1 per cent), 20.17 per cent no change and 68.8 per cent a rise in $\mathrm{SaO} 2$.

PEFR and $\mathrm{SaO} 2$ changes were not related suggesting that the fall in $\mathrm{SaO} 2$ in some subjects was not due to increased airways obstruction but to increased ventilation perfusion imbalance. It appears advisable to use an oxygen driven nebuliser for salbutamol when this is available.

\section{REGISTRAR'S PRIZE DERMATOLOGY} (O.7) SUSCEPTIBILITY TO ULTRAVIOLET LIGHT
INDUCED IMMUNOSUPPRESSION AND SKIN CANCER.

D. B. McKenna, A. O'Grady*, T. O'Leary, E. Kay*, M. Leader*, G. M. Murphy.

Departments of Dermatology and Molecular Biology*, Beaumont Hospital, Dublin.

Ultraviolet radiation (UVR) can impair the immune system both locally and systemically which may facilitate tumour promotion. We investigated the effects Solar Simulated radiation (SSR) on the contact hypersensitivity response (CHS) in irradiated normal and non-melanoma skin cancer (NMSC) patients compared to their respective unirradiated control groups. Sixteen healthy volunteers and 19 patients with NMSC received 3 times the minimal erythemal dose on buttock skin and then sensitised with Diphencyprone (DPC) within this site. CHS was elicited 1 month later on unirradiated arm skin. Ten unirradiated healthy and 11 NMSC patients were similarly sensitised and challenged. Results show no difference in the challenge concentration to elicit $\mathrm{CHS}$ between the 2 unirradiated control groups ( $p=0.5$ ) but was higher for the irradiated normal compared to the unirradiated normal group $(p=0.03)$ and also higher for the irradiated NMSC group compared to their unirradiated controls $(p=0.001)$ signifying reduced sensitivity. This concentration was also higher in the irradiated NMSC patients compared to the irradiated normals $(p=0.03)$ (MannWhitney). 2/16 irradiated normals and 11/19 irradiated NMSC patients required a threshold concentration to elicit $\mathrm{CHS}$ that was higher than the maximum threshold concentration observed in the control groups suggesting susceptibility to UVR induced immunosuppression in these patients. This trait was significantly greater in the NMSC group, $\mathrm{p}=0.013$ (Fisher's Exact Test). These results show that a single dose of SSR suppresses the CHS in normal and NMSC patients. Because susceptibility to this effect is significantly in the later it would seem to be a risk factor for skin cancer development.

\section{GASTROENTEROLOGY}

(O.8) SEROTYPING OF HELICOBACTER PYLORI BY ELISA USING LEWIS BLOOD GROUP ANTIGENS; A NOVEL AND PRACTICAL METHOD.

M. A. Heneghan', A. P. Moran², C. F. McCarthy'. Department of Medicine', Clinical Science Institute,

University College Hospital Galway. Laboratory of Molecular Biochemistry ${ }^{2}$, Department of Microbiology, University College Galway.

It has been shown by biochemical and spectroscopic analysis 
that the Lipopolysaccharide (LPS) $\mathrm{O}$ antigen of Helicobacter pylori ( $H$. pylori) strains contain fucosylated carbohydrates with Lewis $x$ (Le $x$ ) and/or Lewis $y$ (Le y) determinants. These antigens are similar to those commonly occurring in the gastric mucosa especially in the $B$ subunit of the proton pump. Serotyping systems are being developed based on the antigenic determinants of $H$. pylori LPS. We examined 20 clinical isolates of $H$. pylori using monoclonal antibodies (MAbs) with specificities for Lewis $a, b, x, y$, sialyl Le $\mathrm{x}$ and $\mathrm{H}$ type 1 blood group antigens. 16/20 (80 per cent) of clinical isolates were typable using MAbs to Le $x$ and $y$, with $4 / 20$ strains being untypable. There was agreement between the results of Western blot analysis and serology for clinical isolates. Results of biochemical analysis of typed strains NCTC 11637, MO-19, and P466 concurred with regard to presence of Lewis $x$ and/or $y$ antigens with ELISA and immunoblotting, thus validating the serotyping system. Presence of Lewis a, b, sialyl $x$ and $H$ type 1 determinants were not found. In conclusion, serotyping of $H$. pylori using MAbs to Lewis antigens has been validated and is reproducible for a range of clinical isolates. This typing method is simple to perform and may be used potentially for strain differentiation in epidemiological studies of $H$. pylori infection.

(O.9) MULTI DRUG RESISTANCE (PGP-170) LYMPHOCYTE EXPRESSION IN CROHN'S DISEASE

R. J. Farrell*, S. Donnelly*, N. Mahmud, D. O'Toole, P. W. N. Keeling, D. G. Weir, D. Kelleher*.

Sir Patrick Dun's Research Laboratory* and Department of Clinical Medicine, Trinity College Dublin, St. James's Hospital, Dublin.

The Multi Drug Resistance gene (MDR-1) codes for a cell membrane based drug efflux pump Pgp-170 which pumps out glucocorticoids and cyclosporin actively lowering their intracellular concentration to subtherapeutic levels. Pgp-170 is expressed on lymphocytes and bowel epithelium the putative target of pharmacotherapy in Crohn's disease (CD).

We assessed MDR expression on peripheral blood lymphocytes (PBLs) in $72 \mathrm{CD}$ patients and 40 controls. Forty inactive $C D$ patients had previous bowel resections (mean 60.8 mths. post-op, range 3-192 mths.) and were off immunosuppressants at the time of MDR assessment. Twentysix required 1 resection while 14 required 2 or more resections (range 2-8). Eighteen of these patients had required azathiopnne $(1-2 \mathrm{mg} / \mathrm{kg}$ daily) therapy for at least $6 \mathrm{mths}$ in the past. Thirtytwo additional CD patients required no surgery. Eighteen had inactive $C D$ and 14 had active disease. MDR expression on PBLs was assessed by flow cytometry with intracellular staining for Pgp-170 using monoclonal antibody ISB-1.

MDR expression in the CD patients was significantly elevated only in those patients who required multiple resections (mean \pm S.E. 25.4 $\pm 5.1 \mathrm{MFI}$ ) and those who required azathiopnne maintenance (mean \pm S.E. 23.6 \pm 3.2 ) compared to controls (11.8 $\pm 1.6 \mathrm{MFI})$. Multiple regression confirmed that MDR expression was not influenced by age, sex, disease activity, duration, extent or current azathioprine therapy.

The finding of high MDR expression in refractory CD suggests that $\mathrm{T}$-lymphocytes in refractory $\mathrm{CD}$ may escape immunosuppression through upregulation of MDR expression.

\section{IMMUNOLOGY}

\section{(O.11) LYMPHOHAEMATOPOIETIC POTENTIAL OF THE ADULT HUMAN LIVER}

O. Crosbie. M. Reynolds, J. Hegarty, C. O'Farrelly. Liver Unit and Education and Research Centre, St. Vincent's Hospital, Elm Park, Dublin 4.

The aim of this study was to examine adult human liver for the presence of stem cells (the common precursor of all lymphohaematopoietic cell lines), which would support the hypothesis that the liver continues to contributes to lymphohaematopoiesis in adult life.

Hepatic mononuclear cells (HMCs) were isolated from 16 hepatic biopsy specimens. Flow cytometry was used to quantify the population of HMCs expressing the stem cell marker CD34. Methylcellulose-based tissue culture was used to demonstrate the ability of the HMC to form colonies - a function unique to stem cells and culture in association with murine foetal thymus (FTOC) was used to access the lymphocytic differentiation ability of HMCs. Flow cytometry revealed significant CD34 expression by HMCs (mean 11.9 per cent, range 2.9 - 34.6). All 3 types of lineage colonies were identified following culture of $5 \times 10^{5}$ cell aliquots from 4 liver specimens: 10.6 erythroid colonies, range (0-41), 2.6 granulocyte-macrophage colonies, range $(0-9)$ and 0.23 mixed colonies, range $(0-2)$, per $5 \times 10^{5}$ cells plated. Lymphoid differentiation was observed from HMNs following incubation in the FTOC system.

The identification of a large population of CD34+ cells and their ability to form multilineage colonies is in vitro evidence for the presence of stem cells and early progenitors in the adult human liver. The finding of stem cells in the adult liver has important implications for the understanding and future therapy of immunological disease processes originating in the liver.

\section{RESPIRATORY}

(O.13) SEQUENTIAL PHYSIOLOGICAL AND IMMUNOLOGIC EFFECTS OF TREATMENT WITH INHALED CORTICOSTEROIDS IN ASTHMA

J. L. Faul, V. J. Tormey*, C. T. Leonard, S. Horne, L. W. Poulter, C. M. Burke.

Department of Respiratory Medicine, JCMH, Blanchardstown, Dublin 15, Ireland, *Department of Immunology, Royal Free Hospital School of Medicine, London, England.

Although corticosteroids are the first line of therapy asthma, their precise effects on disease activity remain unclear. It is unknown what components of airway inflammation are the key targets of corticosteroid therapy.

This randomised, double-blind, placebo-controlled trial of high-dose inhaled fluticasone propionate (FP), $2 \mathrm{mg} /$ day, in mild/ moderate asthma, examines sequential pathophysiological effects after short-term ( 2 weeks) and then prolonged ( 8 weeks) therapy. At baseline, 2 weeks and then 8 weeks, histamine bronchial challenges, bronchial reversibility studies, and fibreoptic bronchoscopy with bronchial mucosal biopsies were performed. Frozen sections of bronchial mucosa underwent immunological analysis and numbers of immunocompetent cells were compared at the 3 time points. 
Twenty-five adult subjects (13 placebo, 12 FP) (age: $19-45$ yrs, mean: 28.5 yrs) completed the protocol. FP-treated subjects reported significantly improved asthma control compared to the placebo group. Compared to placebo, inhaled FP caused significantly increased (pre-bronchodilator) FEV 1 at 2 weeks $(\mathrm{p}<0.006)$ and 8 weeks $(\mathrm{p}<0.03) ; \mathrm{FEF}_{25-75}$ at 2 weeks $(\mathrm{p}<0.008)$ and 8 weeks $(\mathrm{p}<0.006)$ and $F E V_{1} / F V C$ percentages after 2 weeks $(\mathrm{p}<0.03)$ and then 8 weeks $(\mathrm{p}<0.03)$, in addition to significant reductions in bronchial reversibility at 2 weeks $(\mathrm{p}<0.02)$ and 8 weeks $(p<0.005)$. In terms of airway inflammation, compared to the placebo group, significantly reduced numbers of memory T lymphocytes $(\mathrm{p}=0.04)$, macrophages $(\mathrm{CD} 68+)(\mathrm{p}=0.03)$, and eosinophils EG1 $(\mathrm{p}<0.05)$ were seen after 2 weeks of therapy with inhaled FP. After 8 weeks, significant reductions in activated eosinophils EG2 ( $p=0.0057)$, and reduced HLA-DR expression $(\mathrm{p}=0.037)$ were apparent.

Conclusions: In addition to improved asthma control and bronchial reversibility, short-term ( 2 weeks) therapy with highdose inhaled FP results in significant reductions in memory $\mathrm{T}$ cells, macrophages and resting eosinophils. Prolonged ( 8 weeks) therapy causes significant reduction in eosinophil activation.

\section{Poster Presentations}

\section{ENDOCRINOLOGY/METABOLISM/LIPIDS}

\section{(1) THE RELATIONSHIP BETWEEN IN VITRO OXIDATION OF LOW DENSITY LIPOPROTEIN AND ITS VITAMIN E CONTENT}

\author{
Y. Wen, S. Killalea, P. McGettigan, J. Feely. \\ Department of Therapeutics, Trinity Centre for Health \\ Sciences, St. James's Hospital, Dublin 8.
}

Free radical mediated low-density lipoprotein(LDL) oxidation may play a causal role in pathogenesis of atherosclerosis and this may be inhibited by natural antioxidants contained in LDL. Vitamin $E$ ( $\alpha$-tocopherol) is the most abundant and active endogenous antioxidant in LDL but the relationship between its content in LDL and the susceptibility of LDL to metal ion-dependent in vitro oxidation is controversial. We investigated plasma and LDL $\alpha$-tocopherol levels and copper sulphate induced LDL oxidation in 33 middle aged healthy subjects ( 18 male). LDL was isolated from plasma by ultracentrifugation and the susceptibility to oxidation was determined as the lag phase of the production of conjugated dienes. $\alpha$-tocopherol was measured by HPLC. Linear regression analysis revealed that plasma lipid standardized a-tocopherol level is positively associated with its content in LDL $(r=0.54$ $\mathrm{p}<0.05$ ). A weak but significant correlation between the lag phase of diene production and the concentration of a-tocopherol in either plasma or LDL was found $(r=0.54$ and 0.59 , plasma and $L D L$ respectively, $p<0.02$ for both). The results suggest that copper induced in vitro LDL oxidation, the most commonly employed method for estimating the resistance of LDL to oxidative stress, may be greatly influenced by LDL vitamin $\mathrm{E}$ level and the high intake of vitamin E may possibly lower the incidence of atherosclerotic events.

The study was supported by the Irish Heart Foundation.

\section{(2) OSTEOMALACIA: UNUSUAL PRESENTATION OF MEN TYPE 1: ZOLLINGER-ELLISON SYNDROME WITH MASKED PRIMARY HYPERPARATHYROIDISM}

\author{
R. Freaney, P. Byrne, Y. McBrinn, B. Murray, \\ M. J. McKenna.
}

Metabolism Laboratory, St. Vincent's Hospital, Dublin.

We report a case of multiple endocrine neoplasia (HEN) type 1 in which the malabsorption associated with Zollinger-Ellison syndrome (ZES) may have initially masked the presence of primary hyperparathyroidism. A 29 yr old man presented with a 6 month history of weight loss, steatorrhoea, proximal muscle weakness and bone pain. At presentation ionised calcium was normal at $1.24 \mathrm{mmol} / \mathrm{L}(1.19-1.35)$. Parathyroid hormone (PTH) was raised at $87.3 \mathrm{pmol} / \mathrm{L}(0.2-5.5)$ and serum 25 Hydroxyvitamin D $(25(\mathrm{OH}) \mathrm{D})<5 \mathrm{nmol} / \mathrm{L}$. Serum gastrin was elevated at $427 \mathrm{ng} / \mathrm{L}(0-100)$ and OGD showed ulcers in the descending duodenum consistent with ZES. He was treated with a proton pump inhibitor and calciferol. He became hypercalcaemic with serum ionised calcium of $1.49 \mathrm{mmol} / \mathrm{L}$. PTH remained elevated at $42.1 \mathrm{pmol} / \mathrm{L}$ and serum $25(\mathrm{OH}) \mathrm{D}$ was normal at $53.3 \mathrm{nmol} / \mathrm{L}$. He had a total parathyroidectomy with reimplantation of one gland. The parathyroid glands were hyperplastic. Serum ionised calcium returned to normal at 1.24 $\mathrm{mmol} / \mathrm{L}$.

The malabsorption associated with ZES resulted in vitamin $D$ deficiency. The hypercalcaemia of primary hyperparathyroidism only became manifest after the hypovitaminosis D was corrected.

\section{(3) THYROID FUNCTION TESTS - HOW, WHY, AND WHAT COST?}

G. Houlihan, O. Lanigan, D. Powell.

Endocrinology Laboratory, Mater Hospital, Dublin.

Despite improvements in analytical methods for "thyroid" hormones, debate continues on the most accurate and cost effective strategy for testing thyroid function. The objective of this study was to review a cascade strategy for testing thyroid function practiced in this laboratory since introduction of Free T4 measurement in January 1996, and to review costing implications.

All assays are performed by Wallac AutoDELFIA.

Total T4 and TSH are measured as front-line test on all patients. All request forms are screened by senior staff Requests for Free T4 and/or T3 from the Endocrine and Cardiac teams, for pregnant or private patients are accepted automatically: and may be added for other patient groups. All printed reports are viewed before issue, and Free T4/T3 may be added as secondline tests to clarify results.

Data was reviewed at 2 months and 6 months, with emphasis on particular patient groups. ICU, Hepatitis clinic, GP, and maternity hospital patients; and changing reference ranges during normal pregnancy

Pattern of Free T4 Test Usage: Of 1,800 thyroid function tests in July, only 160 had Free T4 analysed. Of these, 60 per cent were processed immediately, 40 per cent followed as second-line tests. Furthermore, 50 ( 3 per cent of total requests) were not analysed for Free T4. 
Cost of Different Test Strategies where the cost of one TSH Test=1 Cost Unit

\begin{tabular}{lccccccc} 
& Workload & \multicolumn{2}{c}{ Cost Units } & \multicolumn{2}{c}{ Calculated Annual Cost Units } \\
& $\mathbf{1 9 9 6}$ & Per test & Per year & Only & TSH + FT4 & Mater \\
(+T3) & Strategy \\
TSH & 20,000 & 1.0 & 20,000 & & & \\
Total T4 & 20,000 & 0.6 & 12000 & & & \\
Free T4 & 2000 & 1.1 & 2,200 & 32,000 & 43,260 & 35,460
\end{tabular}

Conclusion: User "complaints" are extremely rare. Changing to a simpler strategy (TSH + Free T4 on all patients) would cost 22 per cent more - an extra 7,800 units this year - and does not seem necessary or justified.

\section{(4) CHOLESTEROL MANAGEMENT PRACTICES IN A GENERAL MEDICINE/CARDIOLOGY CLINIC}

\section{O’Connell.}

Department of Medicine, Meath Hospital, Dublin.

The purpose of the study was to outline treatment practises in comparison to recommended guidelines 1,2 , to investigate the frequency of lipid level measurement and side-effect monitoring.

Retrospective review of 123 patient records from 1988 to December 1996, under the following parameters: Age / Sex / Primary or Secondary prevention / lipid levels and measurement frequency / diet / drug treatment / liver function test and Creatinine Phosphokinase monitoring / response to treatment.

Eighty-six per cent of patients had lipids measured at least once, of which 69 per cent had repeat measurements at an average frequency of $\mathbf{1 2 . 6}$ months. Sixty-four per cent and 75 per cent of Primary and Secondary prevention patients respectively, with raised cholesterol, were referred for dietary intervention. Thirteen per cent had an adequate response to diet, which was sustained. Twenty-three per cent of patients with elevated cholesterol values overall were treated with either Pravastatin or Simvastatin. Four per cent did not have an adequate trial of diet initially. Of these 35 per cent had their cholesterol levels lowered to normal. Twenty-five per cent had a liver function test performed at least once. These results were within normal reference ranges. Creatinine Phosphokinase levels were not measured.

Conclusion: A significant proportion of the study population did not have repeat cholesterol measurement. Not enough patients were sent for dietary referral. A response to drug treatment was not confirmed in an adequate number of patients. Liver function tests were randomly investigated in 25 per cent of the cohort. These findings indicate that there is still room for improvement to conform to recommended guidelines in this clinic.

\section{References}

1. Guidelines for treatment of hypercholesterolaemia. The European Atherosclerosis Society. 1994.

2. NCEP(II) expert panel on detection, evaluation and treatment of high blood cholesterol in adults. 1994.

\section{(5) THYROID STIMULATORS IN SERA FROM BREAST CANCER PATIENTS}

M. T. Kilbane, P. P. A. Smyth, D. F. Smith, M. J. Murray,

S. G. Shering, E. W. M. McDermott, N. J. O'Higgins.

Endocrine Laboratory, Department of Medicine and

Therapeutics, Department of Surgery, St Vincent's Hospital, University College Dublin.

Sera from 17 patients with breast cancer were assayed for thyroid peroxidase antibodies (TPO.Ab) using a direct radioimmunoasay and thyrotropin receptor antibodies (TRAb) by radioreceptor assay. TPO.Ab were present in $7 / 17$ breast cancer patients and all were TRAb negative. The ability of serum from patients with breast cancer to exert a positive stimulatory effect was tested on 2 cultured cell lines normal rat thyroid (FRTLS) and human breast cancer (MCF7). Cell lines were grown to confluency, plated and incubated for $48 \mathrm{~h}$ with antibody positive and negative serum from patients with breast cancer made up in hormone depleted media. Responses to stimulation were determined using an eluted stain (ESTA) bioassay system. Incubation of FRTL5 cells with TSH $(0.1-100 \mathrm{mU} / \mathrm{l})$ produced a dose-dependent response which was absent in MCF7 cells. Significant stimulation in terms of formazan production in FRTLS cells was seen in $6 / 17$ patients with breast cancer. This stimulatory effect was abolished by inclusion of anti IgG in the incubation medium. In contrast only 1 serum produced a stimulatory effect in MCF7 cells. These findings suggest that the action of the observed stimulators, possibly IgG structured, are confined to cultured thyroid cells.

\section{(6) THE ROLE OF THE PITUITARY AND THE KIDNEY IN THE MAINTENANCE OF NORMAL ALDOSTERONE LEVELS}

T. M. Fiad, T. P. Smith. M. Culliton, T. J. McKenna. Department of Investigative Endocrinology, University College and St. Vincent's Hospital, Dublin.

Angiotensin II and potassium are the major stimulators of aldosterone (Aldo) production. It is also known that ACTH is a potent stimulator of Aldo production in vitro. To assess the role of ACTH in maintaining Aldo levels in vivo the relationship of Aldo and plasma renin activity (PRA) was examined in 7 ambulatory normal subjects under conditions of normal and undetectable ACTH levels. Blood samples for Aldo and PRA measurement were obtained at 2 hourly intervals for $10 \mathrm{~h}$ on a control day and following dexamethasone (Dex), $0.5 \mathrm{mg}$ every $6 \mathrm{~h}$ for $24 \mathrm{~h}$. The Aldo/PRA ratio was used as a sensitive indirect index of the responsiveness of aldosterone secretion to adrenal stimulation with angiotensin. Control day: Aldo levels fell between $8.00 \mathrm{H}, 432 \pm 60$ and $18.00 \mathrm{H}, 263 \pm 40 \mathrm{pmol} / \mathrm{L}, \mathrm{p}<0.05$, mean \pm SEM. PRA levels rose from $1.7 \pm 0.4$ at $8.00 \mathrm{H}$, to $5.6 \pm 1.1$ $\mathrm{ng} / \mathrm{ml} / \mathrm{h}$ at $12.00 \mathrm{~h}(\mathrm{p}<0.05)$ with a progressive fall occurring between $12.00 \mathrm{H}$ and $18.00 \mathrm{H}$. This was associated with lowering of the Aldo/PRA ratio between $8.00 \mathrm{H}, 290 \pm 51$ and $12.00 \mathrm{H}$, $95 \pm 15 \mathrm{pmol} / \mathrm{L}, \mathrm{p}<0.05$. Dex day: no significant change in Aldo levels was observed throughout the day. Aldo levels on control and Dex days were not significantly different. The early rise and the late fall in PRA levels was no longer seen on Dex treatment. Aldo/PRA ratio rose from $81 \pm 16$ at $14.00 \mathrm{H}$ to $174 \pm 16$ at $18.00 \mathrm{H}, \mathrm{p}<0.05$. The data support the concept that ACTH contributes to the early morning production of Aldo indicated by abolition of the fall in Aldo and the rise in PRA levels when ACTH secretion was suppressed. The tendency for Aldo/PRA ratio to rise during Dex treatment in the afternoon awaits elucidation.

\section{(7) ORAL HYPOGLYCAEMIC AGENTS - SECONDARY FAILURE MANAGED BY INSULIN}

N. B. Black L. Giblin, M. Griffin, N. O'Meara, R. G. Firth. Diabetes Unit, Mater Misericordiae Hospital, Dublin.

It is unclear to-date what is the best treatment option in the 
management of patients with NIDDM in whom conventional dietary and oral hypoglycaemic therapy has failed. This study explored the glycaemic response in a group of such patients in whom insulin was added to their usual oral hypoglycaemic agents. Eighteen patients were followed for 6 months and 12 of the 18 for 12 months. Results: Mean age was $65.6 \pm 2.2 \mathrm{y}$. HbAlC fell after 6 months treatment from $10.7 \pm 0.38$ per cent to $8.3 \pm 0.35$ per cent $(p<0.01)$ and remained significantly lower at 12 months at 8.7 \pm 0.34 per cent (Ref. range 4.2-6.2 per cent). During this treatment period no change in mean systolic or diastolic blood pressure was observed. Mean weight did not change significantly over the study period: $79.5 \pm 4 \mathrm{kgs}$ at -6 months, $80.6 \pm 4.1 \mathrm{kgs}$ at baseline, $80.1 \mathrm{kgs}$ at 6 months and $76.6 \pm 4.6 \mathrm{kgs}$ at 12 months. Once a day dosage was used in 8 cases and twice daily insulin in 10 cases. Mean insulin dose was 30 units, range 14 to 90 units; 6 of the 18 ( 33 per cent) patients reported mild hypoglycaemic symptoms but no subject reported severe hypoglycaemia. In conclusion insulin proved a useful adjunct to therapy, following secondary failure of oral hypoglycaemic agents, with respect to measures of glycaemic control without any demonstrable adverse effect on weight or blood pressure.

\section{(8) OESTROGEN INHIBITS IN VITRO OXIDATION OF LOW-DENSITY LIPOPROTEIN BUT NOT IN VIVO}

Y. Wen, *M. Doyle, *R Harrison, J. Feely. Department of Therapeutics, Trinity Centre for Health Sciences, St. James's Hospital, Dublin 8 and *Academic Department, Obstetrics and Gynaecology, RCSI, Rotunda Hospital, Dublin 1.

Vitamin E, the most important lipophilic antioxidant, protects biological materials from free radical mediated oxidation but it is oxidised and loses its antioxidant function. Oestrogen is thought to be antioxidant and may regenerate vitamin $\mathrm{E}(\alpha-$ tocopherol). We investigated the possibility that oestrogen may inhibit ex vivo low-density lipoprotein(LDL) oxidation by reducing the consumption of $\alpha$-tocopherol. We also studied if oral hormone replacement therapy(HRT) containing oestrogen may affect in vitro LDL oxidation. LDL was isolated by ultracentrifugation. In vitro oxidation was induced by adding copper sulphate and determined as the lag phase of conjugated dienes production while in vivo oxidation was determined as the titres of autoantibody to oxidatively modified-LDL. $\alpha$-tocopherol was measured by HPLC. Addition of $17 \mathrm{~B}$-oestradiol at the concentration of 1 to $8 \mu \mathrm{mol} / /$ showed a significant inhibition to oxidation in a dose-dependent manner but the consumption of $\alpha$-tocopherol over time was not delayed. In 18 healthy postmenopausal women receiving combined oestrogen/ progestogen HRT for 6 months, neither LDL vitamin E content ( $234 \pm 0.54$ vs $2.27 \pm 0.47 \mathrm{nmol} / \mathrm{mg} \mathrm{LDL}$, baseline and 6 months, respectively), lag phase ( $51.2 \pm 7.5$ vs $52.7 \pm 10.2 \mathrm{~min}$.), nor the titres of antibody to oxidised-LDL $(1.58 \pm 0.16$ vs $1.66 \pm 0.17)$ were altered. The results suggest that although in vitro oestrogen appears to be an effective antioxidant, it does not preserve vitamin E during oxidation and an in vivo antioxidant function was not seen. This lack of antioxidant effect may be due to its extremely low concentration in vivo.

The study was supported by the Irish Heart Foundation.

\section{(9) THE EFFECT OF AGE AND GENDER ON DEHYDROEPIANDROSTERONE SULPHATE (DHEAS) AND CORTISOL PRODUCTION IN HUMAN ADRENAL CELLS}

M. Rapalai, U. Fearon, D. Clarke, T. P. Smith, T. J. McKenna, S. K. Cunningham.

Departments of Endocrinology and Biochemistry, St. Vincent's Hospital, Dublin 4.

The differential control of cortisol and DHEAS may be modulated by intra-adrenal (ie. age, gender) or extra-adrenal factors. This study was designed to examine the effects of age and gender on the production of DHEAS and cortisol under basal conditions and in response to ACTH in adrenals from 29 kidney transplant donors aged 5-65 years. DHEAS production did not differ between male $(n=17)$ and female $(n=12)$ adrenals (basal: male $148 \pm 54$, female $270 \pm 111 \mathrm{nmol} / \mathrm{L}$, mean $\pm \mathrm{SE} ;+\mathrm{ACTH}$ : male $233 \pm 68$, female $355 \pm 131 \mathrm{nmol} / \mathrm{L}$ ).

Basal DHEAS production did not correlate with age in the total group $(r=0.21, p=0.28)$ or when male and female adrenals were examined separately. DHEAS production in the presence of ACTH did not correlate significantly with age in the total or female groups, but did correlate when male adrenals were examined separately (male: $r=0.57, p=0.029$ ). Cortisol production correlated with age in the total and male groups under basal conditions (total: $\mathrm{r}=0.42, \mathrm{p}=0.03$, male, $\mathrm{r}=0.61, \mathrm{p}=$ 0.019 ) and with ACTH present, but not in the female adrenals.

Since cortisol levels tended to rise with age in vitro, while DHEAS levels did not except in ACTH-stimulated male adrenals, intra-adrenal age related changes do not explain the increase in DHEAS levels occuring in vivo e.g. during adrenarche.

\section{(10) DIABETIC KETOACIDOSIS IN THE 90s: ZERO MORTALITY WITH A RECIDIVIST CORE}

\section{Z. Alavi, J. A. O'Hare.}

Department of Medicine and Endocrinology, Limerick Regional General Hospital, Dooradoyle, Limerick, Ireland:

We report the profile and outcome of diabetic ketoacidosis (DKA) at an Irish regional centre with a primary catchment area of 200,000 for diabetes care. We reviewed 92 consecutive episodes of DKA treated from 1990-96. DKA was defined as blood $\mathrm{pH}<7.30$ and/or serum bicarbonate $<15 \mathrm{mmol} / \mathrm{l}$ and urine ketostix $>++$. Patients were routinely admitted to the intensive care unit with a standard protocol (bicarbonate not used). Patient education was reviewed routinely after episodes. The mean age was $39 \pm 23$ years (s.d.) (range 10-83), 57 per cent female. Twelve per cent were newly diagnosed diabetics. Approximate average incidence was $6.7 / 100,000$ per yr. Of previously known diabetics ( $n=82), 73$ per cent had 2 or more episodes in this $7 \mathrm{yr}$ interval. At presentation (all 92): 11 per cent had coma, 5 per cent had systolic bp $<90 \mathrm{mmHg}$, pH was $7.15 \pm 0.13$ (14 per cent <6.99), glucose $36 \pm 14(11 \mathrm{per}$ cent $>50 \mathrm{mmol} / \mathrm{L})$. Outcomes: no patient died, 1 developed ARDS, 3 had acute renal failure and 1 had cerebral oedema. No identifiable cause of DKA was found in 39 per cent. Psychological/alcoholic problems were known in 25 per cent of established diabetics. While zero mortality and a low complication rate was achieved, DRA continues to be a problem in a core of patients with repeated episodes despite education and access to care. 
(11) HYPERLIPIDAEMIC GESTATIONAL PANCREATITIS DUE TO LIPOPROTEIN LIPASE DEFICIENCY AND A NEW MUTATION OF THE LIPOPROTEIN LIPASE GENE

G. Muruqasu, D. Galton*, D. Owens, G. Creedon, P. Collins, A. Johnson, G. H Tomkin.

The Adelaide Hospital, Trinity College Dublin, The Royal College of Surgeons In Ireland and *St. Bartholomew's Hospital, London.

Lipoprotein lipase (LPL) is the rate limiting enzyme for the hydrolysis of core triglycerides of chylomicrons and very-low density lipoprotein (VLDL) from the circulation. Mutations of the LPL gene can affect the catalytic activity of LPL and result in severe hypertriglyceridaemia.

A 21 yr old Indian primigravida was diagnosed at 16 weeks gestation with acute pancreatitis. Her triglyceride and cholesterol levels were markedly elevated at 29.6 and $11.8 \mathrm{mmol} / \mathrm{L}$ respectively.

Her blood pressure was $130 / 70 \mathrm{mmHg}$, urinalysis was negative for proteinuria and she had a body mass index of 21 $\mathrm{kg} / \mathrm{mz}$. LDL, HDL and triglyceride rich fraction cholesterol were $0.19,0.38$ and $9.2 \mathrm{mmol} / \mathrm{L}$ respectively.

LPL activity was reduced at $6.9 \mathrm{nmol}$ of free fatty acid $/ \mathrm{min} /$ $\mathrm{ml}$ (control 240). DNA sequence analysis revealed a homozygous substitution of cystine by tyrosine at nucleotide position 264 in exon 6 of the LPL gene.

At 4 weeks post-partum serum cholesterol and triglycerides remained elevated at 8.5 and $25.5 \mathrm{mmol} / 1$ respectively. Plasma chylomicron, VLDL, LDL and HDL levels were 5.9, $0.9,0.4$ and 1.3 respectively.

LPL deficiency in this patient resulted in severe hypertriglyceridaemia and very low levels of both LDL and HDL cholesterol, therefore we conclude this mutation of the LPL gene has profound effects on the catalytic activity of LPL. Abolishing cystine residues may have quite profound effects on the structure of the lipase. This LPL gene mutation has not to our knowledge been previousiy reported. LPL gene analysis of both father and xxXXXXXXXXXXXX

\section{GASTROENTEROLOGY}

(13) MAGNETIC RESONANCE CHOLANGIOGRAPHY (MRC) WITH A LOCAL COIL: TECHNIQUE, RESULTS AND IMPLICATIONS FOR CLINICAL PRACTICE

J. C. Varghese, M. A. Farrell, F. Murray, G. Courtney, H. Osborne, M. J. Lee

Departments of Radiology, Gastroenterology \& Surgery Beaumont Hospital, Dublin 9.

The purpose of this study is to evaluate the accuracy efficacy of MRC in diagnosing bile duct abnormalities.

A pilot study was performed comparing MRC with ERCP or direct cholangiography (DC) on 100 consecutive patients. MR images (1.5T;GE) were obtained using a shoulder coil placed on the abdomen with a heavily T2W FSE (TR/TE: 11,000/272, ETL: 32 ) sequence, matrix size $256 \times 128,1$ NEX, FOV $20 \times 20$ and contiguous $3 \mathrm{~mm}$ slices. Imaging acquisition took $44 \mathrm{~s}$, accomplished in 2 breath holds or by quiet breathing in non breath holders. Images were reformatted and prospectively correlated with ERC/DC with was performed within $24 \mathrm{~h}$.

Diagnostic images were obtained in all patients. ERC/DC showed CBD stones in 30 patients, stricture/tumour in 26 , and was normal in 44 . MRC showed stone disease in 29 patients, stricture/tumour in 27 and was normal in 44. MRC had 2 false negatives and 1 false positive for stone disease. The overall sensitivity of MRC was 96.4 per cent, specificity 95.5 per cent, positive predictive value 96.4 per cent and accuracy 96 per cent. MRC directly altered patient management in 6 patients with stone disease who failed ERCP.

MRC is a highly accurate technique for evaluating the biliary tree and can be successfully performed with a local coil and breath hold technique. Its routine use in imaging the biliary tree can now be advocated.

(Supported in part by a grant from the Charitable Infirmary Charitable Trust).

(14) INFECTION WITH HELICOBACTER PYLORI AND LEWIS ANTIGEN PHENOTYPE, LACK OF ASSOCIATION WITH LEWIS B ANTIGEN

M. A. Heneghan ${ }^{1}$, A. P. Moran², K. M. Feeley ${ }^{3}$, J. Flynn', C. L. Little', E. L. Egan ${ }^{4}$, C. E. Connolly ${ }^{3}$, C. F. McCarthy ${ }^{1}$. Departments of Medicine ${ }^{1}$, Microbiology ${ }^{2}$, Pathology ${ }^{3}$ and Haematology $y^{4}$, University College Galway, Ireland.

It has been suggested that the Lewis b $\left(\mathrm{Le}^{\mathrm{h}}\right)$ blood group antigen is a putative receptor for Helicobacter pylori (H. pylori). This antigen is predominantly expressed in secretions and on the epithelial surfaces of persons with the secretor phenotype, while those with the non-secretor phenotype preferentially express the Lewis a (Le') blood group antigen. Previously, it was reported that an increased prevalence of duodenal ulceration was found among patients with the non-secretor phenotype.

We wished therefore to determine the prevalence of $H$. pylori infection among patients with the secretor phenotype in a group of dyspeptic patients undergoing oesophagogastroduodenoscopy. Presence of $H$. pylori infection was confirmed by direct microscopy, culture and histological examination of gastric biopsy specimens. Lewis blood group phenotype (secretor status) was determined for 112 patients ( 60 men and 52 women) and 103 (54 men and 49 women) controls using a red blood cell haemagglutination technique using anti-Lewis $a$ and $b$ monoclonal antibodies.

$66 / 112$ patients were secretors compared to $73 / 103$ controls. Forty per cent (45/112) of patients were $H$. pylori positive. $26 /$ 66 (39 per cent) of secretors were $H$. pylori positive compared to $18 / 42$ ( 43 per cent) of non-secretors $X^{2}=0.024, p=0.876$.

Conclusions: These results suggest that presence of $H$. pylori infection is independent of secretor status, and that the binding of the bacteria to the putative $\mathrm{Le}^{\mathrm{b}}$ receptor observed in vitro, does not reflect that which is found in vivo.

(15) MULTI DRUG RESISTANCE (PGP-170) LYMPHOCYTE EXPRESSION IN ULCERATIVE COLITIS PATIENTS

R. J. Farrell, S. Donnelly, D. O’Toole, N. Mahmud, P. W. N. Keeling, D. G. Weir, D. Kelleher.

Sir Patrick Dun's Research Laboratory and Department of Clinical Medicine, Tnnity College Dublin, St James's Hospital, Dublin.

The Multi Drug Resistance gene (MDR-I) codes for a cell membrane based drug efflux pump Pgp-170 which pumps out glucocorticoids and cyclosponne A actively lowering their intracellular concentration to subtherapeutic levels. Pgp-170 is 
expressed on lymphocytes and colonocytes the putative target of pharmacotherapy in ulcerative colitis (UC).

We assessed MDR expression on peripheral blood lymphocytes (PBLs) in $81 \mathrm{UC}$ patients and 40 controls. Twenty had early panproctocolectomies (PPCs) within $2 \mathrm{yr}$ of disease onset for failure of, medical therapy and 21 with responsive disease had late PPCs for cancer, prevention. These patients were assessed several yrs post-colectomy (mean $4.6 \mathrm{yr}$ ). Twenty-one further patients had inactive UC and 19 had active colitis. MDR expression was assessed by flow cytometry with intracellular staining for Pgp-170 using monoclonal antibody JSB-1.

MDR expression in the early PPC group was found to be significantly elevated compared to controls, Dunnett's test p $<0.05$ (mean \pm S.E. 22.6 \pm 3.1 MFI v 11.8 $\pm 1.6 \mathrm{MFI}$ ). Multiple regression confirmed that MDR expression was not influenced by age, sex, disease activity, duration or extent.

The finding of high MDR expression in UC patients who required early panproctocolectomies suggests that therapy for refractory UC with agents that inhibit activity of Pgp-170 may potentiate the effects of conventional immunosuppressants.

\section{(16) AUTOANTIBODIES TO GASTRIN}

C. J. Larkin, J. E. S. Ardill, D. Fillmore, R. G. P. Watson, K. D. B. Buchanan.

Wellcome Laboratories, Department of Medicine, Royal Victoria Hospital, Belfast, BT12 6BJ.

The regional regulatory peptide laboratory at the Royal Victoria Hospital measures approximately 5000 gastrins annually using a plasma assay with charcoal separation. Since 1970 we have identified 3 patients with significantly high levels of gastrin autoantibodies.

Patient 1: Male aged 42 with IDDM and autoimmune atrophic gastritis: (AAG). His mother suffered AAG and diabetes. He had positive intrinsic factor, antithyroid and antigastrin antibodies. Patient 2: Female aged 34; with seropositive arthritis, allergic rhinitis and AAG. Her brother had rheumatoid arthritis. She had positive antiparietal cell and antigastrin: antibodies. Patient 3: Female aged 78 with AAG. She had positive thyromicrosomal, antiparietal cell and antigastrin antibodies.

No patient suffered dyspepsia. Gastrin levels were normal. All patients' plasma bound gastrin label in excess of 50 per cent in the absence of added antigastrin antisera. The patients' antibodies were partially purified using gel chromatography. Purified antibodies were of low titre and high affinity. They gave a 50 per cent suppression in binding on addition of between 30 and $100 \mathrm{ng} / \mathrm{l}$ of cold gastrin under radioimmunoassay condition.

In conclusion autoantibodies to gastrin are rare. All patients had concomitant AAG. All cases were associated with the presence of other autoantibodies. There were no detectable clinical symptoms attributable to gastrin autoantibodies.

\section{(17) ACTIVATED PROTEIN C RESISTANCE,} HEREDITARY THROMBOPHILIA AND INFLAMMATORY BOWEL DISEASE

\section{A. Heneghan', B. Cleary ${ }^{2}$, M. Murray², T. A. O'Gorman',} C. F. McCarthy'.

Department of Medicine', Clinical Scicnce Institute, University College Hospital Galway and Department of Haematology ${ }^{2}$, University College Hospital, Galway.

Thromboembolic events frequently complicate the clinical course of patients with inflammatory bowel disease (IBD) with this tendency occurring most frequently when the disease is clinically active, or after surgery. Thrombophilia may contribute to this tendency. Activated protein $\mathrm{C}$ resistance is the most recently described thrombophilic state and may account for up to 3010 per cent of patients with thrombophilia. We determined the frequency of a range of thrombophilic abnormalities in an unselected group of patients with IBD attending our clinics, compared to a group of controls. Disease activity was assessed using the Harvey Bradshaw index for patients with Crohn's disease (CD), and the Truelove and Witts grading system for patients with ulcerative colitis (UC). Levels of protein C, protein $S$, antithrombin III, activated protein $C$ resistance, fibrinogen and presence of a lupus inhibitor were determined. Twenty-eight patients with IBD were studied (mean age $39.5 \mathrm{yr}$, range 19-77 yr); 14 with CD ( 7 men and 7 women). Four patients had active disease. Three patients had a history of thrombotic episodes. Thirty-three controls included 23 men and 10 women (mean age $51.2 \mathrm{yr}$, range 19-89 yr). Lupus anticoagulant was detected in $7 / 28$ patients in the IBD group (UC $=4, C D=3$ ) compared to $0 /$ 33 controls. $\left(\chi^{2}=7.02, p=0.0008\right)$ No significant difference was observed between levels of thrombophilic factors between IBD patients and controls, with disease activity unrelated to levels of these parameters. Increased procoagulant activity as determined by presence of a lupus inhibitor is seen in 25 per cent of patients with IBD. Presence of other inherited thrombophilic defects are however, uncommon.

\section{(18) COMPARISON OF AN INEXPENSIVE ENDOSCOPY ROOM RAPID UREASE TEST AND THE COMMERCIAL CLO TEST}

S. Scheuner, F. Lavin, L. J. D. O'Donnell.

Department of Medicine, Mayo General Hospital, Castlebar, Ireland.

A commercially available Clo test (® Delta West Pty Ltd) is the commonest endoscopy room test used for diagnosing Helicobacter pylori in gastric biopsies. It has previously been demonstrated that the Clo test is more sensitive if 2 biopsy specimens rather than 1 are used in the assay. An inexpensive rapid urease test (AS Arvind, The Lancet. 704, $1988 \mathrm{March}$ ) may also be used in the endoscopy room to diagnose $\mathrm{H}$. pylori in biopsy material. We wished to directly compare this rapid urease test and the Clo test and to assess whether 2 biopsy specimens rather than 1 produce superior results with the Clo test. The effects of haemorrhage and a commonly used antifoaming agent on both tests were also investigated. Multiple biopsies were taken from 111 consecutive patients (mean \pm SD age: $53 \pm 19 \mathrm{yr}$ ) having an OGD. Further biopsies wete also taken in a haemorrhage area adjacent to a previous biopsy and after the administration of antifoaming agent. The results were read every 5 minutes during the first h, every 15 minutes during the second $h$, every 30 minutes during the third and fourth $h$ and at $24 \mathrm{~h}$. At $24 \mathrm{~h} 51$ of 111 Clo tests ( 46 per cent) containing 2 biopsies were positive and we regarded this as the 'gold standard' for the purpose of this study. The sensitivities of the other test systems in comparison were as follows:

$\begin{array}{lccc} & \text { CLO (2 biops) } & \text { CLO (1 biops) } & \text { Rapid Urease } \\ 15 \mathrm{~min} & 17.6 \% & 3.9 \% & 70.6 \% \\ 1 \mathrm{~h} & 64.7 \% & 35.3 \% & 86.3 \% \\ 2 \mathrm{~h} & 70.6 \% & 51 \% & 86.3 \% \\ 4 \mathrm{~h} & 76.5 \% & 60.8 \% & 86.3 \% \\ 24 \mathrm{~h} & 100 \% & 88.2 \% & 92.2 \%\end{array}$

Haemorrhage and antifoaming agent did not interfere with any of the tests. 


\section{(19) CONSULTATION PATTERNS IN THE IRRITABLE BOWEL SYNDROME}

S. Scheuner, Z. Mahmood, J. E. Gomborone*, F. Lavin, L. J. D. O'Donnell.

Department of Medicine, Mayo General Hospital, Castlebar, Ireland and *Digestive Disease Research Centre, St.

Bartholomew's \& Royal London School of Medicine \& Dentistry, London, UK.

Irritable Bowel Syndrome (IBS) symptoms are common, although not all people with IBS symptoms consult a doctor. We mounted a study to assess consultation patterns in people with IBS symptoms and to determine why IBS patients consult.

A questionnaire incorporating the Bowel Disease Questionnaire and the Rome and Manning criteria for the diagnosis of IBS was distributed to all employees attending a health screening programme at a local factory. 83.4 per cent completed the questionnaire $(427 \mathrm{~F}, 173 \mathrm{M}$; mean $\pm \mathrm{SD}$ age: 36 $\pm 9 y$ ). 21.8 per cent $F$ and 8.6 per cent $M$ had 3 or more IBS symptoms with consultation rates of 42.6 per cent $F$ and 43.8 per cent M (NS). In people with 3 or more IBS symptoms 15.7 per cent had consulted their doctor within the previous yr only, and 29 per cent prior to the previous year. In the $20-30$ year age group with 3 or more IBS symptoms, 28 per cent had consulted their doctor in the previous yr and 16 per cent prior to the previous yr; whereas in those over 50 yr 6.7 per cent consulted their doctor within the previous yr and 53 per cent prior to the previous year $(\mathrm{p}<0.05)$.

Severity of abdominal pain did not explain why people consulted as most pain was described as mild or moderate and severe or very severe pain occurred only in 17.6 per cent of consulters and 10.4 per cent of non consulters (NS). Consulters, however had pain more frequently (20.4 per cent more than once a week, compared to 12.2 per cent with non consulters; $p<0.05$ ) and had more IBS symptoms (consulters 3.6 \pm 0.7 ; non consulters $3.1 \pm 0.4 ; \mathrm{p}<0.05)$.

The prevalence of IBS symptoms is similar in all age groups, but people, tend to consult at a younger age. People with IBS symptoms who consult doctors have pain more frequently rather than severe pain, and have multiple symptoms.

\section{NEUROLOGY/NEUROSCIENCES}

\section{(20) MUSCLE BIOPSY AND GENETIC ANALYSIS OF A FAMILY WITH CENTRAL CORE MYOPATHY AND MALIGNANT HYPERTHERMIA}

D. Ryan, C. Keohane, M. Lehane, J. J. Heffron, T. McCarthy. Cork University Hospital and University College Cork.

We investigated a $53 \mathrm{yr}$ old mother (case 1) and her $20 \mathrm{yr}$ old son (case 2), who suffered from a previously undiagnosed myopathy. Thirty-two members of their 74 member kindred, spanning 5 generations, were affected. One 3 yr old had previously undergone muscle biopsy, without a definite diagnosis.

Both had mild generalised muscle weakness for many yrs; in case 1 , help was required walking up stairs. ECG, echocardiography and serum triglycerides were normal in each case. In case 1 the resting CPK was at the upper range of normal and electromyography showed changes suggestive of a primary muscle disturbance. In case 2 the resting CPK was elevated and EMG showed minor myopathic changes. Because of a suspicion of susceptibility for malignant hyperthermia ( $\mathrm{MH})$, muscle biopsy with suitable precautions was performed.

In vitro muscle contraction studies revealed $\mathrm{MH}$ susceptibility in both cases. Histology and histochemistry showed single or multiple cores, mainly in type 1 muscle fibres. Type 1 muscle fibres predominated in each case. Cores were present in 85 per cent of fibres in case 1 and in 53 per cent of fibres in case 2. Electron microscopy showed disruption of the myofibrils with retention of $Z$ lines, in keeping with structured cores. Genetic linkage analysis on blood from these 2 patients and other relatives showed localisation of myopathy to chromosome 19, but a mutation has not yet been identified. A diagnosis of central core disease and malignant hyperthermia susceptibility was made.

Central Core Disease is an autosomal dominant inherited congenital myopathy which may be fatal in the neonatal period. It is closely associated with $\mathrm{MH}$, a potentially fatal disorder, triggered in susceptible individuals by inhalational anaesthetics and depolarising muscle relaxants. Both conditions are related to defects in the ryanodine receptor gene (RYRI), located on chrornoiome 19.

\section{(21) A STUDY OF VITAMIN E AND VISUAL EVOKED POTENTIAL IN CYSTIC FIBROSIS}

\author{
P.C. Dodd*, D. O’Donnell**, J. Dowsitt**, J. M. T. \\ Redmond*, M. X. Fitzgerald**.
}

*Department of Neurology, St. James's Hospital, St James's Street, Dublin 8. ${ }^{* *}$ Department of Medicine, St. Vincent's Hospital, Elm Park, Dublin 4.

Cystic Fibrosis (C.F.) may be associated with chronic malabsorption of fat soluble vitamins, including Vitamin E. Vitamin E deficiency may cause neurological disturbances, including myopathy, progressive spino-cerebellar degeneration, peripheral and optic neuropathy.

The aim of this study was to investigate the relationship between vitamin $E$ levels and optic nerve function, as assessed by visual evoked potentials (V.E.P.s), in a group of patients with C.F.

The research protocol was passed by the Ethics Committee in St. Vincent's Hospital. Following informed consent, 20 patients were recruited. Patients were excluded if they had previously documented eye disease, poor visual acuity, elevated c-reactive protein (C.R.P.), abnormal liver function tests, or had onset of an infective exacerbation of their respiratory disease within 1 week of the study. Fasting Vitamin $\mathrm{E}$ and total lipids were assayed, and testing of V.E.Ps performed with $48 \mathrm{hr}$. Vitamin $E$ values were expressed, in standard fashion, as the Vitamin E: lipid ratio.

Two patients had a low ratio with normal V.E.P.s, and 3 patients had abnormal V.E.P.s alone.

Conclusion: There appears to be no association between vitamin E levels and V.E.P. examination. This may result from the relative insensitivity of the standard vitamin $E$ : lipid ratio as a measure of bioavailable vitamin $E$, or from the lack of specificity of the V.E.P. for vitamin E deficiency associated optic neuropathy. 


\section{NUTRITION}

\section{(23) THE EFFECT OF GRAPE FRUIT JUICE AND NICOTINIC ACID ON BLOOD ALCOHOL CONCENTRATION}

S. C. Sharma, J. Feely.

Department of Pharmacology and Therapeutics, Trinity College, Dublin 2.

We have earlier shown that aspirin can increase the amount of alcohol absorbed orally while others have shown that grape fruit juice (GFJ) can alter the bioavailability of some drugs in the body. In this study we have investigated the effect of GFJ and nicotinic acid (a water soluble vitamin which provides NAD for alcohol dehydrogenase) on blood alcohol.

Following an informed consent 24 healthy volunteer, non habitual drinkers on no medication (10 males, 14 females) with a median age of 22 (19-26) yr participated and refrained from alcohol for at least $48 \mathrm{~h}$. On separate days each drank within 15 minutes three standard drinks $(35.5 \mathrm{ml}$ each) of 37.5 per cent vodka (total alcohol content 4.05 units) plus $200 \mathrm{ml} \mathrm{GFJ}$ or diet coke. Nicotinic acid (50 or $100 \mathrm{mg}$ ) was given $1 \mathrm{~h}$ prior to the intake of alcohol in diet coke. Venous blood was collected at 1 and $2 \mathrm{~h}$ after finishing the drink and analyzed for alcohol using enzymatic methods (Sigma diagnostics). Mean $(\mathrm{mg} / 100 \mathrm{ml} \pm$ SEM) blood alcohol when consumed in diet coke was $40.92 \pm$ $3.05 \& 33.98 \pm 2.40$ at $1 \& 2 \mathrm{~h}$ respectively. When taken in GFJ the values were $31.43 \pm 2.97$ and $32.10 \pm 2.39$ at 1 and $2 \mathrm{~h}$. respectively. One $h$ values were also significantly lower than values attained after the consumption of alcohol in diet coke ( $p<0.02$ paired ' $t$ ' test). Nicotinic acid on the other hand increased the amount of alcohol present in blood and concentrations after its $50 \mathrm{mg}$ intake were $47.79 \pm 2.68$ and 37.08 \pm 3.12 at 1 and $2 \mathrm{~h}$. respectively. Following an intake of $100 \mathrm{mg}$ nicotinic acid, the values recorded at 1 and $2 \mathrm{~h}$ were $46.55 \pm$ 5.50 and $31.43 \pm 2.97$ respectively. While the blood concentration after nicotinic acid consumption was higher from the control value at $1 \mathrm{~h}$ of alcohol consumption, there was no difference in the blood concentration obtained after $50 \mathrm{mg}$ and $100 \mathrm{mg}$ of nicotinic acid. These studies suggest that common dietary constituents may have a significant influence on blood alcohol.

\section{PHARMACOLOGY/THERAPEUTICS}

\section{(24) RELATIONSHIP BETWEEN HEART RATE AND VARIABILITY (HRV) DURING BETA-RECEPTOR MODULATION IN MAN}

B. Silke, K. Taylor, J. G. Riddell.

Department of Therapeutics, The Queen's University of

Belfast, Whitla Medical Building, 97 Lisburn Rd, Belfast, BT9 7BL.

HRV parameters predict survival in cardiovascular disease. The extent to which altered HRV parameters merely reflect the strong correlation with the underlying heart rate has not been defined. Heart rate data from 12 volunteers $(22: 00$ to $06: 00 \mathrm{~h}$ ), after oral placebo, celiprolol $200 \mathrm{mg}$ (beta partial agonist) or propranolol $80 \mathrm{mg}$ (beta antagonist), investigated the relationship. All short term variables were linearly correlated but long-term variables exponentially related to the underlying heart rate.
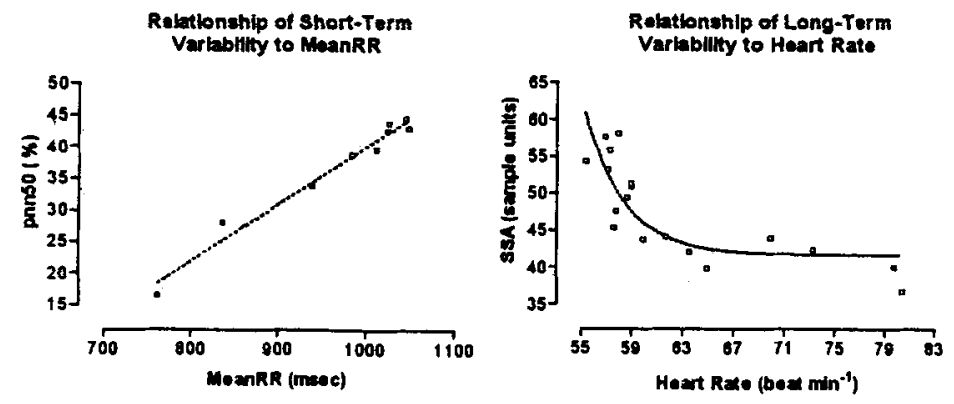

Conclusion. HRV increased following propranolol and decreased after celiprolol. The conventional time-domain HRV parameters do not permit an evaluation of whether variability is altered independent of heart rate or is entirely a consequence of the change in heart rate.

\section{(25) BLOOD PRESSURE DETERMINATION WITH THE FINAPRES}

D. McAuley, B. Silke, S. Farrell.

The Department of Therapeutics and Pharmacology, The Queen's University of Belfast.

The blood pressure (BP) wave-form is modified on distal propagation. The consequent effects on peripheral BP are increased systolic, reduced diastolic and essentially unaltered mean BP (I). The Finapres measures peripheral BP using the voltage clamp principle; it has not been validated under altered physiological conditions and during pharmacodynamic interventions. We studied simultaneous Finapres and brachial BP (using an automated sphygmomanometer) in 10 normal volunteers at rest, during dynamic exercise and a cold pressor test (CPT). The effects of propranolol and celiprolol were examined.

The Finapres systolic pressure was higher than brachial during all 3 test states $(\mathrm{p}<0.05)$. The difference between the systolic pressures measured by the 2 devices increased significantly during the CPT $(\mathrm{p}<0.05)$. The Finapres diastolic pressure was higher than brachial during exercise and the CPT $(p<0.05)$. The differences increased significantly over time $(p<0.05)$. Pharmacodynamic interventions had no significant interaction with the pressure differences $(p>0.05)$.

The results suggest the Finapres can provide BP information which is robust under most circumstances. Although pharmacodynamic intervention did not alter the relationship between the peripheral and central BP as this dynamic relationship is sensitive it is possible that the Finapres could be less reliable where more potent vasoactive measures are administered.

\section{(26) ALTERED 2-METHYL-1,3-BUTADIENE (ISOPRENE) IN HEART FAILURE}

R. Patrick', B. Silke ${ }^{2}$, L. T. McGrath ${ }^{2}$.

Department of Chemistry ${ }^{1}$ and Department of Therapeutics ${ }^{2}$, The Queen's University of Belfast, 97 Lisburn Rd, Belfast.

Polyunsaturated fatty acids in membranes are susceptible to free radical attack resulting in a variety of fragmentation products which include aldehydes and volatile alkanes. One of these volatiles, isoprene, has been shown to reflect in-vivo free radical activity. Reperfusion of ischaemic tissue following 
exercise in heart failure may result in free radical generation and lipid peroxidation with altered isoprene production.

Twenty-eight healthy controls and 10 patients with heart failure were fasted overnight. Breath was collected via a twoway non rebreathing valve into a $60 \mathrm{~L}$ non-diffusing gas collection bag. The collection tubes equilibrated for 60 seconds, the breath being vented to air via a three way tap. Breath was then directed into the collection bag and collected for 3 minutes. A sample of ambient air was collected at the same time. A measured aliquot of sample was drawn through a gas adsorption tube packed with poropak-Q. Volatile organic content of the absorbed samples was analysed by thermal desorption GC/MS and isoprene production rate calculated as mass per minute per $\mathrm{kg}$ body mass.

$$
\begin{array}{cccc} 
& \text { Controls }(\mathrm{n}=28) & & \text { Patients }(\mathrm{n}=10) \\
\text { rate }(\mathrm{ng} / \mathrm{min} / \mathrm{kg}) & 11.4 \pm 7.4 & \mathrm{p}<0.05 & 5.6 \pm 5.2
\end{array}
$$

Contrary to expectations production rate was decreased in patients. As production reflects free radical damage in real time this may be due to substrate depletion in patients.

\section{(27) RESPONSE TO COCAINE: DIFFFERENCES} BETWEEN IRISH, IRANIAN AND CHINESE SUBJECTS

J. Feely, J. H. Hosseini.

Department of Pharmacology and Therapeutics, Trinity College, Dublin 2.

There is increasing evidence of ethnic differences in drug response which cannot be explained by differences in drug disposition. To further investigate this we measured the pupillary response (by infra-red photography) to 3 concentrations (low, medium, high) of a constricting (pilocarpine $0.25,0.5$ and 1.0 per cent) and dilating (cocaine $0.5,1.0$ and 2.0 per cent) agent in 31 Caucasian (Irish), 18 Chinese and 26 Iranian healthy subjects aged 18-26 yr. Pupillary diameter was measured before and following increasing concentrations of eye drops. Irish subjects were significantly $(p<0.01)$ more responsive than Iranian or Chinese subjects to cocaine and pilocarpine. Iranian subjects had a larger response $(\mathrm{p}<0.05)$ to medium and high concentrations of cocaine and medium concentrations of pilocarpine than Chinese subjects. Some of these differences were explicable in part by eye colour with blue and green eyed subjects being more responsive $(p<0.01)$ than brown eyed subjects. Blue eyed Irish were the most sensitive to both drugs followed by green eyed (Iranian) subjects. Within brown eyed subjects the ranking of sensitivity to cocaine and a lesser extent pilocarpine was Irish $>$ Iranian $>$ Chinese. These studies provide additional evidence underlying the importance of ethnic pharmacology.

\section{(28) BEHAVIOURAL PHENOTYPE OF TRANSGENIC DIA DOPAMINE RECEPTOR 'KNOCK-OUT'}

\section{J. Clifford ${ }^{1}$, O. Tighe ${ }^{2}$, D. T. Croke ${ }^{2}$, J. Drago ${ }^{3}$, D. R. Sibley ${ }^{4}$. J. L. Waddington'.}

Departments of 'Clinical Pharmacology \& ${ }^{2}$ Biochemistry,

Royal College of Surgeons in Ireland, Dublin 2; ${ }^{3}$ Department of Anatomy, Monash University, Australia; ${ }^{4}$ NINDS, Bethesda, USA.

The $D_{1}$-like dopamine receptor family $\left[D_{1 A-D}\right.$ ] plays a fundamental role in the regulation of psychomotor behaviour but drugs selective for this family are unable to distinguish between individual members thereof. Targeted gene deletion has been applied to generate mice having 'knockout' of $D_{1 A}$ receptors. We describe here the ethological evaluation of spontaneous behaviour therein. Homoygous 'knockout' $\left[\mathrm{D}_{1 \mathrm{~A}}{ }^{-\mathrm{T}}\right]$ and wildtype controls $\left[\mathrm{D}_{1 \mathrm{~A}}{ }^{+/+}\right]$were genotyped among the offspring of heteroygous $\left[\mathrm{D}_{1 \mathrm{~A}}{ }^{+/}\right.$] matings; young adult 'knockouts' showed reduced body weight [black females, $\approx 8$ weeks: $D_{1 \mathrm{~A}}{ }^{+/+} 19 \pm 3 \mathrm{~g} ; \mathrm{D}_{1 \mathrm{~A}}{ }^{-1-} 13 \pm 5 \mathrm{~g}, \mathrm{~N}=9-11-34$ per cent, $\mathrm{P}<0.02]$, in the absence of gross neurological deficit. Spontaneous behaviour was evaluated using an ethological approach. Relative to wild-types, $D_{1 \mathrm{~A}}$ 'knockout' was associated with: reductions in sniffing $[-11 \%, P<0.01]$, rearing free $[-87$ per cent, $P<0.01]$, and sifting $[-60$ per cent, $P<0.01]$ and chewing $[-63$ per cent, $P<0.05]$ of cage bedding/faecal pellets; increases in locomotion [ +31 per cent, $\mathrm{P}<0.05]$, grooming $[+66$ per cent, $P<0.01]$ and intense grooming $[+78$ per cent, $P<0.01]$ with no other significant alterations in their ethogram. There were very few correlations between body weight and individual behaviours. Though abnormalities of spontaneous behaviour in $D_{1 \mathrm{~A}}$ 'knockout' mice were evident, they could not be encapsulated as either hypo- or hyper-activity; rather, there were significant shifts between multiple individual elements of behaviour. It remains to be established whether other $D_{1}$-like receptors, compensatory mechanisms subsequent to developmental absence of $D_{1 \mathrm{~A}}$ receptors or other mechanisms, perhaps related to the complex genetic background of these animals, contribute to these effects.

These studies were supported by RCSI.

\section{(29) FEATURES OF ANTI-DEPRESSANT PRESCRIBING IN IRELAND}

P. McGettigan, A. Kelly*, M. Carvalho*, J. Feely. Pharmacoepidemiology Unit, Department of Therapeutics and * Department of Community Health, Trinity College, Dublin.

Anti-depressants should normally be used at full dosage for some months. In Ireland, in the General Medical Services (GMS) scheme, anti-depressant prescribing is rising by 7 per cent 8 per cent yearly, due mainly to increasing use of selective serotonin reuptake inhibitors (SSRIs). In the Eastern Health Board area, during 11 months of 1995, an average of 11,741 anti-depressant prescriptions / month was dispensed (70 per cent to females), tricylic agents (TCAs) comprising 67 per cent, SSRIs 26 per cent and 'others' 7 per cent. Some 1.5 per cent of prescriptions had 2 or more anti-depressants, while hypnotics were coprescribed in 30 per cent, anxiolytics in 30 per cent, antiepileptics in 5 per cent and anti-psychotics in 2 per cent. Some 8895 patients, 25 per cent of all individuals receiving a prescription, were dispensed an anti-depressant on 1 occasion only (TCA 64 per cent, SSRI 32 per cent, others 4 per cent). Of 3030 patients who commenced and continued therapy with TCAs ( 65 per cent) or SSRIs ( 35 per cent) between month 3 and 7, only 12 per cent and 15 per cent respectively collected a prescription every month, with little difference among the remainder in the drop-out rate. Some 26 per cent of those on TCAs but just 2 per cent of SSRI patients were continuously on less than 50 per cent of defined daily dose while 32 per cent and 51 per cent respectively were on $50-150$ per cent and 2 per cent and 3 per cent were on more than 150 per cent. The remainder had dose changes throughout the period. Single dispensings, poor adherence and low dose TCA use are features of antidepressant prescribing in the GMS which merit further attention. 
(30) PRESCRIBING FOR CONGESTIVE HEART FAILURE (CHF) IN GENERAL PRACTICE

J. P. Connolly, B. Silke, H. McGavock, K. Wilson-Davis. Department of Therapeutics, The Queen's University of Belfast,

The Whitla Medical Building, 97 Lisburn Rd, Belfast, BT9 7BL.

A stratified quota sample of 22 practices in Northern Ireland obtained all prescription data over $2 \mathrm{wk}$. The principle diagnosis was CHF in 383 patients. The majority were prescribed a diuretic (79.9 per cent), but few received an ACE inhibitor (18.5 per cent). The mean daily dosages were for bumetanide $(1.3 \mathrm{mg})$, frusemide $(43.2 \mathrm{mg})$, captopril $(50.3 \mathrm{mg})$, and lisinopril $(9.2$ $\mathrm{mg}$ ). Eleven CHF patients (2.9 per cent) were co-prescribed a beta-adrenoreceptor antagonist. Concurrent insomnia was common ( 11.2 per cent) in CHF, with 14.1 per cent co-prescribed a hypnotic drug. CHF was a minor indication (25.3 per cent) for ACE inhibitor compared with the hypertension indication (62.6 per cent). Despite contrary recommendations, 10.3 per cent of CHF patients taking ACE inhibitors received either potassium-sparing diuretic, or potassium supplementation. NSAID's were given for 7.5 per cent of CHF patients taking ACE inhibitors.

Treatment protocols for CHF appear to be poorly implemented in clinical practice. ACE inhibitors were under prescribed, and the dosage prescribed appeared suboptimal. The frequent diagnosis of insomnia in CHF patients may reflect inadequate symptom control; the intercurrent prescription of contra-indicated therapy is a worrying finding.

\section{(31) DO PRESCRIBING PRACTICES REFLECT THERAPEUTIC ADVANCES?}

P. McGettigan, J. Feely.

Departments of Pharmacology \& Therapeutics and Pharmacy, Trinity Centre, St. James's Hospital, Dublin 8.

Pharmacoepidemiology studies may assess how prescribing reflects therapeutic advances. Cardiovascular (CVS) and central nervous system (CNS) prescribing in a general hospital was reviewed by recording diagnoses and current drug therapy from charts and cardexs of 578 in-patients. Of 92 patients with stroke, 45 per cent were on anti-platelet agents, 13 per cent anticoagulatcd. Among 38 with atrial fibrillation, 29 per cent were on aspirin, 21 per cent anti-coagulated and 61 per cent on digoxin. Of 34 patients with myocardial infarction, 50 per cent were on aspirin, 12 per cent anti-coagulated, 21 per cent on an angiotensin converting enzyme inhibitor (ACEI) and 12 per cent beta-blocked. Forty patients had heart failure; all were on diuretics, 28 per cent on ACEIs and 45 per cent on digoxin. Of patients on aspirin (114), warfarin (26), digoxin (70) and ACEIs (42), 86 per cent, 92 per cent, 84 per cent and 95 per cent respectively had an indication. Some 119 anti-depressants (61 per cent tricyclics (TCAs), 39 per cent selective serotonin reuptake inhibitors (SSRIs)) were prescribed to 109 patients, of whom 43 per cent had listed depression/CNS disorder. All SSRIs, but only 28 per cent of TCAs, were prescribed at 100 per cent or more of defined daily dose. Some 69 per cent were on anxiolytics, hypnotics or anti-psychotics concomitantly. Not one of 236 patients on hypnotics had a diagnosis of insomnia. Though the literature supports anti-coagulant, aspirin etc. use, contra-indications/reasons for not using such therapy were rarely documented. In contrast to TCAs, SSRIs were prescribed at optimal dosage. Compared with CVS, diagnostic review of CNS therapy was less likely to reveal an indication. Pharmacoepidemiology studies, in identifying and quantifying such uptake deficits, have potential to help optimise prescribing.

\section{(32) SNAPSHOT OF PRESCRIBING IN A GENERAL HOSPITAL [NAAS GENERAL HOSPITAL]}

P. M. E. McCormack, P. McGettigan, M. Doona, J. Feely. Naas General Hospital, Naas, Co Kildare \&

Pharmacoepidemiology and Medicines Evaluation Unit, TCD, Dublin 8.

Prescribing practices have not been well documented in general, non teaching hospitals. Thie aims of this study were to describe prescriptions $[R x]$ in relation to recorded diagnoses in Naas General Hospital on a designated day using the ATC [Anatomical Therapeutic Chemical, WHO 1995] system. There were 68 evaluable patients - 42 medical and 26 surgical; 35 female and 33 male; aged $16-89 \mathrm{yr}$. The primary medical diagnosis was mainly cardiovascular-CVS [41 per cent], respiratory [ 21 per cent] cerebrovascular [ 14 per cent] and peripheral vascular [7 per cent]. Surgical diagnoses were GIT [46 per cent], trauma [ 15 per cent], malignancy [ 12 per cent], cellulitis [ 12 per cent]. Of the $379 \mathrm{Rx}$ the most common were [see table].

\begin{tabular}{|c|c|c|c|c|c|}
\hline \multicolumn{2}{|c|}{ ATC CLASS } & \multicolumn{2}{|c|}{$\%$ medical $[n=263]$} & \multicolumn{2}{|c|}{$\%$ surgical $[n=116]$} \\
\hline A & GIT agents & $17.5 \%$ & 46 & $13.8 \%$ & 16 \\
\hline B & affecting blood & $13 \%$ & 34 & $8.6 \%$ & 10 \\
\hline C & CVS agents & $25 \%$ & 66 & $6 \%$ & 7 \\
\hline $\mathbf{J}$ & anti infectives & $9.5 \%$ & 24 & $18.1 \%$ & 21 \\
\hline M & musculoskeletal & $3 \%$ & 8 & $16.4 \%$ & 19 \\
\hline $\mathbf{N}$ & CNS agents & $16.3 \%$ & 43 & $33.6 \%$ & 39 \\
\hline $\mathbf{S}$ & respiratory & $10.6 \%$ & 28 & $1.7 \%$ & 2 \\
\hline
\end{tabular}

The most common medical admitting diagnosis was circulatory [ 62 per cent] which parallelled the most common Rx - ATC class B \& C [ 38 per cent]. GIT were 7 per cent diagnoses and 18 per cent $\mathrm{Rx}$ suggesting symptomatic prescribing as in CNS - 7 per cent diagnoses and 16 per cent $\mathrm{Rx}$; in these cases chart review revealed no indication for the Rx. These results suggest trends in types of and reasons for prescribing and we found it a useful means of auditing prescribing practices in a general hospital.

\section{(33) AGE DOES NOT IMPAIR ENDOTHELIAL FUNCTION}

D. McAuley, S. Maguire, C. McGurk, A. G. Nugent, C. Hanratty, D. P. Nicholls, G. D. Johnston.

The Department of Therapeutics and Pharmacology, The Queen's University of Belfast.

Endothelial dysfunction is an important initiating event in the development of atherosclerosis. Impaired endothelial function with advancing age could promote atherosclerosis. The evidence for age related impairment of endothelial function in human studies is contradictory ${ }^{1,2}$. The aim of this study was to determine whether endothelial function is altered with age. Sixteen healthy young subjects and 10 healthy older subjects underwent brachial artery cannulation. Acetylcholine ( $\mathrm{ACh}$ ) was infused to assess endothelium-dependent vasodilatation. Forearm blood flow (FBF) was measured during drug infusion using venous occlusion plethysmography. Results were 
expressed as change in FBF from baseline ( $\mathrm{ml} 100 \mathrm{ml}^{-1} \mathrm{~min}^{-1}$ ) and analysed using repeated measures analysis of variance with basal blood flow as a covariate. There was no significant difference in response between the groups in response to $\mathrm{ACh}$ ( $p>0.05$ ). In conclusion ageing is not associated with impaired en tothelial function in healthy subjects. This suggests that advancing age alone does not explain the increased atherosclerosis seen in the elderly.

\section{References}

1. Celermajer, D. S. et al. Aging is associated with endothelial dysfunction in healthy men years before the age-related decline in women. J. Amer. Coll. Cardiology 1994; 24(2): 471-6.

2. Imaizumi, T. et al. Age-independent forearm vasodilation by $\operatorname{xxxxxxxx}$

\section{RHEUMATOLOGY AND REHABILITATION}

\section{(34) ULTRASOUND IN THE DIAGNOSIS AND TREATMENT OF PLANTAR FASCIITIS}

D. Kane', T. Greaney ${ }^{2}$, B. Bresnihan ${ }^{1}$, R. G. Gibney ${ }^{2}$, O. Fitzgerald'.

Departments of Rheumatology', and Diagnostic Imaging ${ }^{2}$, St. Vincent's Hospital, Dublin 4.

Plantar fasciitis is diagnosed on the basis of heel tenderness localising to the medial tubercle of the calcaneus. Stress fracture of the os calcis and tarsal tunnel syndrome may present identically and cannot be completely differentiated on clinical examination or by plain radiography. Ultrasound examination of the heel has recently been reported to have a high specificity and sensitivity for the diagnosis of plantar fasciitis.

Four patients who presented with localised heel pain diagnosed as plantar fasciitis on clinical examination and unresponsive to injection of triamcinolone and local anaesthetic - underwent ultrasound examination with a $10 \mathrm{MHz}$ linear array transducer.

The following features were noted on ultrasound examination of all 4 patients:- 1$)$ increased mean maximal thickness $(6.16 \mathrm{~mm}$ $v 4.1 \mathrm{mnm}$ ) of plantar fascia in symptomatic heels as compared to asymptomatic heels; 2) loss of distinction and parallelism of the borders of plantar fascia and 3) hypoechogenicity of the plantar fascia in symptomatic heels. Ultrasound guided injection resulted in persistent relief (mean $=24$ months) in 3 cases. One patient developed a recurrence of symptoms after 6 months and awaits further injection.

Conclusion: Ultrasound of the heel is a useful investigation in confirming the diagnosis of plantar fasciitis. Ultrasound guided injection produced a good clinical response when unguided injection had failed. A prospective trial comparing guided to unguided injection is in progress.

\section{(35) ULTRASONIC EXAMINATION OF PSORIATIC DACTYLITIS}

D. Kane ${ }^{1}$, T. Greaney², B. Bresnihan', R. G. Gibney ${ }^{2}$, O. Fitzgerald ${ }^{1}$.

Departments of Rheumatology ${ }^{1}$, and Diagnostic Imaging ${ }^{2}$, St. Vincent's Hospital, Dublin 4.

Dactylitis in psoriatic arthritis is thought to be due to a combination of flexor tenosynovitis and articular synovitis. However clinical examination of the metacarpophalangeal and interphalangeali joints is difficult when flexor tenosynovilis is present. We describe the ultrasonographic features of dacylitis in a series of patients with psoriatic arthritis.

Thirteen consecutive patients were included. Nine had dactylitis of the fingers and 4 had toe involvement (total of 19 digits). Ultrasonography of digits was performed in long and short axis using a $10 \mathrm{MHz}$ linear array transducer. Flexor lendon complex and joints were compared with opposite uninvolved digits. Changes were correlated with plain film findings.

Diffuse flexor tenosynovitis was confirmed in nearly all digits (95 per cent) while half had evidence of articular disease (56 per cent). One demonstrated involvement of joints only ( 5 per cent). Thirty-six per cent had erosions on plain film.

Other abnormal features detected by ultrasound included 1) thickened, hypoechoic nexor tendon shcath; 2) asymmetry and irregularity of synovial thickening in the tendon sheath; 3 ) extension of tendon sheath thickening into palm; 4) peri-articular synovial thickening; 5) thickened flexor tendon; 6) thickened extensor tendon; 7) joint effusion; 8) joint deformity; 9) cortical erosion; 10) thickened subcutaneous tissues.

Conclusion: While flexor tenosynovitis and articular synovitis are the most consistent findings in psoriatic dactylitis, ultrasound demonstrates a wider spectrum of abnormal findings in dactylitis than would be obtained on clinical examination. Ultrasound is better at differentiating the components of dactylitis than clinical examination.

\section{(36) EVIDENCE FOR INCREASED BONE TURNOVER IN PATIENTS WITH DYSTROPHIC CALCIFICATION}

\author{
E. Murphy, R. Freaney, B. Bresnihan, M. McKenna, \\ O. FitzGerald. \\ St. Vincent's Hospital, Dublin 4.
}

Dystrophic calcification is a recognised complication of progressive systemic sclerosis (PSS) and dermatomyositis (DM). The mechanism underlying this process is unclear and treatment strategies unsuccessful. The aim of this study was to assess bone turnover in patients with and without calcinosis.

Three groups of patients were studied: A) PSS/DM with extensive calcinosis; B) PSS/DM with limited or no calcinosis; C) pre-menopausal females on steroid therapy for asthma. Blood and urine samples were obtained for measurement of the following: 1) Markers of bone formation [serum procollagen 1 carboxypeptide (PICP), osteocalcin (OC) and bone alkaline phosphatase (BAP)]; 2) Markers of bone resorption [urinary pyridinoline (UPYR/Cr), urinary D-pyridinoline (UDPYR/Cr) and urinary hydroxyproline (UOHP/Cr)]; 3) Parameters of calcium metabolism including serum ionized calcium (Cai) and parathyroid hormone (PTH) and urinary calcium/creatinine ratio $(\mathrm{U} \mathrm{Ca} / \mathrm{Cr}$ ). Normal healthy controls were used to establish a standard reference range.

Figures in brackets indicate standard deviation.

PIPC OC BAP UPYR/Cr UDPYR/Cr UOHP/Cr Cai PTH U Ca/Cr $\begin{array}{llllllllll}(72-196) & (4.6-23) & (1-21.5) & (<40) & (<8.9) & (6.5-27.4) & (1.19-1.35) & (2-52) & (0.07-0.41)\end{array}$ A $\quad 166.1(44.7) \cdot 13.9(9.1) \quad 20.5(9.5) \quad 128.9(46.9) 15.7(3.1) \quad 52.3(14.4) \quad 1.2(0.03) \quad 52.6(16.2) \quad 0.08(0.08)$ $\begin{array}{llllllllll}\text { B } & 122.4(31.2) & 11.6(6.1) & 8.2(2.7) & 52.7(18.8) & 8.6(2.4) & 25.8(11.9) & 1.3(0.05) & 31.8(16.4) & 0.24(0.16)\end{array}$ $\begin{array}{lllllllll}\text { C } 98.0(45) & 6.2(1.1) & 8.5(1.1) & 33.0(1.1) & 6.1(1.9) & 30.2(16.2) & 1.2(0.05) & 37.2(14.0) & 0.37(0.24)\end{array}$

Conclusion: Results suggest that bone formation is slightly increased in those with DM/PSS and extensive calcinosis. However, significantly elevated bone resorption is seen in this group alone. As a rise in $\mathrm{U} \mathrm{Ca} / \mathrm{Cr}$ is not observed, this suggests a mechanism for deposition of calcium in the soft tissues of $x x$ $\mathrm{x} \times \mathrm{x} \times \mathrm{x} \times \mathrm{x} \times \mathrm{x}$ 


\section{GENERAL PRACTICE}

(37) HIDDEN CAUSES OF FATIGUE IN GENERAL PRACTICE

M. F. Grehan.

Department of General Practice, Rath Cottage, Ardee Rd., Dundalk, Co. Louth.

It was noticed in the practice on routine testing that young pregnant women showed very low levels of Vitamin B 12 when their Folic Acid and B 12 was screened in early pregnancy. Was this a factor of early pregnancy of were we unaware that this might be a factor in the general population? A retrospective study was undertaken in the practice of all patients having blood taken in the previous $3 \mathrm{yr}$. This looked at 1014 individual patients, their levels of B12, Folic Acid, Liver Function Tests, Thyroid Function Tests, and W.C.C.'s. All patients were under $60 \mathrm{yr}$ of age. The youngest patients $2 \mathrm{yr}$ of age. The highest groups showing abnormal results were under 35 yr of age. Low levels of B 12 were present in 41 per cent of 1 age group Abnormal L.F.T's were present in 51 per cent of one age group. One in 15 patients had abnormal T.F.T's. The most common presenting feature was fatigue.

\section{(38) PERSONALITY, LIFESTYLE AND ETHNICITY INFLUENCES ON MENTAL HEALTH AMONG MEDICAL STUDENTS}

R. Siriwardena, H. McGee, A. W. Murphy, N. Britten ${ }^{1}$. Department of General Practice, Royal College of Surgeons in Ireland, Dublin 2; 'UMDS, London SW 12.

Medical students have been found to suffer higher stress ${ }^{1}$, anxiety ${ }^{2}$ and emotional distress levels ${ }^{3}$ than the general population. The objective of this study is to measure levels of anxiety and depression among medical students and to determine associations, if any, with individuals levels of self efficacy and self esteem. It will also examine the influence of lifestyle features, personality and ethnicity on these results.

The Royal College of Surgeons in Ireland Medical School (RCSI) has over one thousand undergraduate medical students from 78 different countries. Classes are truly multicultural and multiethnic facilitating the conduct of this study.

The method used is an anonymous self administered questionnaire administered to all students at the RCSI. The areas examined in the questionnaire are: self efficacy using the generalised self-efficacy scale, self-esteem using Rosenberg's self-esteem (RSE) scale, somatic symptoms, anxiety and insomnia, social dysfunction and severe depression using the 28 item General Health Questionnaire (GHQ-28), stressful events that the student has experienced in the yr preceding the questionnaire and individual demographic data. Data has been collected from over 900 students. The above data is currently being analysed and will be available in April 1997.

Discussion: As part of the project, a sensitive literature search has been conducted and the results of this project will be placed in the context of the international literature.

References

1. Firth, J. Levels and sources of stress in medical students. British Medical Journal, Volume 292, 3 May 1986.

2. Ashton, C. H., Kamali, F. Personality, lifestyles, aicohol and drug consumption in a sample of British medical students. Medical education 1995; 29: 187-192.

3. Firth-Cozens, J., Morrison, L. Sources of stress and ways of coping in junior house officers. Stress medicine. Vol. 5: 121-126.
(39) SYMPTOM CONTROL IN PATIENTS WITH

HELICOBACTER PYLORI ANTIBODIES: A STUDY FROM A GENERAL PRACTICE

D. Smith, B. D. Bonar.

Dungloe Medical Centre, Dungloe, Co. Donegal.

The purpose of this study is to determine the extent of symptom control following triple therapy in symptomatic patients with Helicobacter Pylori ( $\mathrm{Hp}$ ) infection.

Blood serology to determine the presence of $\mathrm{Hp}$ infection were performed on 87 patients presenting to their General Practitioner with uncomplicated dyspepsia or for repeat prescription of longterm anti-ulcer medication. Positive tests were treated with a standard triple therapy regime. Follow-up was by postal questionnaire. Main outcome measures were subjective symptom control, experience of side-effects and reported compliance assessed no less than 3 months after completion of treatment.

Sixty-six patients tested positive for $\mathrm{Hp}$ infection and were treated accordingly. Of 65 questionnaires sent out, 46 were returned. Twenty-five patients ( 55 per cent) indicated that they were cured; 5 (10.8 per cent) were improved; 7 (15.2 per cent) unchanged; 7 (15.2 per cent) relapsed and 1 . (2 per cent) disimproved. Nine patients (19.5 per cent) experienced sideeffects and 44 (95.6 per cent) reported full compliance.

We concluded that with a low side-effect profile, approx. half of our patients receiving appropriate triple therapy gained complete relief of their symptoms.

\section{GERONTOLOGY}

(40) MALNUTRITION IN AN ACUTE GERIATRIC UNIT: ITS IDENTIFICATION, ASSESSMENT AND TREATMENT

\author{
R. Charles, S. Mulligan, D. O'Neill.
}

Departments of Clinical Nutrition and Age Related Health Care, Meath Hospital, Dublin 8.

Malnutrition among the over 65 's has been well documented. Causes are muitifactorial and have been shown to carry a huge cost burden. A study was undertaken to 1) assess the incidence and development of malnutrition on admission to and during length of stay within our unit, 2) assess the efficacy of clinical nutrition support and intervention and 3) design a screening tool for those most at risk of malnutrition.

Forty-nine consecutive admissions were recruited. Thirtythree parameters were assessed on admission and during length. A diagnosis of malnutrition was made according to a specifically designed flow chart. All patients received nutrition intervention. A screening tool was devised and circulated to Medical Registrar, Registered General Nurse and Dietitian for completion.

There was an 84 per cent incidence of malnutrition on admission. In those not initially malnourished there was a 29 per cent disimprovement from baseline nutritional status during hospitalisation. Nutrition intervention resulted in a 71-75 per cent improvement from baseline status. Inter-rater reliability for the screening tool was 99 per cent.

Conclusions: Malnutrition featured prominently on admission and during hospitalisation. Screening is essential for early identification and prompt treatment, as the costs of malnutrition are reduced once those at risk are screened, identified and treated. Geriatric assessment should not be considered complete 
unless it includes nutritional assessment. Multidimensional Geriatric Services should provide for the inclusion of Clinical Nutrition services.

\section{(41) CLINICAL ASSESSMENT OF REHABILITATION POTENTIAL}

C. Cunningham, F. Horgan, N. Keane, P. Connolly, A. Mannion, A. Kelly*, D. O'Neill.

Age Related Health Care Department, Meath Hospital and

*Department of Community Health and Community Practice, Trinity College, Dublin.

Access to scarce geriatric rehabilitation beds is usually given to those with "good" rehabilitation potential. The assessment of this potential is usually a matter of clinical judgement. The factors which influence individual clinicians in this assessment are not known. This study investigated which factors influenced different clinicians making this judgement.

Thirty consecutive patients admitted to a geriatric rehabilitation ward were assessed by a geriatrician, nursing sister, occupational therapist (OT) and physiotherapist (PT). A standard questionnaire was administered to evaluate their opinion of the patients rehabilitation potential, which disabilities they felt were present and if they felt the patient would return home. A multiple logistic regression was performed to ascertain which factors were significant in determining rehabilitation potential.

Between 50 and 60 per cent of patients were felt to have "good" rehabilitation potential by different team members. Several patient characteristics were found to significantly influence clinical opinion. These included continence for the physician and PT and likelihood of returning home for the OT and nurse. There was good agreement among 3 of the 4 clinicians with respect to assessment of rehabilitation potential. However all team members differed in the factors which influenced their decision and no one factor was common to all clinicians.

Further study is needed to see if the differences observed were due to personal characteristics or differences in the professional training of the team members. Liaison between professionals should increase the accuracy of such clinical judgements.

\section{(42) THE EFFECT OF AGE ON OUTCOMES IN ROAD TRAFFIC ACCIDENT PATIENTS}

C. Cunningham, D. Howard*, D. O'Neill*.

Mercers Institute for Research on Ageing, St. James' Hospital and *Centre for Mobility Enhancement, Meath Hospital,

Dublin.

Road traffic accidents (RTA) are the second commonest cause of accidental death in people aged over 65 . The phenomenonology and resource utilisation of Irish RTA patients is not documented. We studied older RTA patients admitted to 2 Irish trauma centres in 1995 . Of 525 patients, 42 (8 per cent) were aged over 65 . We compared 38 patients aged 16-64 yr for comparison and reviewed the notes in detail.

Elderly patients were mostly pedestrians ( 59 per cent): 21 per cent were drivers and 8 per cent on public transport. Younger patients were mostly drivers ( 37 per cent), cyclists ( 24 per cent) or motorcyclists (16 per cent). Older patients had a higher median Injury Severity Score, $p<0.05$, were more likely to be female ( $p<0.05$ ), involved in RTA's between 9 am-5pm $(p<0.01)$ and have pre-existing medical conditions $(p<0.001)$. The following were significantly increased in older patients ( $p$ values): surgical $(<0.01)$, medical $(<0.01)$ and therapist workload $(p<0.05)$, complications $(<0.0001)$, length of stay $(<0.01)$. Less elderly were discharged directly to home $(p<0.05)$. Strategies to reduce the mortality and morbidity associated with RTA in the elderly should emphasize a) older pedestrians during daytime hours, b) attention to safety in public transport. Treatment must ensure adequate medical and therapist input to anticipate higher complication rates.

\section{(43) REHABILITATION, AN AUDIT OF THE HOSPITAL COMMUNITY INTERFACE}

J. Durkin, D. O'Neill.

Age Related Health Care, Meath Hospital, Dublin 8.

A significant number of older medical and surgical patients have multiple diseases and functional impairments such that they require rehabilitation as an integral part of their treatment. As one of the main emphases of The Health Strategy is to provide care in the community where possible we decided to study the interface between hospital and community based rehabilitation services. Since 1980 a service, the District Care Unit (Community Wards) has provided a team consisting of physiotherapist, occupational therapist, team leader, public health nurse and home care attendants to help provide rehabilitation in the community A total of 53 patients were discharged to the District Care Unit in 1994/95 from Age-Related Health Care (an assessment and rehabilitation service for older medical patients). The average length of time taken to be accepted by the DCU was 17.8 days (range 5-30 days) in year 1 and 11.5 days (range $2-20$ days) in year 2 . Those with the longest delay tended to be discharged between the months of October and February which is the busiest period of referrals from the hospital. Summaries were received on 41 of the patients. Three patients refused assistance from the DCU and 4 patients were rejected as it was felt that they had reached their maximum potential and had no further rehabilitation potential. In average the patients received treatment over a period of 38.5 days (range 14-90 days). There was a very high correlation between a recommendation for physiotherapy in the hospital and in the second assessment by the DCU therapists. Our findings suggest that there is a high concordance between the therapists in the hospital and the community which may imply that second assessment may not be indicated in all cases. There is a delay of 10-12 working days in starting rehabilitation which needs to be factored into any care plans and may limit the immediacy of the service.

\section{(44) A SIMPLE SCREEN FOR FUNCTIONAL IMPAIRMENT IN OLDER MEDICAL PATIENTS}

M. Egan, D. Breen, Y. Hall, D. O'Neill.

Department of Medicine for the Elderly, St. James's Hospital, Dublin.

Medical staff often fail to detect functional impairment in older patients': this has implications for accurate diagnosis, treatment and discharge. Functional assessment should be incorporated in clinical assessment ${ }^{2}$ but can be time-consuming and is not widely used: we propose a simple 5 question screen 
We screened 63 patients (ages 67-94 yr, mean $80 \mathrm{yr}$ ) within 72 $h$ of admission to an acute geriatric medical ward. The abbreviated mental test score (AMTS), the Barthel Activities of Daily Living Index (BADL) were also used: a BADL $<15 / 20$ indicates significant functional impairment. An AMTS $<7$ or $\geq 3$ negative answers on our scale had a sensitivity of 83 per cent and a specificity of 70 per cent for functional impairment on admission: corresponding values for functional impairment 1 month prior to admission were 89 per cent and 69 per cent. This simple scale has a high probability of detecting functional impairment, and a study on larger groups may further confirm its utility.

\section{References}

1. Ryall, N. et al. Ir. J. Med. Sci. 1994.

2. Dickinson, E. J. Lancet 1990: 335: 778-9.

\section{(45) OUTCOME OF SWALLOW DISORDER IN OVERT ACUTE STROKE AND OTHER CONDITIONS}

\section{Z. Farrell, A. Henke. D. O'Neill}

Departments of Speech \& Language Therapy \& Age-Related Health Care, Meath Hospital, Dublin 8.

The occurrence of swallow disorders (dysphagia) is common in older patients and is well documented in several clinical groupings e.g. acute stroke, progressive neurological diseases, head and neck surgery. However, there is little objective documentation to date to indicate prognosis and outcome for these populations. Outcome quantification is important for service provision and patient advice. This study evaluates and compares the outcome of swallow disorders in overt acute stroke and other presenting conditions. Retrospective analysis of speech and language therapy with videofluoroscopic records for a 12 month period was carried out. For each patient the following was documented:- 1 . Medical diagnosis. 2. Initial swallow status. 3. Videofluoroscopic assessment findings. 4. Intervention. 5. Functional outcome (measured according to outcome scale rating $1-9$ as described by 1 indicating Nil Orally and 9 indicating a return to pre-morbid diet). Of 104 patients seen, 31 presented with overt acute stroke (OAS); the remaining 73 presented with aetiologies including progressive neurological diseases, respiratory disease, multiple medical problems, cerebral vascular disease, tracheostomy, general surgery.

$\begin{array}{llllll}\text { OAS } & \begin{array}{l}\text { Multiple } \\ \text { Medical } \\ \text { Problems }\end{array} & \begin{array}{l}\text { Progressive } \\ \text { Disease }\end{array} & \text { Neurological } & \begin{array}{l}\text { Old } \\ \text { Stroke }\end{array} & \begin{array}{l}\text { Respiratory } \\ \text { Diseases }\end{array} \\ 7.6 \pm 2.1^{*} & 6 \pm 2.8^{*} & 6 \pm 2.5 & 7.9 \pm 2.1 & 7.4 \pm 2.3\end{array}$

Patients with OAS generally had a good functional outcome i.e. they mostly returned to pre-morbid feeding status, other groups indicated lower functional outcomes particularly those presenting with multiple medical aetiologies $(p<0.05)$. Awareness of group prognosis can be helpful in therapy, prognosis and health service planning.

\section{(46) ASSESSMENT OF FITNESS TO DRIVE}

L. Mulholland, T. O'Regan*, D. O'Neill. Centre for Mobility Enhancement, Meath Hospital, Dublin 8. *Irish Wheelchair Association, Blackheath Drive, Dublin 3.

The proportion of elderly drivers is increasing. For many older people the car is a vital link for maintaining an independent lifestyle. Loneliness, lower life satisfaction and lower activity levels are linked with the loss of driving ability among the elderly. Much of the legislation and literature on the older driver has an over-emphasis on selecting those who should not drive rather than enabling and empowering older drivers. In Ireland, the assessment of the older driver has been non-structured, and the need has been fuelled by the requirement for medical certification of drivers over the age of 70 . The Centre for Mobility Enhancement was founded in 1996 to maximise mobility of older drivers. We report on the first 10 patients assessed, using a cascade methodology: doctor \pm occupational therapist \pm specialized Driving assessment:

$\begin{array}{ccc}\text { Medical Assessment } & \text { O.T. Assessment } & \begin{array}{c}\text { Referral for } \\ \text { Specialized Driving } \\ \text { Assessment }\end{array} \\ 10 & 8 & 6\end{array}$

The most common presenting disorders were neurological: 40 per cent with stroke disease and 20 per cent with Parkinson's disease. Of the 8 assessed by an OT, 50 per cent reported placing limitations on their driving, 20 per cent were not driving at the time of assessment. Following assessment 60 per cent were deemed suitable for an 'on-road' assessment in the Irish Wheelchair Association. driving assessment ought to be incorporated into the work of rehabilitation centres. The Centre for Mobility Enhancement will serve as a back-up to family.

\section{(47) LIFTING AND HANDLING TECHNIQUES, OLDER} PATENTS AND HEALTHCARE PERSONNEL

\author{
S. Murphy, M. Kelly, D. O'Neill.
}

Department of Physiotherapy \& Age-Related Health Care, Meath Hospital, Dublin 8.

Older patients in hospital represent the largest group requiring specialized lifting and handling, particularly those with stroke. It is established that inappropriate handling techniques increase the complications of stroke rehabilitation, in particular shoulder pain'. Also healthcare staff may themselves be harmed by inappropriate technique. To examine a stroke patient may require lifting and handling: we were concerned that all healthcare staff may not be appropriately trained, despite the European directive 90-269-EEC, 1993 on lifting and handling. We studied i) training, ii) awareness of principles of lifting and handling iii) perceived confidence among 5 groups of healthcare staff routinely involved in the care of older people.

Among our results we showed deficits in training, particularly among medical staff:

\begin{tabular}{ccccccc} 
& \multicolumn{6}{c}{ Trained in lifting and handling (Yes/Total Number) } \\
NCHD & Staff & Student & OT & Physio & Attendant & Speech \& \\
& Nurses & Nurses & & & s & Language \\
$3 / 13$ & $16 / 18$ & $10 / 10$ & $4 / 4$ & $8 / 8$ & $3 / 3$ & $2 / 2$
\end{tabular}

and all of these indicated that their examination or clinical routine involved manoeuvres which could damage a vulnerable shoulder in a patient with a hemiplegia following stroke. It is important that all healthcare staff involved in the care of patients with stroke should have basic training in lifting and handling.

\section{Reference}

1. Jensen, E. The hemiplegic shoulder. Scand. J. Rehab. Med. 1980; Supp. 1: 11-3-9. A. 


\section{(48) ERYTHROCYTE MEMBRANE FATTY ACIDS IN ELDERLY PEOPLE}

Stockman, L. E. McGrath, M. Rea.

The Queen's University of Belfast

Free radical activity is implicated in the chronic diseases associated with ageing, and with normal age-related degenerative changes. Free radicals attack polyunsaturated fatty acids and this pilot study optimised a gas-liquid chromatographic assay of the fatty acid composition of erythrocyte membranes from a healthy elderly individuals.

Fifty-two subjects (19 male, 33 female) with a mean age 83.3 yr (range 71-98 yr) were studied. Chromatographic separation of pentafluorobenzyl esters of the membrane fatty acids was achieved isothermally at $210^{\circ} \mathrm{C}$. There were no significant associations between levels in mole percent of the polyunsaturates, monosaturates, saturates or any individual fatty acids and age or sex, nor between essential fatty acids and age or body mass index. However, there may be a trend towards an increase in total polyunsaturates in the $>90$ group. Additionally, docosenoic acid and docosadienoic acid were only ever detected in the $>90$ age group.

A trend for an increase in total polyunsaturated fat was found in the oldest subjects but not for total saturated or monosaturated fat. This finding is consistent with the selective survival hypothesis of ageing and requires further investigation in a much larger number of subjects.

Funded by a Wellcome Vacation Grant 1996.

\section{(49) ONCE-DAILY MEDICATION FOR OLDER PATIENTS - CAN WE DO BETTER?}

L. Sweetman, D. Howard, D. O'Neill.

Age-Related Health Care, Meath Hospital, Dublin 8.

It is well recognised that polypharmacy contributes to poor compliance. Less well researched is the potential for improving compliance by reducing dosage intervals bearing in mind newer once daily formulations.

We assessed the possibilities of reduction of dosage intervals in 523 consecutive consults seen by a Geriatric Medical Service. Medications were listed and a set protocol for using once daily and twice daily medications was applied.

The results indicated that it is possible to reduce dose intervals in 172 patients and of these in 62 ( 11.8 per cent) it was possible to reduce from multiple doses to a once daily regime.

$\begin{array}{cccccc}\text { bd } \rightarrow \text { od } & \text { tid } \rightarrow \text { od } & \text { ti } \rightarrow \text { bd } & \text { qid } \rightarrow \text { od } & \text { qid } \rightarrow \text { bd } & \text { qid } \rightarrow \text { tid } \\ 160 & 20 & 21 & 1 & 0 & 2\end{array}$

These findings suggest that in a general hospital setting among older patients there is significant potential to improve compliance by using newer formulations to reduce dosage intervals.

(50) AWARENESS OF THERAPEUTIC INTERVENTIONS OF OTHER DISCIPLINES IN THE INTERDISCIPLINARY SETTING

D. R. Collins, S. Murphy, L. Mulholland, P. Sweeney, D. O'Neill.

Age-Related Health Care, Meath Hospital, Dublin 8.

Little has been written about the dynamics of the interdisciplinary team. Our group has investigated the concordance of clinical assessment among the different specialities in the interdisciplinary team. We sought to examine the awareness of each others therapeutic intervention in patient rehabilitation. Twenty patients in our acute/rehabilitative unit were assessed 1 week after admission by the physician, physiotherapist, occupational therapist and staff nurse involved in the study. Each team member was asked to list up to 5 interventions relevant to their discipline while at the same time projecting what they felt to be the top 3 interventions of the other disciplines in each patient's rehabilitation programme. Each discipline then scored the others projections for each patient with regard to correlation with their own intervention plan. A score of 2 was awarded for correlation, 1 for approximation and 0 for non-correlation with regard to each proposed intervention so that the maximum possible correlation score was 6 for any discipline assessing anothers role in the rehabilitation of a given patient (i.e. a maximum score of 120 for the study group of 20 patients).

The results are tabulated below:

\begin{tabular}{lcccl} 
& \multicolumn{4}{c}{ Discipline assessed } \\
Assessing discipline & Medicine & Nursing & Physio & OT \\
Medicine & - & TBA & 77 & 106 \\
Nursing & 60 & - & 52 & 59 \\
Physiotherapy & 70 & TBA & - & 108 \\
Occupational & 63 & TBA & 86 & -
\end{tabular}

These results show that between 13 per cent and 90 per cent of interventions are understood by other members of the interdisciplinary team and areas requiring further interdisciplinary training are highlighted.

\section{(51) PATTERNS OF INTERVENTION IN ELDERLY STROKE REFERRALS TO AN AGE-RELATED HEALTH CARE SERVICE}

D. R. Collins. D. O'Neill.

Age-Related Health Care, Meath Hospital, Dublin 8.

We sought to assess the patterns of intervention in elderly stroke patients referred to our service from the general medical setting. A standard pro-forma is used for all such consultations.

One hundred consultations involving elderly stroke patients were reviewed retrospectively and the advice and input of the consultation analysed. In 49 per cent of cases a specific recommendation regarding medical therapy was made, most commonly the initiation of the most suitable form of thromboembolic prophylaxis and anti-depressant therapy. Specific investigative tests and procedures were advocated in 48 per cent of consultations ranging from a simple dementia screen to carotid dopplers and holter monitoring. Further advice regarding physiotherapy, occupational therapy and speech \& language therapy was given in 61 per cent of consultations. Transfer of care was accepted in 19 per cent of cases which 28 per cent of patients required listing for longterm care. Social Work intervention with patient and family was initiated in 33 support by Day Hospital was offered to 18 per cent of patients.

While medical complications are common in the elderly stroke patient our survey shows that an Age-Related medical team can offer both medical and rehabilitative help to many patients referred from the general medical setting. 


\section{(52) MEDICAL CO-MORBIDITY AND STROKE}

\author{
R. Collins, D. O'Neill.
}

Age-Related Health Care, Meath Hospital, Dublin 8.

Stroke rehabilitation is a medically active process and many studies have shown the incidences of significant neuro-medical complications developing in between 56 and 96 per cent of stroke patients undergoing rehabilitation1. Despite this evidence. rehabilitation for stroke has been descnbed as "step-down" and units are planned without specialist medical input. We sought to assess the degree of medical comorbidity amongst an Irish in-patient stroke populabon. One hundred consecutive patients referred to our service because of stroke were evaluated for significant accompanying neuro-medical problems. This group included 91 cerebral infarcts, 5 haemorrhagic infarcts and 4 intra-cerebral bleeds. 89 per cent of patients had 1 or more significant neuro-medical problems in addibon to stroke. The range of significant co-morbidities was up to 7 with an average of 3 per patient. Psychiatnc problems were commonest (54 per cent) with 17 per cent patients having significant depression, while 49 per cent showed evidence of cognitive impairment. Fifth-three per cent of patients had specific neurological problems of which 21 per cent were swallow disorders. Fortyseven per cent of patients had cardiovascular disease of which hypertension, ischaemic heart disease and atrial fibrillation were commonest. Twenty-eight per cent had significant disorder of the renal tract with infection and incontinence being the most common problems. Rheumatological disease occurred in 16 per cent of patients and gastrointestinal pathology was present in 15 per cent. Thirteen per cent of patients had significant endocrine disease of which hypothyroidism and diabetes were commonest. Respiratory disease was present to a significant degree in 14 per cent of patients.

Medical co-morbidity is extremely common in the elderly patient with strokes and rehabilitation of such patients requires active specialist medical input.

Reference

1. Kalra, L., Yu, G., Wilson, K., Roots, P. Medical complications during stroke rehabilitation. Stroke 1995: Vol 26, No. 6: 990-993.

\section{OCCUPATIONAL MEDICINE}

\section{(53) UNDER-REPORTING OF OCCUPATIONAL BACK} INJURIES

T. O'Reilly, C. C. Kelleher.

Department of Health Promotion, Clinical Sciences Institute, University College Hospital, Galway.

This case control study was undertaken to estimate the proportion of occupational back injuries reported to the Health and Safety Authority and to see if there were significant differences between those whose injuries occurred at work and those whose injuries were not work-related. A total of $358 \mathrm{men}$, who sustained back injuries during the period January 1993 through December 1993, were identified from x-records and contacted by postal questionnaire. The majority of acute occupational back injuries were referred from the Casualty Department. Only 4 per cent of all back injuries surveyed causing more than 3 days absence from work had been reported. The findings indicate that 24 per cent of men were unable to continue in the same job and 42 per cent of men were forced to change their work practices following an occupational back injury. Knowledge and awareness was found to be significantly associated with age and social class. Less than one-third of all respondents were aware of their workplace reporting policy and only 13 per cent of all respondents knew about reporting requirements. These figures suggest that the general awareness of injury reporting is below that which would be necessary in order to have a useful level of occupational incident reporting.

\section{PSYCHIATRY}

(54) CO-ABUSE OF SHORT ACTING BENZODIAZEPINES BY OPIATE ADDICTS: DIFFICULTIES IN DETECTION

\section{R. Browne, D. Sloan, S. Fahy, S. Keating, C. Moran,} J. O'Connor.

National Drug Treatment Centre Board, 30/31 Pearse Street, Dublin.

The co-abuse of benzodiazepines and opiates is associated with poor treatment outcome and greater risk of HIV infection. It is essential to be aware of benzodiazepine abuse to allow early intervention to minimise poly drug abuse.

This study based in the Drug Treatment Centre Board, Dublin tested urines from all patients in the centre on 1. day. The samples are tested routinely using a EMIT assay which detects most benzodiazepines however for the purpose of this study samples were re-tested using a more sensitive technique to detect the very short acting agents such as flunitrazepam which is abused heavily by the opiate addicted population who are aware of the difficulties with its detection in urine.

One hundred and seven patients urines were tested. Thirtyfive per cent of samples were positive on routine testing $(n=37)$. With the sensitive test a further 11 cases were found to be positive suggesting that up to 10 per cent of cases of opiate/ benzodiazepine co-abuse are missed on routine testing. Interestingly in patients identified as using opiates in addition to prescribed methadone the percentage of missed benzodiazepine co-abuse rose to 16 per cent. The abuse of benzodiazepines in opiate addicts is confirmed in this study. Missed flunitrazepam abuse in 10 per cent or more of cases with subsequent delay in clinical intervention may allow chaotic poly drug abuse to become established.

\section{(55) EVALUATION OF A VIDEOTAPE GROUP TREATMENT PROGRAMME FOR PARENTS OF CHILDREN WITH BEHAVIOUR DISORDERS}

L. Connolly, J. Sharry, C. Fitzpatrick.

St. John of God Child \& Adolescent Mental Health Services; Our Lady's Hospital for Sick Children, Crumlin, Dublin 12.

Children with behaviour disorders account for over 60 per cent of referrals to child mental health services. Results of treatment with this group have been inconsistent but parent training approaches have shown interesting potential.

A 10 week videotape based group treatment programme was used with parents of 70 children in a number of child mental health settings. Evaluation measures included the Achenbach Child Behaviour Checklist (CBCL), the Conner's Teachers Scale and the General Health Questionnaire (GHQ) completed before and after the programme and at 6 month follow-up. A waiting list control group was included

Results showed significant reduction is measures of somatisation, social problems and internalising symptomatology 
in children whose parents had completed the parent training programme. Parents' emotional well being, as measured by the GHQ showed a trend towards improvement.

Parent training offers a cost effective approach to managing children with behaviour disorders

\section{(56) THE FINAL MEDICAL EXAMINATION IN PSYCHIATRY MYTH AND REALITY}

R. Cullivan, S. Rooney.

St. Vincent's Hospital, Elm Park, Dublin 4.

The objective was to clarify gender differences in performance in various aspects of the psychiatry exam. Expectations were that females would perform significantly better overall, in oral examinations and males would perform better in the more "scientific" Multiple Choice Question Exam (M.C.Q). We also investigated bow well non-nationals were achieving within the framework of the present curriculum.

The results of the final examination in psychiatry of 140 medical students from one year were analyzed. Areas examined included: "continuous assessment", MCQ, essay and oral examination. Results were subjected to statistical tests of significance.

Contradictory to expectation although females performed slightly better in all aspects, results were not statistically significant. While non-nationals achieved comparably in continuous assessment, they scored significantly less in all other aspects of the final exam. The component of the exam which most closely correlated with the total final mark was the essay paper mark and the least significant association was between continuous assessment and final mark.

Although some myths have been dispelled, other useful information has emerged. The needs of the non-nationals particularly are highlighted as they performed less well in language based areas - reflected in poorer marks in all written papers and the oral examination.

Results suggest the need to restructure the teaching programme in psychiatry for non-nationals.

\section{(57) CHANGES IN PRACTICE AND CLINICAL OUTCOME OF ELECTROCONVULSIVE THERAPY - THE BENEFITS OF AUDIT}

R. Cullivan, F. Johnson.

St. John of God Hospital, Co. Dublin.

The objective of this study was to evaluate the impact of audit or, the practice and clinical outcome of electroconvulsive therapy (E.C.T.).

An audit of the practice of E.C.T. had begun in St. John of God Hospital in 1989 and resulted in several changes including alterations in documentation and purchase of a new E.C.T. machine. We reviewed all courses of E.C.T. administered over a 1 yr period following these changes. We examined documentation, practice and outcome of E.C.T. With regard to outcome we noted average seizure length and length of time to discharge from hospital, following completion of course of E.C.T.

We compared our findings with those which had existed prior to the changes resulting from audit. Improvement was noted in the area of documentation, for example, consent forms were present in 100 per cent of our sample compared to only 80.7 per cent previously. The most obvious improvement was in the area of clinical outcome. This was measured by average seizure length and time to discharge from hospital following completion of course of E.C.T. In our sample over 75 per cent were discharged within two weeks compared to 30 per cent previously. Average seizure length increased from 25.2 seconds to 29.3 seconds in our sample.

While we recognize the limitations of this study we feel it reaffirms the benefits of audit in clinical practice.

\section{(58) CONSULTATION LIAISON PSYCHIATRY - A TALE OF TWO CITIES}

R. Cullivan, I. Durkin.

Beaumont Hospital, Dublin and St. Vincent's Hospital Dublin.

The objective of the study was to compare patterns of referral to consultation liaison psychiatric services of 2 major general hospitals. Our expectation was that significant numbers of referrals would prove inappropriate and would not result in psychiatric diagnoses. We also expected to find a delay in referral until medical investigations were exhausted. We also sought to estimate whether advice was utilized

A proforma was compiled and completed for all patients referred to the 2 services over a 6 month period. Information comprised demographic details, the source and reason for referral, delay in referral, psychiatric and medical diagnoses and suggested management. Statistical analysis was carried out using a statistical package.

Four hundred and ninety-one requests for psychiatric consultation were received. Referral rates varied between departments. Most common diagnoses were; depression, adjustment disorders, substance abuse and deliberate self harm (D.S.H). D.S.H accounted for over 33 per cent of referrals in both hospitals Management most often consisted of advice with medication being recommended in up to 44 per cent of cases

Patterns of referral were broadly similar in both hospitals. Most referrals were, in fact, appropriate and there was not as great a delay as expected in referral. Generally, advice given was followed up by the referring teams.

\section{(59) AN EVALUATION OF THE CAGE QUESTIONNAIRE IN AN ELDERLY POPULATION}

S. Fahy, B. Farragher, M. Wrigley.

Department of Psychiatry of Old Age, 61 Eccles Street, Dublin 7.

The objective of this study was to examine the sensitivity and specificity of the CAGE questionnaire as a screening instrument for alcoholism in an elderly population. All new referrals to the psychiatry of old age service over a 6 month period were included. The CAGE questionnaire and a psychiatric examination was completed on each patient. A collateral history was also obtained whenever possible

One hundred and fifty new patients were referred. A CAGE questionnaire was administered to 143 of these patients. Eleven patients screened positive for alcoholism on the CAGE. On obtaining their psychiatric and collateral histories a further 12 patients were found to suffer from alcoholism. In this particular group the CAGE questionnaire was found to have a sensitivity 
for alcoholism of 48 per cent and a specificity of 100 per cent.

The sensitivity of the CAGE questionnaire for alcoholism in this age group was disappointing when compared to its efficiency in younger populations. Identification of alcoholism in the elderly still depends on adequate history taking and the inclusion of a collateral history.

\section{(60) FACTORS ASSOCIATED WITH VIOLENCE IN A HIV POSITIVE DRUG USING COHORT ATTENDING A DRUG TREATMENT CENTRE.}

S. Fahy, R. Browne, D. Sloan, S. Keating, F. Mulcahy,

$$
\text { J. J. O'Connor. }
$$

National Drug Treatment Centre, 30-31 Pearse Street, Dublin.

The majority of violent incidents recorded in a drug treatment centre, were of grade 1 severity; verbal abuse/anti-social behaviour. Incidents occurred between December 1991 and July 1996. Forty-nine per cent of patients involved were HIV positive. This rate did not reflect the seroprevalance of 2 per cent in the clinic population. The clinical records regarding HIV status of 28 patients at the time of the incident, were reviewed. All except 2 , were reviewed within 6 months of the incident. There were 22 males and 6 females. Their mean age was 30.1 (range 2341). Twenty-eight patients were involved in 2 prior incidents and 5 patients in one prior incident. Centre of Disease Control (CDC) stages were stage II $-\mathrm{n}=15$ (55 per cent), stage III $-\mathrm{n}=9$ ( 33 per cent) and stage IV - $n=2$ ( 7.4 per cent). Mean T-helper cell (CD4) count was 543 (range 150-1170). In no case were neurological symptoms or signs elicited nor was CT brain scan indicated. Violent incidents in this HIV positive drug using cohort cannot be attributed to neurological manifestation of the disease. In a confrontational setting this group may feel they have less to lose by violent behaviour. Furthermore, violence may be a function of the risk taking behaviour which initially led to needle sharing and ultimately to the acquisition of HIV.

\section{(61) JOINT CARE ADMISSIONS TO A PSYCHIATRIC UNIT - A PROSPECTIVE ANALYSIS}

B. Farragher, N. Walsh.

Department of Psychiatry, St. Vincent's Hospital, Elm Park, Dublin 4.

The objectives of this study were to examine prospectively the profile of patients admitted to a medical psychiatric joint care unit, to study their treatment and follow-up and to examine the difficulties associated with the treatment of these patients on a general hospital psychiatric unit.

A staff completion questionnaire was compiled on each consecutive admission to the joint care beds in St. Vincent's Hospital over a 6 month period.

Eighty-nine patients were admitted. The median length of stay was 2 days (range 1 to 52 days). Fifty six (50) percent were female. The majority $(68,76$ per cent) of the group were admitted following acts of deliberate self-harm. The predominant psychiatric diagnosis was depression (41, 46 per cent). During admission 23 ( 26 per cent) patients were found to have behavioural and psychiatric problems which were difficult to manage on the ward. Eleven patients caused difficulties for staff from the management of their physical illness. Thirty-three per cent (36) patients were referred for further psychiatric in-patient care.
The joint care unit provided a combined psychiatric and medical service. It was used predominantly by patients following acts of deliberate self-harm. Joint care allowed a comprehensive assessment and initiation of treatment of this patient group. The inclusion of such a unit is a worthwhile consideration in any general hospital psychiatric service.

\section{(62) HYPOTHALAMIC-PITUITARY-ADRENAL AXIS FUNCTION IN CHRONIC FATIGUE SYNDROME: A STUDY OF FAST FEEDBACK MECHANISMS}

E. T. Lavelle, T. G. Dinan.

Department of Psychological Medicine, St. Bartholomew's Hospital, London.

The Centre for Disease Control (CDC) definition of Chronic Fatigue Syndrome has provided an objective basis for the diagnosis of this common syndrome. Recently Demitrack et al (1991) reported significant abnormalities, i.e. low production of cortisol and blunted CRH mediated ACTH release in the HPA axis. In an effort to further explore this phenomenon we examined the fast feedback responses in patients with a CDC diagnosis of Chronic Fatigue Syndrome.

The patients aged between 18-40 years with a CDC diagnosis of Chronic Fatigue Syndrome and on no medication took part in the investigation. Patients fasted from midnight and presented at $08: 30 \mathrm{~h}$. They relaxed for $30 \mathrm{~min}$ following insertion of a cannula in each forearm vein. A baseline sample of blood was taken by vacuum extraction at $0 \mathrm{~min}$ for ACTH. Hydrocortisone was infused at a rate of $5 \mu \mathrm{g}$ per $\mathrm{kg}$ per min for $60 \mathrm{~min}$. Subsequent blood samples were extracted for $\mathrm{ACTH}$ at $+15,+30$, $+60,+90 \mathrm{~min}$

The patients with a diagnosis of Chronic Fatigue Syndrome responded with lower falls in ACTH than did healthy controls. The mean + SEM ng/L drop in ACTH was $15.3 \pm 3.2 \mathrm{ng} / \mathrm{L}$ in patients with Chronic Fatigue Syndrome and for healthy comparison subjects was $24.1 \pm 2.7 \mathrm{ng} / \mathrm{L}$. There was no difference in basal ACTH or cortisol levels between the 2 groups.

Conclusions: Patients with Chronic fatigue Syndrome have attenuated rate sensitive fastfeedback in the HypothalamicPituitary-adrenal axis.

References

Holmes, G. P., Kaplan, J. E., Gantz, N. M. et al. Chronic fatigue syndrome: a working case definition. Ann. Intern. Med. 1988; 108; 387-9.

Demitrack, Dale J. K., Straus, S. E., Laue, L. et al. Evidence for impaired activation of the Hypothalamic-Pituitary-Adrenal axis in patients with Chronic Fatigue Syndrome. Journ. of Clinical Endocrinology and Metabolism 1991; 73; 6; 1224-1234.

\section{(63) SHOPLIFTING IN AN ELDERLY MAN}

\author{
C. Maher, M. Wrigley. \\ Department of Old Age Psychiatry, 61 Eccles Street, \\ Dublin 7.
}

Shoplifting is a cause of significant economic loss to society. The majority of perpetrators do so for financial gain, but in a certain proportion the shoplifting behaviour is found to be secondary to a psychiatric disorder. A typical profile of the psychiatrically ill shoplifter is that of a young professional woman who is suffering from depression. Shoplifting in the elderly is rarely reported, particularly in elderly men and in those without a dementing illness. 
We describe a case of shoplifting unusually occurring in a $70 \mathrm{yr}$ old man who exhibited classical features of depression, and low self esteem. Cognitive functioning was normal. Following treatment his depression resolved, but he only stopped shoplifting after being caught and cautioned.

Men usually shoplift for criminal purposes rather than secondary to psychiatric illness, but of those who do, substance abuse is the commonest diagnosis.

Reduced self esteem has been described before in association with shoplifting and treatment has been directed at enhancement.

The previous ly raised question as to whether or not a caution may prove helpful in stopping shoplifting was answered affirmatively in this case.

\section{(64) THE PSYCHOPATHOLOGY OF SCHIZOPHRENIA: RELATION TO DURATION OF INITIALLY UNTREATED PSYCHOSIS}

D. Meagher', J. Quinn ${ }^{2}$, P. Murphy ${ }^{3}$, A. Kinsella ${ }^{4}$, J. Mullaney ${ }^{5}$, J. L. Waddington ${ }^{6}$.

${ }^{1}$ St. Vincent's Hospital, Dublin; ${ }^{2}$ St. Davnet's Hospital, Monaghan; ${ }^{3}$ St. Loman's Hospital, Mullingar; ${ }^{4} \mathrm{DIT}$; ${ }^{5} \mathrm{St}$. Ita's Hospital, Co. Dublin; ${ }^{6}$ RCSI, Dublin.

In schizophrenia, the longer initial psychosis proceeds unchecked by neuroleptic medication, the poorer may be the subsequent course. We have studied this issue further in older patients, many of whom were admitted in the preneuroleptic era. Inpatients with DSM IV schizophrenia [N=129, 75M/54F; age 69.9 \pm 11.0 ; duration of initially untreated psychosis $9.2 \pm 7.7$; duration of illness subsequent to first treatment 35.3 \pm 3.2 ] were evaluated using the PANSS, MMSE and EXIT. Using stepwise regression, increasing PANSS negative symptom score was predicted only by duration of initially untreated psychosis $[\mathrm{P}<0.001]$, with this being more prominent in females than in males $[\mathrm{P}<0.05]$, and by absence of a leucotomy; each year of untreated psychosis was associated with an increase of 0.49 [95 per cent CI 0.31 to 0.67 ] PANSS points. Positive symptom score was predicted only by current dose of neuroleptics. Poorer general cognitive function on the MMSE, but not frontal function on the EXIT, tended to be predicted by, inter alia, duration of initially untreated psychosis $[\mathrm{P}=0.1]$; each year of untreated psychosis was associated with a decrease of 0.18 [95 per cent $\mathrm{CI}+0.06$ to 0.42 ] MMSE points. Prolonged untreated psychosis has an adverse effect on the long-term outcome of schizophrenia.

These studies were supported by the Stanley Foundation.

\section{(65) SUCCESSFUL MANAGEMENT OF ATTENTION DEFICIT HYPERACTIVITY DISORDER WITH METHYLPHENIDATE (RITALIN) IN A BOY WITH LEARNING DISABILITY}

J. Montwill, L. Ramsay.

St. John of God Services, Carmona Services, Dunmore House, Glenageary, Co. Dublin.

$\mathrm{D}$ is a $12 \mathrm{yr}$ old boy with a moderate learning disability and Attention Deficit Hyperactivity Disorder (ADHD). Socialisation and learning were marred by aggressive "target behaviours", impulsiveness and extractability. He had a "lamh" vocabulary of twenty signs, would not remain seated for more than 2 minutes and required "one-to-one" supervision. "Target behaviours" were documented in class and at home by staff and parents respectively.

Since 1991 D's parents were informed regarding treatment using Methylphenidate (Ritalin); a central stimulant, but declined this option until November 1995.

An initial dose of $5 \mathrm{mgs}$ was increased to $10 \mathrm{mgs}$ after 2 weeks. Improvement was maintained until May 1996 when dose was increased to $15 \mathrm{mgs}$ daily.

Currently D can sustain on-task activity and remain seated for up to 50 minutes. He has learned 100 "lamh" signs and was accepted for special school placement in August 1996, having previously been rejected. "Target behaviours" have reduced by 50 per cent.

Although Methylphenidate has been used with success in children with ADHD; its use within the learning disability population has been limited. We would conclude that it is an important option within this population.

\section{(66) HOMELESSNESS IN A PSYCHIATRIC INPATIENT POPULATION}

M. O'Doherty, V. Mak', M. Pierides ${ }^{2}$.

St. Vincent's Hospital, Fairview, Dublin; 'Lambeth Healthcare NHS Trust, London; ${ }^{2}$ Lambeth Healthcare NHS Trust, London.

Homelessness among the mentally ill in inner city areas appears to be an increasing problem. Limited data, particularly regarding gender differences, are available.

This study took the form of a retrospective case note study of admissions of all patients of no fixed abode (NFA) to an inner city psychiatric inpatient unit over a 30 month period.

A total of 133 patients (101 males and 32 females) of NFA, representing 11 per cent of all admissions, were admitted during the study period. Mean age at referral was $33 \mathrm{yr}$. At the time of admission approximately two-thirds of patients were unmarried; 99 males (98 per cent) and 33 females (100 per cent) were unemployed and 3 males and no females were "sleeping rough". Fifty-three males ( 52 per cent) and 18 females ( 56 per cent) had made contact with their family within the previous year. Approximately one-third of all NFA patients were registered with a general practitioner. Mean duration of stay was 18 days for males and 24 days for females. Data regarding diagnosis were lacking in about half of males and one-third of females. Of the remainder, 51 per cent of males and 33 per cent of females had a diagnosis of schizophrenia; 85 per cent of males and 62 per cent of females had a primary or secondary diagnosis of substance misuse.

Contrary to previous studies there is little evidence that females of NFA were socially more stable than males. Information regarding psychiatric diagnosis and history was inadequate. Data collection regarding this disadvantaged group of psychiatric patients must improve in order to plan a service appropriate to their needs.

(67) HOW SATISFIED ARE MEDICAL STUDENTS WITH THEIR TRAINING?

S. Rooney, R. Cullivan.

St. Vincent's Hospital, Elm Park, Dublin 4.

This study assessed medical students' attitude towards their 
training and outlines improvements students have suggested that would be beneficial for undergraduate and post-graduate teaching.

A questionnaire was compiled which investigated demographic details, views on pre-clinical and clinical training, students feelings of competency in dealing with issues surrounding patient care and communication, suggested improvements for teaching programmes, relevancy of the premedical and Internship year and concerns regarding postgraduate training. The questionnaire was administered to final year medical students. Results were analysed using a statistical package.

Seventy-eight students responded of which 14 were nonnationals. Significantly greater dissatisfaction was expressed towards pre-clinical training especially by students who were undecided about their career choice. Large numbers of students were dissatisfied with issues surrounding "Death and Dying" (77.3 per cent), dealing with difficult people ( 79.2 per cent) and teaching of computerskills ( 89.5 per cent).

Suggested improvements included increased use of patient management problems, patient presentations and use of small group tutorials.

79.2 per cent of students felt pre-medical year should be abolished and 77.5 per cent wished Internship to remain at a post-graduate level.

While 91.5 per cent of students thought they would emigrate, 74.6 per cent expressed a wish to remain in Ireland.

Despite negative attitudes expressed, students were constructive regarding possible improvements in training.

\section{(68) PREGNANT OPIATE ADDICTS: A SOCIODEMOGRAPHIC PROFILE OF 60 CASES}

\author{
D. Sloan, J. J. O'Connor. \\ National Drug Treatment Centre, 30-31 Pearse Street, \\ Dublin 2.
}

There has been a dramatic increase in the incidence of pregnant opiate addicts in Ireland. Patients who are both opiate dependent and pregnant have an increased risk of medical, psychiatric, obstetrical and neonatal problems. The purpose of this study was to examine a prospective cohort of pregnant opiate dependent females. 60 pregnant opiate dependent clients presented for treatment during the study period. The majority were single, self referred, and had not received previous treatment. Heroin was the main drug of abuse, with 15 per cent using the intravenous route. The mean age was 22.4 . Ninety per cent were primigravid and the remaining 10 per cent were multiparous. The average length of gestation at presentation was 27 weeks, with the mean time for recognizing the pregnancy being 18 weeks. Most pregnancies were unplanned and the majority of women had not used contraception. The mean gestation at the initial antenatal visit was 28 weeks. Four per cent of this group were HIV positive and 12 per cent were HCV positive. The mean number of cigarettes smoked was 30 daily. The average dose of methadone used to maintain this group was $35 \mathrm{mg}$ daily. Forty per cent of this group continued to use opiates during the pregnancy. Partners were also opiate dependent in 41 per cent of cases. This growing problem necessitates close liaison between obstetric and drug dependency services.

\section{(69) GENERAL PRACTITIONER REFERRAL LETTERS TO A COMMUNITY PSYCHIATRIC CLINIC: AN AUDIT \\ D. Sloan, B. McCaffrey. \\ St. Vincent's Hospital Fairview, Dublin 3.}

General Practitioner (GP) referral letters vary enormously with regard to quantity and quality of information, and legibility. The purpose of this study was firstly to examine a consecutive series of GP referral letters to a community psychiatric clinic, and secondly to measure the impact of introducing a specialised referral form for GPs. Sixty referral letters were examined in total, 30 letters were selected prior to the introduction of the new referral form and 30 referrals using the new form, following its introduction. Data was coded and analyzed using SPSS. Chisquared statistics were used to assess the significance of change after the introduction of the new process. Results showed that the new referral form was associated with a significant increase in information regarding patients past psychiatric history $(p=0.05)$, previous psychiatric treatment $(p=0.001)$, family psychiatric history $(p=0.02)$, as well as details regarding patients' regular alcohol intake $(\mathrm{p}=0.05)$.

\section{PUBLIC HEALTH/EPIDEMIOLOGY}

\section{(71) THE PRODUCTION AND DISTRIBUTION OF A WEEKLY COMMUNICABLE DISEASE REPORT}

\author{
John Brazil. \\ Virus Reference Laboratory, University College Dublin, \\ Belfield, Dublin 4.
}

Recent events in Ireland and around the world have underscored the need for the communication of timely and accurate information on the occurrence of infectious disease. An important source of such information is the infectious disease laboratory.

In the past laboratories have notified certain results obtained to the relevant agencies but this information was generally collected by hand, a process both tedious and time-consuming. With increasing workloads in laboratories this is less easy to achieve and has restricted the current voluntary laboratory-based communicable disease reports in Ireland (such as Virus Alert, Infoscan, Datainform and I.D. Bulletin) to publication no more than 4-5 times a yr.

An important development in infectious disease laboratories over the past few yrs has been computerisation. Laboratory computer systems (LIS) are now being recognised as valuable sources of information. This information is being used increasingly for research, workload measurement, resource management, and cost control. With the appropriate software it can now also be used to monitor significant intectious disease test results and trends.

The requirements of the Virus Reference Laboratory (VRL) were identified and software specified from our LIS supplier. Extraction scripts were prepared identifying significant test results and scheduled to extract the appropriate data on a weekly basis. The results were compiled into tabular form and examined in-house for a period of 3 months. In September 1996 the distribution of this weekly datasheet was extended outside the VRL using fax, email and the World Wide Web. 


\section{(72) NEISSERIA MENINGITIDIS CARRIAGE DURING AN OUTBREAK OF MENINGOCOCCAL DISEASE INVOLVING A SECONDARY SCHOOL}

P. Fitzpatrick, M. Thalanany*, M. Manche*, P. Hunter**, R. Roberts*, R. Salmon, S. R. Palmer.

PHLS Communicable Disease Surveillance Centre, Cardiff, Wales. *North Wales Health Authority, Preswylfa, Wales. **Chester PHL, Wales.

The aim of this study was to determine the prevalence of Neisseria meningitidis carriage in a large secondary school and to examine potential risk factors associated with such carriage following 2 cases of meningococcal disease (one type B 15 P1.16) from a single school year (Year II) and 2 cases of meningococcal disease from the same local community (1 type B 15 P1.16). A throat swab was taken from 626 students who completed a questionnaire which enquired about personal and household details, lifestyle and social behaviour and health. Logistic regression was used to determine independently associated with carriage of Neisseria meningitidis. Neisseria meningitidis was cultured from throat swabs of 53 (8.5 per cent), 11 of whom were B15 P1.16; all B15 P1.16 carriers were aged over 14. Having more that 2 smokers in the household, being in the same year as the index cases and having received significant bad news in the preceding 3 months were significantly associated with carriage of any strain of Neisseria meningitidis. Two factors were significantly associated with carriage of type B15 P1.16; being over 14 and being in Year II. Screening results are too late to influence decision making in the acute situation; however examination of disease spread, carrier status of school contacts in clusters and determinants of both may allow patterns to emerge which will assist the management of future similar situations.

\section{(73) PROSTATE CANCER - HOW AWARE IS THE PUBLIC?}

P. Fitzpatrick, N. Corcoran*, J. M. Fitzpatrick*.

Department of Public Health Medicine \& Epidemiology, University College Dublin. * Surgical Professorial Unit, Mater Misericordiae Hospital, Dublin.

The aim of this study was to assess public awareness of prostate cancer and willingness to seek medical attention for urinary symptoms and to determine factors associated. A community survey was conducted by interviewer-administered questionnaire to 280 randomly selected Irish males aged 40-69.

One quarter had not heard of prostate cancer; factors associated with having heard were non-manual social class, living with a female partner and history of treatment for urinary disease. Eighty per cent said they would be willing to attend a GP with urinary symptoms; associated factors were living with a female partner, having heard of prostate cancer and having seen a GP more than once in the preceding year. Just over half deemed attendance to be urgent/important; associated factors were having heard of prostate cancer, living with a female partner and having a relative with cancer; possession of a GMS card was negatively associated. There is a marked social class gradient in knowledge and willingness to seek medical advice. In the absence of population screening earlier clinical presentation with prostate cancer is essential if prognosis is to be improved; there is an evident need to improve prostate cancer awareness, particularly in the lower social classes, if this goal is to achieved.

\section{(74) COMPARISON OF THREE MENINGOCOCCAL DISEASE REPORTING DATABASES IN WALES}

\author{
P. Fitzpatrick, S. R. Palmer. \\ Communicable Disease Surveillance Centre (Welsh Unit), \\ Cardiff.
}

The 3 databases used for national surveillance of meningococcal disease (statutory notifications, laboratory isolates and Reference Laboratory (RL) isolates) were compared for the years 1991-1995 to estimate the completeness of reporting of laboratory-confirmed meningococcal disease and to estimate trends in laboratory-confirmed notifications versus all notifications of meningococcal disease. The laboratory and RL lists were merged to circumvent dependence of the 2 lists; two-sample capture- recapture methods were then applied to the combined list and the laboratory-confirmed notifications to estimate the number of cases corrected for ascertainment. Over the $5 \mathrm{yr}$ period laboratory-confirmed notifications $(n=297)$ comprised 60.2 per cent of RL isolates $(n=493)$ and 77.7 per cent of laboratory reports $(n=382)$. Fifty per cent of all reported cases of meningococcal disease could be identified in the RL database. Ascertainment rates ranged from 45.3 per cent to 72.4 per cent. The overall case ascertainment rate was calculated as 61.2 per cent, representing a discrepancy of 477 cases. This study demonstrates major discrepancies in the documentation of meningococcal disease by each of the 3 sources of data and an apparent under-reporting of laboratory-confirmed meningococcal disease. Electronic transfer of all laboratory data, after single entry onto laboratory computer, to CDSC would automatically improve reporting by laboratories, without additional data punching workload. Accurate and complete reporting is imperative before meaningful interpretation of national statistics can be undertaken.

\section{(75) BREAST FEEDING IN A HEALTH BOARD REGION}

F. Howell, D. Bedford, B. O' Keefe, R. Corcoran. Department of Public Health Medicine, North Eastern Health Board, Navan, Co. Meath.

Breastfeeding is regarded as being superior to bottlefeeding. Policy documents have been developed to increase the rate of breastfeeding. This study looks at breastfeeding rates in a region and why the uptake is low. Of the 308 women who had a live singleton birth in a 4 week period, data, collected by the Public Health Nurses, were available for 287 (93.2 per cent). The following proportions breastfed: at birth -34.8 per cent, hospital discharge - 29.6 per cent, 6 weeks - 20.2 per cent, 16 weeks 10.1 per cent. Most of the differences in demographics between breastfeeders and bottlefeeders are explained by social class. Women who breast fed were more likely to have been spoken to about the benefits during pregnancy than were bottlefeeders. Of those who bottlefed, 27 per cent did not want to breastfeed and 18 per cent felt it was too time consuming. Further, 24 per cent were unable to give any benefits for breastfeeding and 9 per cent said there were no benefits. Of those who breastfed, 54 per cent felt that people wanted them out of sight, 22 per cent stopped because of poor supply, 19 per cent because they were tired and 18 per cent because the baby was unhappy. Existing policies to increase breastfeeding rates have either failed or not been implemented. Breastfeeding and the promotion of same needs to become a more attractive issue for mothers. 


\section{(76) FOLIC ACID CONSUMPTION}

F. Howell, D. Bedford, B. O' Keefe, R. Corcoran. Department of Public Health Medicine, North Eastern Health Board, Navan, Co. Meath.

Periconceptual folic acid is recommended for women in order to prevent a neural tube defect in their offspring. Little information is available on the uptake of this important public health topic.

This study looks at the consumption of folic acid in a cohort group of 308 women who had a singleton birth in a 4 week period in a health board region. Data is available for 287 ( 93.2 per cent). Of these, 26.5 per cent were taking folic acid before they become pregnant. This increased to 65.9 per cent during the pregnancy. Those in lower socio-economic groupings were less likely to have taken folic acid. Only 57.8 per cent knew why they should take folic acid at any time.

This study has important implications. Obviously, the message about the need to take folic acid to prevent neural tube defects is not getting to those who need to know and hence it raises the question as to whether foods need to be fortified with folic acid in order to prevent the tragedy of neural tube defects.

\section{(77) APPROPRIATENESS OF USE OF ACUTE HOSPITAL BEDS IN DUBLIN}

D. Igoe, E. Connolly, M. Hynes.

Department of Public Health, Eastern Health Board, Dr. Steeven's Hospital, Dublin 8.

Health care services are facing increasing demands as a result of rising patient expectations, developments in technology and aging of the population. There is a need to ensure that current resources are being managed effectively and efficiently. Evidence from both Ireland and abroad indicates that inappropriate bed usage is sizeable.

The objectives of this study were to evaluate the appropriateness of admissions and days of care in acute hospitals in Dublin and to document the reasons for inappropriate use of acute hospital facilities, with a view to implementing corrective action plans.

A random sample of 1600 patients in 6 acute hospitals was taken during November 1995 using a diagnosis independent, appropriateness evaluation protocol (Restuccia).

Overall, 21 per cent of admissions and 31 per cent of days of care were judged inappropriate. More than 50 per cent of all inappropriate admissions could have been managed as outpatients. One third of patients with inappropriate days of care still required hospital treatment but had difficulty obtaining results or scheduling procedures. The remaining two thirds no longer required acute hospital care. The barriers identified here were unavailability of long term care and patients remaining in hospital when they could have been managed as outpatients.

This study showed where the barriers to optimal bed management lie, both within the control of the hospital and in the external environment. It has therefore highlighted areas to focus on to achieve quality bed management.

\section{(78) TUBERCULOSIS CLINIC AUDIT SYSTEM}

H. Johnson, T. Grein, B. Lee, T. McDonnell*. Eastern Health Board, Dr. Steevens Hospital, Dublin 18; *St. Vincent's Hospital, Elm Park, Dublin 4.

Ongoing evaluation of the management of tuberculosis cases and contacts is essential at clinic level to monitor adherence to local guidelines, and at regional and national level to provide epidemiological data for planning purposes.

A manual monitoring system was developed. The Contact Monitor, Tuberculosis Register and Therapy Monitor forms are A4 size. For contacts variables include: name; address; birth date; type of contact with the case; BCG status; tuberculin test dates and results; chest X-ray dates and results; and final outcome (tuberculosis diagnosed, preventive therapy prescribed). On the Tuberculosis Register variables include: diagnostic details (radiology, microscopy, culture); planned therapy; and outcome (cure, non compliance). For each tuberculosis case or contact on therapy, the Therapy Monitor records details over 6 months: ongoing therapy; microscopy; culture and blood test dates and results; and a check list of common adverse effects to therapy. Using Epi Info software a menu-driven computerised system was developed with screens matching the paper records.

The relevance and simplicity of both manual and computerised systems has led to their introduction on a national basis.

The integrated components of the system permit ongoing audit of all aspects of clinical management in a tuberculosis clinic and the encouragement of best practice.

\section{(79) IMPACT OF FOLIC ACID PROMOTION}

\author{
G. M. Sayers, E. Scallan, Z. Johnson.
}

The Health Information Unit, Dr. Steeven's Hospital, Steeven's Lane, Dublin 8.

A cross-sectional survey was undertaken among 300 women attending their first antenatal appointment in the 3 major maternity hospitals in Dublin. The aim of the study was to document the knowledge and behaviour with respect to periconceptional folic acid and thus evaluate the impact of health promotion campaigns to date on this topic. There was a 98 per cent $(295 / 300)$ response rate.

53.6 per cent (158/295) had heard of folic acid. Such knowledge was significantly associated with increasing age $(\mathrm{p}<0.00000)$ and a planned pregnancy $(\mathrm{p}<0.00000)$. The majority ( 58.2 per cent) found out about folic acid from lay sources such as friends or the media.

One eighth (12.9 per cent, $38 / 295)$ had been advised to take folic acid before becoming pregnant, the majority ( 55.3 per cent, $21 / 38$ ) having been advised by doctors. Twenty-one per cent ( $62 /$ 295) knew that folic acid prevents spina bifida. 5.8 per cent (17/ 295) had taken folic acid before becoming pregnant. Having a planned pregnancy was significantly associated $(p<0.005)$ with taking folic acid before becoming pregnant. This study highlights the poor impact of health promotion campaigns to date and provides a challenge to health professionals to improve on this situation.

\section{(80) PREVENTION OF HEART DISEASE: THE USE OF PRAVASTATIN TO LOWER CHOLESTEROL \\ D. Kilcoyne, L. Daly.}

Department of Preventive Cardiology, University College Dublin at The Research Centre, St. Vincent's Hospital, Dublin 4.

There is a long association between high cholesterol and the incidence of coronary heart disease. The West of Scotland Heart Study conducted a randomised trial of the use of Pravastatin in 
men with a cholesterol, $7.1 \mathrm{mmol} / \mathrm{l}$. The study concluded that the treated group had a significant reduction in cholesterol and coronary disease.

The present study examined records of 52,382 screeenees between 1986 and 1991. Of these there were 35,324 males with a mean age of $40 \mathrm{yr}$. They had taken part in a cardiovasular risk factor screening and had cholesterol measured in addition to other risk factors. Five thousand and 32 men were found to have cholesterols $7.1 \mathrm{mmol} / 1$.

The results show that the majority of the group were within the age range 35-65 yr. Additional risk factor measurements also indicated slightly higher blood pressures in the group and a higher percentage of overweight people.

We conclude that in this population of 52,000 well people 14 per cent fall into the guidelines of WOSCOP indicating benefit from treatment by Pravastatin with subsequent reduction in the incidence of coronary disease.

\section{(81) LIPID LOWERING DRUGS - UNDER USED BUT A} NEED FOR COST EFFICIENCY TO DIRECT GROWTH

P. McGettigan, A. Kelly, M. Carvalho, J. Feely. Pharmacoeconomics Unit, Department of Therapeutics, Trinity Centre for Health Sciences, St. James's Hospital, Dublin 8.

Recent studies have established the safety and efficacy of lipid lowering drugs (LLD) in patients with and without preexisting coronary heart disease (CHD). To estimate the current use of LLD in Ireland we analysed prescription data from the General Medical Services (GMS) Scheme which provides free medical care, including medicines on a means test basis to 36 per cent of the population.

The prevalence of hypercholesterolaemia at which primary preventative therapy may be required (greater than $6.4 \mathrm{mmol} / \mathrm{l}$ ) in our population aged 35 to $64 \mathrm{yr}$ is approximately 30 per cent (Irish Heart Foundation, 1992). The prescription of LLD doubled from 1992 to 1994 to 0.2 per cent of total GMS prescriptions. Within the Eastern Health Board approximately 455,000 drug items are dispensed each month to 144,000 patients ( 39 per cent of registered GMS patients). Of those 908 (or 0.6 per cent of those receiving a prescription) prescribed LLD, 59 per cent were female, two-thirds aged between 55 and 74 yr, 7 per cent under $35 \mathrm{yr}$, and 9 per cent over 74 while some 30 per cent of the population aged 45-64 are on other cardiovascular drugs. Statins, (particularly pravastatin) were the most widely used, commonly at $10 \mathrm{mg}$ not the $40 \mathrm{mg}$ shown to reduce deaths in clinical trials. Clofibrate is still in use, particularly in the elderly. Recent guidelines (Lancet, 1996, 348: 1251) recommending a statin when the risk of CHD exceeds 3 per cent per year, would apply to 0.4 per cent of females, 5.7 per cent of males, costing $\mathfrak{f} 10 \mathrm{k}$ per life year saved. As less than 0.5 per cent are now treated, at sub-optimal dosage and more females than males, it is important that the rise in LLD is directed in the most cost efficient manner.

\section{(82) MRSA IN CYSTIC FIBROSIS PATIENTS}

T. O'Connell, M. X. FitzGerald, L. Fenelon. Departments of Microbiology and Medicine, St. Vincent's Hospital, Elm Park, Dublin 4.

The epidemiology of MRSA in cystic fibrosis has not previously been documented. This study documents the epidemiology of MRSA in CF patients in the National Aduit CF Referral Centre.

Retrospective review of patient records from July 1990 to June 1996. Age / Sex / Epidemic Curve / Culture Site / Persistence or Non-Persistence / Hospital at Onset documented.

Thirty-one patients identified, with complete documentation on 25 (these are discussed). Mean age of onset of MRSA was $20 \mathrm{yr}$ with a male predominance $(16 / 25)$. Peak of new cases noted in $1994(7 / 25)$. MRSA was isolated from sputum in all 25 patients, but interestingly was isolated from other carriage sites in only 4 patients. Intermittent colonisation was seen in 6 patients, transient colonisation in 14 , and permanent colonisation in 5. Most patients first became positive in St. Vincent's (23/ 25).

Conclusion: MRSA is an increasing problem in CF, but unlike other MRSA patients, skin and mucous membrane colonisation is not commonly seen. This may have implications for infection control in these patients.

\section{(83) THE ROTUNDA STOP SMOKING PROGRAMME}

\author{
L. Thornton, C. Gogan, P. McKenna.
}

Eastern Health Board, Dr. Steevens' Hospital, Dublin 8 and Rotunda Hospital, Dublin 1.

The aim of the Rotunda Stop Smoking Programme was to encourage and support women to stop smoking in pregnancy and to maintain smoking abstinence after delivery.

This was a randomised controlled trial. The study population was 418 women smokers attending the public ante-natal clinic for a first visit during a 3 month period in 1995. The intervention consisted of structured one-to-one counselling by the stop smoking facilitator, use of an information pack specifically designed for this programme, use of a carbon monoxide monitor, and stop smoking support groups.

There was no difference in gestation or birth weight between the intervention and control groups. There were more quitters (though not statistically significant) in the intervention group at delivery (r.r. 1.33, 95 per cent c.i. $0.69-2.55$ ) and at 3 months post-partum (r.r. $2.0,95$ per cent c.i. $0.88-4.54$ ). There was a greater dose reduction in the intervention group, both at time of delivery $(p=0.004)$ and at 3 months post-partum $(p=0.05)$. The intervention group had more quit attempts. Feedback on the programme was positive.

It is recommended that smoking cessation counselling should be delivered to all pregnant women, the written materials developed for this programme be disseminated for use in other hospitals, an educational video should be developed for use in ante-natal clinics, and midwives and obstetricians should receive training in smoking cessation counselling.

\section{ANAESTHESIOLOGY}

\section{(84) EDUCATION AND PATIENT CONTROLLED ANALGESIA}

L. Brennan, M. J. Griffin, A. J. McShane.

Department of Anaesthesia and Intensive Care, St. Vincent's Hospital, EIm Park, Dublin 4.

Patient Controlled Analgesia has numerous advantages. However, inadequate analgesia and significant symptoms ascribed to $\mathrm{PCA}$ often result in premature termination and 
unsatisfactory results. Anxiety and poor coping skills predict postoperative pain and may be reduced by education (1). This study determined the effect of detailed preoperative education on postoperative PCA utilization, pain, patient satisfaction, side effect profile and antiemetic use.

Eighty-five patients were randomly assigned to Group A (special tuition) or Group B (no special tuition). Group A received in-depth explanation of PCA and a visual demonstration. Group B received nonstandardized information from their anaesthetist at preoperative visit. Visual Analogue Scale assessment of pain and satisfaction, morphine consumption, side effects, antiemetic use and rescue analgesia requirement were recorded in recovery, at $6 \mathrm{~h}, 24 \mathrm{~h}$ and $48 \mathrm{~h}$. Statistical analysis was with the Mann-Whitney-U test and the Chi-squared test.

Morphine consumption, pain scores and satisfaction scores were similar at all times. Pain scores were low and satisfaction scores were high. Group A had significantly less nausea and vomiting at 6 and $24 \mathrm{~h}$ and significantly increased antiemetic use.

Discussion: Preoperative PCA tuition results in increased and more efficient use of antiemetic medication and an improved side effect profile but does not affect patient analgesia or satisfaction. The authors acknowledge grant support from the Health Research Board.

\section{(85) SINGLE RESUSCITATOR CPR - A NEW METHOD?}

\section{A. Fanning, P. Naughton, M. McCarroll.}

Department of Anaesthesia, Mater/Cappagh Hospital, Dublin.

This study evaluates a new method of single resuscitator CPR. As part of our new technique, the resuscitators position is changed leading to easier ventilation of the patient.

Twenty volunteers participated in the study. Each participant had previously attended a course in advanced cardiac life support (ACLS). After an introduction to the new method of CPR, each participant performed single handed CPR for 3 minutes using the ACLS technique and after a 10 minute rest period performed the same procedure using our method. 'Ambu Resus' simulators were used with on line measurement of individual performance available. Statistical significance was shown $(p=0.003)$ when the 2 methods were compared for the percentage of correct ventilations given to the simulator. This did not occur in respect of the percentage of correct chest compressions performed $(p=$ 0.14 ). Our new method was shown to require less work on the behalf of the rescuer as shown by differences in heart rates at 1 minute $(p=0.004)$. Sixteen ( 80 per cent) of the participants had a preference for our method.

Conclusion: Improved performance and a preference tor the new technique was shown.

\section{(86) HYPERKALAEMIC PERIODIC PARALYSIS: ANAESTHETIC MANAGEMENT OF A FAMILY}

A. Lydon, G. Ormonde.

Waterford Regional Hospital.

Hyperkalaemic periodic paralysis is an autosomal dominant disorder, characterised by muscle weakness in response to elevations in serum potassium: Paramyotonia features myotonia exacerbated by cold and exercise. Abnormalities of sodium channel function underlie both disorders, which may be variants of one disease.

We present the management of a family suffering from both hyperkalaemic periodic paralysis and paramyotonia, undergoing multiple anaesthetic procedures.

Although advances over the last 5 yrs have enabled accurate diagnosis of the ion channel defect, clinical anaesthetic management still poses significant dilemmas, such as the safety of neuromuscular relaxants, regional anaesthesia and malignant hyperpyrexia susceptibility.

\section{References}

Anaesth. 1992; 47: 579-584.

Anesth. Analg. 1994: 79: 1012-4.

\section{(87) ACUTE UPPER AIRWAY OBSTRUCTION AND ANGIOTENSIN CONVERTING ENZYME INHIBITOR THERAPY}

A. Lydon, R. Rooney, C. Burke.

James Connolly Memorial Hospital, Blanchardstown, Dublin 15.

Angiotensin converting enzyme inhibitor therapy is increasingly popular in the management of hypertension and congestive cardiac failure. Angioeodema of the head and neck resulting in life threatening airway obstruction is a complication of such treatment, and may occur even after long term therapy. If milder episodes go unrecognised, it may recur with unpredictable severity.

We present a case of acute angioeodema resulting in airway compromise in a patient on long term angiotensin converting enzyme inhibitor therapy, and discuss the contrasting treatments of acquired and hereditary angioeodema.

In view of the widespread use of angiotensin converting enayme inhibitors, clinicians across a wide range of specialties should be made aware of this potentially fatal adverse effect.

References

Anaesth. Analg. 1992: 74 (4): 602-4. Laryngoscope 1992: 102 (3): 256-60.

\section{(88) PYREXIA, LEUCOCYTOSIS AND BACKPAIN AFTER REPEATED SPINAL ANAESTHESIA}

D. J. Malkan, E. Tierney.

Department of Anaesthesia, Wexford General Hospital, Wexford, Ireland.

A 58 yr old female, ASA Class I, underwent surgery for extensive varicose veins of the right leg. This was followed by similar surgery on the left leg 2 days later. The Anaesthetic technique used on both occasions was lumbar spinal anaesthesia. Anaesthesia and surgery were uneventful on both occasions. Post-operatively after the second procedure the patient developed pyrexia, leucocytosis and severe low back pain with localised tenderness. No signs of any infective focus were found. There was no evidence of meningism, but one brief episode of confusion was noted. In view of the 2 recent spinal anaesthetics and the absence of any other localising signs of infection, we considered the possibility of spinal infection, which, although rare, needed to be ruled out. The investigation of choice for spinal / epidural abscess is an MRI scan, but this was unavailable to us. An eventual MRI seemed to confirm a spinal epidural 
abscess initially. The patient's condition later deteriorated, necessitating a surgical procedure which answered all our queries and helped us to reach a final diagnosis.

\section{(89) AN ACUTE PAIN SERVICE - AN 18 MONTH EXPERIENCE}

P. Naughton, A. Thompson, J. Keaveney. Department of Anaesthesia, Beaumont Hospital, Dublin.

Patient controlled analgesia (PCA) is a technique of pain relief which was introduced in the past decade for the management of patients with acute pain when it became accepted that conventional methods did not lead to patient satisfaction. An acute pain service (APS) was set up in our hospital during 1993. The aim of this survey was to describe our experience with the APS over an 18 month period starting 1/7/1995.

Data on all our patients has been recorded contemporaneously since the APS was commenced. This data was examined retrospectively.

We have treated 1850 patients during this period, all with PCA using either intravenous morphine or pethidine. 51.8 per cent of our patients were male. 95.6 per cent of patients were postoperative, 36.4 per cent under the care of a general surgical team. The most frequent age group of the patients was $60-69 \mathrm{yr}$ (16.4 per cent) (range 8-88 yr). 39.8 per cent of patients spent 1 or 2 days using PCA (range 0-43 days). Nausea was the most common complication affecting 14 per cent. Respiratory depression occurred in 4 per cent (resp. rate $<10$ ) and naloxone was required in 5 patients. There were no serious complications.

We have found PCA to be a safe and affective form of managing the patient with acute pain.

\section{(90) ANALGESIA FOLLOWING REGIONAL} ANAESTHESIA FOR CATARACT SURGERY

\section{Fahy, D. Buggy, J. McAdoo.}

Department of Anaesthesia \& Pain Management, Cork University Hospital, Cork.

Pain following regional anaesthesia for cataract surgery and its optimum management in an ambulatory (day-case) setting is unknown. We investigated pain in patients following cataract surgery under regional anaesthesia and the analgesic efficacy of 2 oral analgesic agents. Ninety-six consecutive patients after cataract surgery under regional anaesthesia were randomised into 4 groups: Group 1 and group 3 received paracetemol $500 \mathrm{mg}$ and copraxamol (a combination of codeine and paracetemol) respectively in recovery room. Groups 2 and 4 received paracetemol and copraxamol respectively as required only on the ward. Pain was measured at $2,4,6,8$ and $24 \mathrm{~h}$ on a 10 point verbal response scale (VRS). Pain was documented by nurses who were blind to the study groups. Regional anaesthesia was a peribulbar block, performed by the same anaesthetist, highly skilled in the technique. Fifty-seven per cent of patients reported no pain at any time after their surgery. Pain was mild $($ VRS $<5$ ) in those who did experience pain, except for $n=2$ who reported a VRS $=6$. There were no significant differences between the groups in terms of VRS, analgesic requirements the numbers reporting any pain. We conclude that analgesia after regional anaesthesia for cataract surgery may be unnecessary in over 50 per cent patients and when it occurs, it may be managed adequately by oral paracetemol $500 \mathrm{mg}$. Our data support the performance of this surgery in an ambulatory anaesthesia setting.

\section{(91) PATIENT UNDERSTANDING OF AND COMPLIANCE WITH INSTRUCTIONS GIVEN FOR AMBULATORY SURGERY}

J. Laffey, M. Carroll, J. Boylan.

Department of Anaesthesia, St. Vincent's Hospital, Elm Park, Dublin 4.

Ambulatory surgery has proliferated as a result of increasing inpatient costs ${ }^{1}$, with high levels of safety demonstrated ${ }^{2}$, resulting in its extension to less healthy, often elderly patients ${ }^{3}$. Patient compliance with instructions is essential to avoid morbidity. We aimed to identify subgroups potentially at risk due to non-compliance with instructions.

A questionnaire was administered to 200 consenting patients. Data included: demographics, fasting duration, taking of medications that morning, importance of fasting/medication instructions and postdischarge transport.

$\begin{array}{lcc}\text { Instruction } & \text { Nonessential } & \text { Essential } \\ \text { Fasting } & 19 / 200 & 181 / 200 \\ \text { Medication } & 9 / 59 & 50 / 59\end{array}$

Patients most likely not to comply with fasting instructions were male $(P=0.03)$ and older than average $(49 \pm 5$ vs $43 \pm 1, P$ $=0.10$ ). Of 59 patients taking medication, 13 took it before admission. SE group did not predict compliance with fasting or medication instructions. Eight ( 4 per cent) of patients admitted intending to drive home postoperatively and 5 ( 2.5 per cent) intended to take public transport home alone; these patients were predominantly male $(\mathrm{P}=0.046) .14$ ( 7 per cent) admitted to having no-one to stay with them on the night of surgery; these patients were predominantly older $(\mathrm{P}=0.054)$.

Many patients (particularly male) admit to noncompliance with instructions; these figures may be underestimates. Absence of medical/anaesthetic input and lack of reinforcement probably contribute to noncompliance. Some medication-related noncompliance may be appropriate (e.g., antihypertensives, antianginals) and may reflect conflicting patient instructions.

References

1. Kitz, D. S. et al. Anesthesiology 1988: 69 383-386.

2. Natof, N. E. JAMA 1980: 291 1116-1118.

3. $\times x \times x \times x$

\section{(92) ANAESTHETIC DEPTH / CLINICAL EYE SIGNS / EEG POLYSOMNOGRAPHY}

C. Power, C. Crowe, P. Higgins, D. C. Moriarty. Mater Misericordiae Hospital, Eccles Street, Dublin 7.

We examined John Snow's hypothesis (1847) that when the eyes assume an upward gaze during gas induction of anaesthesia the patient is protected from the risk of awareness. Before induction EEG electrodes were attached to the scalp, and scored (1-4) on the basis of standard polysomnographic principles.

Eye movements were recorded by noting five clinical end points normal 2, "drunk" 3 , central 4 , excitement 5 - eyes positioned upwards or the stage 4 position remained unaltered for 3 minutes. Eye movements were measured using electrodes on the right and left canthi referenced to the opposite ear lobe. 
Anaesthesia was induced with 8 per cent sevoflurane in oxygen which was maintained until eye position 5 was reached:

Twenty patients were recruited, 3 failed the protocol due to excess excitement. The 17 patients $(8 \mathrm{M}, 9 \mathrm{~F})$ had the following results expressed as median (range) -24 yrs (1640), latency to sleep; stage one - 4.5 mins $(2.5$ - 7.5), stage two - 5 mins (3.5 8.5) stage three - 5.5 mins $(4-12)$, stage four - 6 mins (4.5 $15.5)$. With regard to eye movement position 5 was reached after 9 mins $(5.5-18.5)$. This was significantly longer than the time taken to reach the deepest, level of the sleep EEG - stage 4 ( $p<$ 0.01 ). In conclusion this observation supports Snow's assertion, highlighting the value of investigating eye movement and the EEG polysomnography as monitors of anaesthetic depth.

\section{CARDIOVASCULAR}

\section{(93) ISOMETRIC EXERCISE IN HYPERTENSIVES:} EVALUATION OF A STRESS TEST FOR 31P MRS

M. Conway, M. Hall, L. Hemeryck, J. Feely. Department Pharmacology \& Therapeutics, Trinity College, Dublin.

Isometric exercise (ISOMEX) leads to a reduction in the myocardial creatine phosphate to ATP ratio ( $\mathrm{PCr} / \mathrm{ATP}$ ) in patients with ischaemic heart disease. In order to examine the efficacy of ISOMEX for future studies of high energy phosphorus metabolism in the hypertensive heart (HTN), we assessed the cardiovascular responses in untreated (n:6) and treated hypertensives ( $\mathrm{n}: 17$; mean age: $51 \pm 15 \mathrm{yr}$ ) and age matched non-hypertensive controls (n:7). Blood pressure (SBP, $\mathrm{DBP}, \mathrm{mmHg}$ ) and heart rate were recorded before and after 3 min of ISOMEX at 33 per cent of max grip strength. Compared to baseline, ISOMEX increased all parameters (after 1 and 3 minutes). In particular, the rate pressure product (RPP) was elevated in treated (and untreated patients) and in controls to a similar degree (mean \pm S.D.).

$\begin{array}{lllllll} & \text { \% rise } & \text { SBP } & \text { \% rise } & \text { DBP } & \text { \% rise } & \text { RPP } \\ & \min 1 & \min 3 & \min 1 & \min 3 & \min 1 & \min 3 \\ \text { CON } & 8.9 & 16.7 & 8.8 & 13.2 & 21.0 & 34.7^{*} \\ \text { [7] } & (5) & (6) & (5) & (6) & (10) & (13) \\ \text { HTN: } & 11.3 & 15.3 & 10.3 & 16.7 & 16.2 & 28.2^{*} \\ {[23]} & (8) & (11) & (7) & (10) & (11) & (17)\end{array}$

(CON: Controls; *: CON vs HTN : NS)

Thus, ISOMEX increases the RPP by c 30 per cent. It does not induce severe blood pressure responses, and can be tolerated for at least 3 minutes. 31P MRS data should, ideally, be recorded in the final minute of ISOMEX.

(94) LOW DOSE ANGIOTENSIN CONVERTING ENZYME INHIBITION FOR TREATMENT OF CARDIAC FAILURE IN THE ELDERLY

R. M. Doyle, M. Sinnott, R. O’Moore, D. Coakley, J. B. Walsh.

Mercers Institute for Research on Ageing and Department of Biochemistry, St. James's Hospital, Dublin.

Patients over 65 yr of age with Congestive Cardiac Failure N.Y.H.A. Class (ii), (iii) or (iv), were treated with Angiotension converting enzyme inhibitors (ACE inhibitors). The aim of the study was to determine if there was (a) a clinical improvement, (b) a deterioration in renal function, (c) a change in magnesium or urate and (d) a change in renin and aldosterone.

A clinical assessment, renal profile, serum magnesium, urate, renin and aldosterone (lying and standing) were taken at baseline and after 3 months of ACE inhibition. The dose of ACE Inhibition used was $6.25 \mathrm{mg}$ b.i.d. to $12.5 \mathrm{mg}$ t.i.d. or equivalent. The number of patients was 11 .

(a) $9 / 11$ (81.8 per cent) patients showed overall clinical improvement with reduction of dyspnoea and 8/11 (72.7 per cent) had diminution of ankle and or sacral oedema. (b) $8 / 11$ (81.8 per cent) patients had normal renal function at baseline and renal parameters remained within normal limits. Of 3 patients with initial evidence of renal impairment, 1 revealed a slight deterioration, a second had an increase in urea without an increase in creatinine and a third showed a slight improvement. (c) There were no significant changes in magnesium or urate. (d) 3/11 (27.3 per cent) had secondary hyperaldosteronism at baseline ( 2 of these had normal renal function) and aldosterone fell to within normal limits in all cases. One patient had a markedly raised renin at baseline which fell to within normal limits after treatment. All other cases had normal renin and aldosterone levels at baseline and these did not alter significantly.

In Conclusion 9/11 patients improved clinically on low dose ACE inhibition with only 2 showing deterioration of renal function. The 3 cases of secondary hyperaldosteronism reverted to normal after treatment.

\section{(95) SECONDARY PREVENTION OF CORONARY HEART} DISEASE - ARE WE IGNORING THE EVIDENCE?

\section{Hall, S. Killalea, P. Crean*. M. Walsh*, B. Foley*,

$$
\text { J. Feely. }
$$

Departments of Pharmacology and Therapeutics and *Cardiology, Trinity Centre, St. James's Hospital, Dublin 8.

Recent studies have shown that cholesterol reduction with statins results in a significant reduction in morbidity and mortality in patients with coronary heart disease. Yet, there is considerable evidence that secondary prevention of coronary heart disease is not being addressed adequately at hospital or community level. We assessed risk factor management in a cohort of patients who had suffered acute myocardial infarction on average 2.7 yr ago.

Of 240 patients with a discharge diagnosis of acute $\mathrm{MI}$ in 1993-94, 62 patients had died by the time of follow-up and 28 were not contacted for various reasons. Of 150 patients contacted, 96 (60 per cent, 74 male, 22 female) attended for interview, physical measurements and blood tests. Fifty-nine per cent of patients had a total cholesterol level $>5.5 \mathrm{mmol} / 1$ and only 10.5 per cent of these were on a lipid lowering drug. Over one-third of all patients had no evidence of having had their cholesterol checked in the past. There was no significant difference in lipid levels between those attending a hospital physician compared to a general practitioner. Twenty-eight per cent of patients were active smokers and about two-thirds of patients were overweight. One-fifth of patients were on antihypertensive therapy with a mean blood pressure of $127 / 71$ suggesting active management of this factor.

Our results highlight the need for targeted risk factor management in patients with coronary heart disease and suggest that there is under-utilisation of lipid lowering therapy. 
(96) BODY SURFACE MAPPING IS MORE SENSITIVE THAN THE 12-LEAD ECG FOR DETECTION OF LEFT VENTRICULAR HYPERTROPHY

S. Hameed, R. S. H. W. Patterson, I. B. A. Menown, S. R. McMechan, N. P. S. Campbell, A. A. J. Adgey.

Regional Medical Cardiology Centre, Royal Victoria Hospital, Belfast, N. Ireland

Left ventricular hypertrophy (LVH) is associated with higher cardiovascular morbidity and mortality. Standard ECG-criteria for detection of LVH have poor sensitivity. We compared a 64electrode anterior body surface mapping (BSM) system with the 12-lead ECG for detection of LVH. Thirty-nine patients undergoing routine ECHO for assessment of hypertension or valvular heart disease were recruited. Those with asymmetric septal hypertrophy, LBBB and previous myocardial infarction were excluded. Patients were grouped into those with or without LVH based on M-Mode criteria (Penn-convention) with threshold for LV-mass indexed to body surface-area (men $134 \mathrm{~g} / \mathrm{m}^{2}$ and women $110 \mathrm{~g} / \mathrm{m}^{2}$ ). From a 12 -lead ECG, voltage criteria for LVH were calculated: Cornell ( $\mathrm{rAVL}+\mathrm{sV}_{3}$ ), SokolowLyon $\left(\mathrm{sV}_{1}+\mathrm{rV}_{5}\right.$ or $\left.\mathrm{rV}_{6}\right)$, Rodstein ( $\left.\mathrm{I}+\mathrm{sIII}\right), \Sigma \mathrm{QRS}$ voltages and 12-lead product (: $Q R S$ voltages $x$ QRS duration). BSMs were recorded from which QRS potentials and isointegral features were obtained. According to ECHO, 24/39 patients had LVH. Cornell ECG criteria correctly determined presence of LVH in $10 / 24$ patients ( 42 per cent sensitivity, 80 per cent specificity). Inclusion of the other ECG criteria did not improve discrimination. Using multiple logistic regression analysis of BSM, 2 variables were derived (QRS maxima from 2 electrodes high on the left anterior chest, outside standard precordial lead positions) which correctly determined presence of LVH in 20 / 24 patients ( 83 per cent sensitivity, 67 per cent specificity). This study demonstrates the superior sensitivity of BSM over the 12lead ECG for detection of LVH.

\section{(97) TRANSOESOPHAGEAL ECHOCARDIOGRAPHIC EVALUATION OF LEFT VENTRICULAR OUTFLOW TRACT OBSTRUCTION}

T. Hennessy, P. Dardas, G. Filippatos, J. Crowley, C. Wisbey, L. Shapiro.

Regional Cardiac Unit, Papworth Hospital, Cambridge, CB3 8RE.

The role of multiplane transoesophageal echocardiography (MTOE) in the assessment of patients with hypertrophic cardiomyopathy (HCM) has not yet been fully elucidated. Higher resolution, and multiplane images should improve the assessment of left ventricular outflow tract (LVOT) obstruction compared to transthoracic echocardiography (TTE). For comparison of both modalities detailed assessment of the LVOT and mitral valve were performed. A total of 35 patients were studied ( 21 males, mean age was $55+17 \mathrm{yrs})$, of which $10(29$ per cent) had LVOT obstruction. Systolic anterior motion of the mitral valve was clearly seen in all these patients with MTOE in at least 2 views, but in only 5 patients with TTE. Eccentricity of MR jet was assessed in 2 patients with TTE (posterior) and in all 10 patients with TOE ( 9 posterior, 1 posterior and central). Coaptation site of mitral valve leaflets was seen in all 10 patients with TOE, but in only 4 with TTE. Thus, MTOE affords more detailed assessment of the nature of LVOT obstruction and mitral regurgitation compared to $\mathrm{TTE}$.
(98) DOES A BEDSIDE DECISION SUPPORT COMPUTER PROGRAM (DSCP) PROLONG THROMBOLYSIS "DOOR TO NEEDLE TIME"?

C. Keane, J. Kellett.

Nenagh Hospital, Nenagh, Co. Tipperary, Ireland.

The "door to needle time" delay of thrombolysis was assessed before and after the introduction of a decision support computer program (DSCP) for the management of suspected acute myocardial infarction (AMI). The DSCP estimates the chance of AMI and death from AMI from immediately available bedside parameters. It then determines by decision analysis the risks and benefits of thrombolysis for any individual patient: 2 to 3 minutes are required for data entry.

Admission times and subsequent time of thrombolytic administration before and after the introduction of the DSCP were retrospectively reviewed in 94 consecutive patients with suspected AMI. Half the patients (Phase I) were managed without, and half (Phase II) with DSCP support.

Both groups of patients were similar, with comparable ages, vital signs, times of presentation, and ECG findings.

The mean "door to needle time" for Phase II patients (75.7 \pm 39.7 minutes, range 20 to 215 minutes) was slightly, but insignificantly ( $p>0.05$ ), less than for Phase I patients $(86.5 \pm$ 53.3 minutes, range 21 to 363 minutes). The median "door to needle time" for both groups of patients was identical ( 70 minutes). Therefore, despite the time required for its use, the DSCP did not delay thrombolysis.

\section{(99) AUDIT OF DIAGNOSTIC RESOURCE UTILISATION IN PATENTS WITH NON-FATAL STROKE}

P. C. Keelan, J. B. O'Sullivan, P. O'Raghallaigh,

D. D. Sugrue.

Department of Cardiology, Mater Misericordiae Hospital, Dublin.

Non-fatal stroke (NFS) has major effects on quality of life and significant cost implications. There is confusion regarding which tests should be routinely utilised in evaluating patients with NFS.

A chart review of 100 consecutive NFS patients was conducted. Clinical and demographic data were tabulated. The value of physical exam and 12-lead ECG in predicting clinically significant results was assessed. The number of patients having brain CT scans, $24 \mathrm{hr}$ holter monitor (HM), carotid duplex scans and transthoracic echo (TTE) was noted. The number of investigations yielding a result which impacted on clinical management was documented.

Ninety patients had brain CT scans. Thirty-six patients had carotid duplex studies of which 12 (33 per cent) showed significant disease. All patients with carotid bruits had significant disease while 8 of 32 ( 25 per cent) without bruits had significant carotid disease. Thirty-one patients had HM of which 20 (62.5 per cent) revealed an arrhythmia. In only one case did the patient have neither a suspected clinical arrhythmia nor abnormal ECG. Of the 24 patients who had TTE, 8 (33 per cent) had a clinically significant finding. Only 1 of 5 patients with a normal ECG and normal cardiac examination had a clinically significant finding on TTE.

Conclusion: In most NFS patients, non-invasive vascular investigations give predictable or clinically insignificant findings. Careful physical examination and ECG evaluation can optimise use of diagnostic resources in these patients. 
(100) STROKE RISK AFTER MYOCARDIAL INFARCTION WITH OR WITHOUT THROMBOLYSIS: BEDSIDE DECISION SUPPORT

\section{J. G. Kellett.}

Nenagh Hospital, Nenagh, Co. Tipperary, Ireland.

As stroke is the major risk associated with thrombolytic therapy an exhaustive review of the MEDLINE literature was undertaken to determine the best bedside way to estimate stroke risk for any individual patient.

Several excellent bedside instruments have been developed that accurately estimate infarct size and mortality. Meta-analysis of 20,169 patients treated prior to the thrombolytic era shows a highly significant $(P<0.0001)$ linear relationship between the risk of infarct associated stroke and the chance of death from infarction (i.e. chance of stroke $=\left(0.21+0.036^{*}\right.$ (chance of death from infarction* 100))/100.

Without thrombolysis aspirin eliminates 45 per cent of infarct related strokes: only 2.5 per cent of such strokes are hemorrhagic. In 122,702 patients reported in the literature the risk of hemorrhagic stroke after thrombolysis relates to patient age, blood pressure, thrombolytic agent used and, possibly, body weight.

Although thrombolytics increase the overall chance of stroke by increasing hemorrhagic stroke risk, because they reduce infarct size and mortality they may produce a trivial lowering of the chance of non-hemorrhagic stroke.

All this information was captured in a simple computer program that calculates at the bedside the risk of stroke for any individual patient with acute infarction. The program requires as input: patient age, systolic and diastolic blood pressure, estimated chance of death, thrombolytic agent to be used, and body weight.

\section{(101) BODY SURFACE MAPPING FOR DETECTION OF. ACUTE MYOCARDIAL INFARCTION IN PATIENTS WITH LEFT BUNDLE BRANCH BLOCK}

I. B. A. Menown, J. Allen, S. Hameed, S. R. McMechan, J. Anderson, A. A. J. Adgey.

Regional Medical Cardiology Centre, Royal Victoria

Hospital, and University of Ulster, Belfast, N. Ireland.

Detection of acute myocardial infarction (AMI) with left bundle branch block (LBBB) remains a diagnostic challenge. We thus evaluated the diagnostic potential of body-surface mapping (BSM) which consists of a screen-printed 64-electrode anterior harness and 16-electrode posterior harness applied to the chest wall. Maps are displayed in isointegral or isopotential formats. We recruited 24 patients with chest pain and LBBB, and 23 controls with LBBB but without chest pain. A 12-lead ECG and 80-lead BSM were obtained in all subjects, and cardiac enzymes in those with chest pain. QRS and ST-T isointegral maps and an ST60 isopotential map (60ms after the J point), were derived from each BSM. Seven of the 24 patients had AMI as defined by maximum $C K \geq 2 x$ upper normal limit. Only $2 / 7$ fulfilled Sgarbossa's ECG criteria for AMI with LBBB (NEJM. 1996; 334(8): 481-487). BSM analysis showed that in both controls and patients without AMI, loci of maxima and minima typically reversed positions when comparing the QRS isointegral map with the ST-T isointegral and/or ST60 isopotential maps i.e. a vector shift of $180^{\circ}\left( \pm 15^{\circ}\right)$. In contrast, patients with AMI typically showed a vector shift outside these limits. This technique correctly identified AMI in 5/7 subjects and excluded
AMI in 36/40 subjects ( 71 per cent sensitivity, 90 per cent specificity). Thus, in comparison with the 12-lead ECG, analysis of static vector patterns from BSM appears a promising method of detecting AMI in patients with chest pain and LBBB.

\section{(102) CLINICAL AUDIT OF ECHOCARDIOGRAPHY FACILITIES IN A TERTIARY REFERRAL DUBLIN HOSPITAL \\ P. Owens, P. Gallagher. T. Gumbrielle, E. T. O'Brien, J. H. Horgan. \\ Department of Cardiology, Beaumont Hospital, Dublin.}

This audit of echocardiography facilities was undertaken to determine efficiency in the department, in response to prolonged waiting times for inpatient procedures, and to determine whether the introduction of a Saturday echo session would significantly shorten waiting lists.

A real-time log of echoes performed over 5 weeks was kept, and data pertaining to ordering patterns and waiting times was gathered prospectively on specially designed forms. The data collected was summarised on a computer database. The Saturday echo session was financed by the hospital over a 2 week period, and prospective data collection was continued during this time. Data regarding inpatient waiting times and echoes performed before and during this intervention were compared to determine utility of this approach in reducing inpatient procedure waiting times. Data is presented below.

$\begin{array}{lcc} & \text { No. of echoes per week } & \text { Wait time (days) } \\ \text { Pre-Intervention } & 64.2 & 2.55 \\ \text { Post-Intervention } & 87 & 2.03 \\ \text { Percent change } & +35 \% & -25 \%\end{array}$

The time-efficiency of the service was high, with inpatient delays due to heavy workload. The introduction of a Saturday session appreciably reduced waiting times for echocardiography. This was evident over a 2 week trial period, so results are almost certainly an underestimation. This has significant financial implications, and implications for patient welfare.

\section{(103) BRONCHO-OESOPHAGEAL FISTULA COMPLICATING CARDIAC SURGERY}

\section{P. Sidhu, S. MacGowan.}

Department of Cardiac Surgery, Royal Victoria Hospital, Belfast.

As a minimally invasive tool to assess cardiac anatomy and function the use of intra-operative trans-oesophageal echocardiography (TEE) in cardiac surgery is rapidly expanding. Reported complications are rare. A 73 yr old male presented with a diagnosis of post-infarction ventricular septal defect (no history of respiratory or gastrointestinal disease). At operation the Toronto technique was used to close the defect and the result assessed with TEE. Despite good haemodynamics, the postoperative course was complicated by sepsis and pneumonia, with worsening chest radiography, despite aggressive antibiotic therapy. The patient eventually succumbed. Post-mortem examination of the oesophagus revealed an area of ulceration with a fistula leading to the left main bronchus. Instrumentation of the oesophagus is the commonest cause of oesophageal injury'. Contact pressures at the tip of the TEE probe of up to 
$60 \mathrm{mmHg}$ can be produced ${ }^{2}$. Although complications are rare with intra-operative $\mathrm{TEE}^{3}$, they may be seen more often as the technique becomes more routine. We advise 1) screening patients for a history of oesophageal disease and 2) a high index of suspicion for oesophageal injury in cases of sepsis where oesophageal instrumentation has taken place.

\section{References}

1. Jones, G. J., Ginsberg, R. J. Esophageal perforation: a continuing challenge. Ann. Thorac. Surg. 1992; 53:534-43.

2. Urbanowicz, J. H., Kernff, R. S., Oppenheim, G. et al. Transoesophageal echocardiography and its potential for esophageal damage. Anesthesiology 1990; 72: 40-3.

3. Daniel, W. G., Erbel, R., Kasper, W. et al. Safety of transoesophageal echocardiography. A multicenter survey of 10,419 examinations. Circulation 1991: 83: 817-821.

(104) NATURAL ANTIOXIDANT STATUS AND LOWDENSITY LIPOPROTEIN OXIDATION IN POSTMENOPAUSAL SMOKERS AND NON-SMOKERS

Y. Wen, *M. Doyle, *R. Harrison, J. Feely. Department of Therapeutics, Trinity Centre for Health Sciences, St James's Hospital, Dublin 8 and *Academic Department, Obstetrics and Gynaecology, RCSI, Rotunda Hospital, Dublin 1.

Postmenopausal women have a significantly increased incidence of atherosclerotic heart disease. Free radical mediated oxidation of low-density lipoprotein (LDL) is thought to be the earliest step of atherosclerosis and cigarette smokers have low natural antioxidant levels possibly due to abundant free radicals contained in smoke. We studied natural antioxidant status and the oxidation of LDL in healthy postmenopausal non-smokers $(n=12)$ and smokers $(n=8)$ who were free of medication and antioxidant supplementation. Fasting blood samples were taken from each subject for measurements of plasma ascorbate, red cell a-tocopherol and reduced glutathione (GSH) and LDL $\alpha$ tocopherol. LDL was isolated by using ultracentrifugation and the ex vivo oxidation was induced by adding copper sulphate and determined as lag phase of the production of conjugated dienes. Although it did not reach statistical significance, LDL $\alpha$-tocopherol level appeared higher in postmenopausal nonsmokers $(2.35 \pm-0.21 \mathrm{nmol} / \mathrm{mg}$ LDL, mean $\pm \mathrm{SD})$ but lower in smokers $(2.15 \pm 0.19)$ in comparison to 11 pre-menopausal nonsmokers $(2.26 \pm 0.20)$. Plasma ascorbate $(35.4 \pm 14.3$ vs $49.6 \pm 16.5$ $\mu \mathrm{mol} / 1$, postmenopausal smokers and non-smokers, respectively, $\mathrm{p}<0.05)$ and red cell GSH $(52.7 \pm 21.5$ vs $65.4 \pm 26.3 \mathrm{mg} / \mathrm{dl}$, $\mathrm{p}<0.05)$ were significantly lower in smokers. Significantly shortened lag phase, indicating a higher rate of oxidation, was found in smokers ( $48.6 \pm 9$ vs $54.6 \pm 12 \mathrm{~min}$., $\mathrm{p}<0.05$ ). These data indicate that there may be an increased risk of oxidatively mediated atherosclerosis in postmenopausal smokers. It may be possible to modify this through antioxidant supplements.

The study was supported by the Irish Heart Foundation.

(105) SLEEP DISTURBANCE DURING AMBULATORY BLOOD PRESSURE MONITORING IN HYPERTENSIVE PATIENTS

A. C. Leary, M. B. Murphy.

Department of Pharmacology and Therapeutics, University College Cork and Mercy Hospital, Cork, Ireland.

Our objective was to determine whether hypertensive patients experience poorer sleep quality during 24-hour ABPM than normotensives, due to discomfort secondary to higher cuff inflation pressures. In a case-control; study, 33 hypertensives who had undergone simultaneous ABPM and activity monitoring with a piezoelectric wrist accelerometer were age-matched to 66 normotensive controls. The accelerometer integrated activity scores ranging from 0 to 253 units at 10 second intervals; these data were used to determine sleeptime, waketime and sleep quality. Average daytime BP (162 $\pm 8 / 97 \pm 10$ in hypertensives; $121 \pm 7 / 80 \pm 7$ in normotensives) and night-time BP $(143 \pm 11 / 85 \pm 9$ and $103 \pm 9 / 65 \pm 7$ respectively), differed significantly $(P<0.001)$. Compared to normotensives, hypertensives exhibited higher mean nocturnal activity scores $(2.8 \pm 1.9$ vs. $1.8 \pm 0.9, P=0.0051)$, and more nocturnal scores $>1$ unit $(7.7 \pm 4.9$ per cent vs. $5.4 \pm 2.8$ per cent, $\mathrm{P}=0.014)$. Hypertensives also exhibited more episodes of nocturnal disturbance (defined as at least 4 consecutive readings $>10$ units; $5.6 \pm 3.6$ vs. $3.7 \pm 2.9, P=0.013$ ), and showed less nocturnal "dip" in blood pressure compared to normotensives $(11.6 \pm 4.8$ per cent/12.1 14.7 per cent vs. $15.0 \pm 6.6$ per cent/17.9 \pm 7.0 per cent, $P<0.005$ ). There was no difference in sleep duration or daytime activity scores between groups. These findings suggest that higher cuff inflation pressures experienced by hypertensive patients are associated with increased nocturnal disturbance and may minimize the fall in blood pressure at night.

(106) ALTERNATIVE TREATMENTS IN ACUTE SEVERE PULMONARY EMBOLISM; PERCUTANEOUS CATHETER AND GUIDEWIRE FRAGMENTATION WITH AND WITHOUT THE LOCAL ADMINISTRATION OF RECOMBINANT TISSUE PLASMINOGEN ACTIVATOR (RT-PA)

N. Mulvihill, J. Murphy, D. Mulcahy, B. Foley, P. Smiddy, M. Molloy.

Department of Cardiology and Department of Diagnostic Imaging, St. James's Hospital, Dublin 8.

Acute severe pulmonary embolism is a serious clinical problem with a high mortality. Current therapeutic options include intravenous heparin, intravenous thrombolytic agents with or without heparin, embolectomy or catheter fragmentation. The prevention of acute right heart failure is the primary aim of treatment, however in some cases this will not be achieved using the modalities listed above.

Acute lower limb emboli are often treated by percutaneous catheter and guidewire fragmentation followed by the local infusion of a thrombolytic agent. We applied this protocol to treat acute pulmonary emboli. We describe 5 cases of acute severe pulmonary embolism treated in this manner.

Catheter and guidewire fragmentation leads to dispersion of the embolus distally. This increases the surface area of embolus available to be acted upon by the thrombolytic agent. Local administration of the recombinant t-PA allows a high concentration of the thrombolytic to act upon the obstructing embolus.

In our series to date all patients have made excellent recoveries. We propose that mechanical fragmentation of thrombus followed by intra-pulmonary arterial infusion of rtPA is a valuable method of treating acute severe pulmonary embolism. Further research is required in this area. 


\section{CRITICAL CARE MEDICINE}

\section{(107) MEDICO-LEGAL STUDY OF THE PERSISTENT} VEGETATIVE STATE

J. Hyslop, D. A. Cusack.

Division of Legal Medicine, University College Dublin.

This clinical, scientific and jurisprudential study reviewed the medical, ethical and medico-legal criteria in establishing the diagnosis of persistent vegetative state (PVS) with reference to national and international studies and case histories.

Published criteria from several international medical bodies were analysed and clinical contact time and professional interviews were completed with intensivists, neurologists and rehabilitation physicians. Very recent studies have emerged which question the accuracy of diagnosis in PVS patients. Despite having apparently fulfilled the criteria for diagnosis of PVS, a small number of patients are reported to have regained awareness. Therefore, the diagnosis is one of probability and not one of certainty.

The study analysed Re a Ward of Court and cases of PVS patients in other jurisdictions and the current guidelines of the Medical Council and An Bord Altranais on the separate and distinct issues of treatment withdrawal and euthanasia. In particular, futility of treatment and the legal and ethical criteria for treatment withdrawal were investigated. In this context, the June 1996 BMA Ethics Committee guidelines of the treatment decisions for patients in PVS were found to form an instructive and caring basis for physician decision making on PVS.

The complex relationship between modern clinical medicine, law and ethics in the matter of PVS and selective treatment or treatment withdrawal where such may be futile are put into clear focus by this study, which is ongoing. The preliminary recommendations arising are that:

1. research into the condition of PVS patients be continued and expanded;

2. the prevalence and incidence of PVS in Ireland be established;

3. a multi-professional and multi-disciplinary task force be set up to review the issues comprehensively;

4. the Medical Council and An Bord Altranais review and add to their current guidelines on selective non-treatment and treatment withdrawal;

5. local hospital protocols and guidelines on these issues be drawn up under the direction of hospital ethics committees in anticipation of such

\section{(108) ERYTHROMYCIN: A NOVEL USE IN THE ICU}

\section{P. Naughton, M. Griffin, K. Crowley.}

Department of Intensive Care, St. Vincent's Hospital, Dublin.

Enteral feeding has numerous well recognised advantages over parenteral nutrition. Stomach dysmotility is the commonest cause of failure to tolerate enteral feeding. Small intestinal motility and function tends to be maintained in septic and postoperative patients. The macrolide antibiotic erythromycin interacts with the motilin receptor, and similar to motilin, enhances stomach motility. It has been used successfully in the management of gastroparesis due to neuropathy, particularly secondary to diabetes.

We investigated the use of erythromycin in the noninvasive placement of nasojejunal feeding tubes in a group of 11 patients in whom conventional nasogastric feeding had failed. One gramme of erythromycin was administered intravenously over 25 minutes following which the nasojejunal tube was blindly advanced. A clockwise rotatory wrist movement was used to aid movement of the nasojejunal tip into the duodenum. A plain film of the abdomen was taken to determine tube position. The nasojejunal tube was successfully placed in the small bowel in 9 of 11 patients. All of these patients subsequently tolerated enteral feeding.

We feel that this is a useful technique and may allow continuation of enteral feeding in a significantly greater number of patients. Erythromycin analogues without antibiotic action will be available in the future.

\section{(109) ALLERGY TO CEPHALOSPORINS AND PENICILLINS}

M. Harnett, D. Moriarty

Department of Anaesthesia and Intensive Care Mater Misericordiae Hospital, Dublin 7.

In 1995 Anne reported that it was safe to administer cephalosporin antibiotics to penicillin allergic patients ${ }^{1}$. This begs the question it is safe to administer penicillin compounds to patients with a documented history of an allergic reaction to a cephalosporin?

A 79 yr old patient was admitted through the A\&E Department. She had been prescribed Cephalexin (Keflex) by her G.P. for a RTI. She had no previous history of drug allergy. Thirty minutes after ingestion of same she had become acutely dyspneoic and her tongue had become swollen. Adrenaline, chlorpheniramine and hydrocortisone were administered intravenously and a nasopharyngeal airway was required to relieve her upper airway obstruction.

Eight months later she represented to the A\&E Department. On this occasion she had been prescribed amoxycillin by her G.P. for a sore throat. Twenty minutes after taking same she developed lingual swelling, angiodema and was unable to swallow. The event was promptly terminated with intravenous adrenaline, chlorpheniramine and hydrocortisone.

The risk of penicillin allergy in a patient with a history of cephalosporin anaphylaxis is not known, because such patients are so rare $^{2}$. However it would seem prudent to steer clear of penicillin compounds in patients with a known history of cephalosporin allergy.

References

1. Anne, S, Reisman, R. E. Risk of administering cephalosporin antibiotics to patients with histories of penicillin allergy. Annals of Allergy, Asthma and Immunologv 74(2): 167-170, 1995 February. 2. Van Arsdel, P. P. Allergy to cephalosporins.

\section{OBSTETRICS / GYNAECOLOGY}

(110) IS GENETIC SCREENING NEEDED BEFORE TREATMENT WITH INTRACYTOPLASMIC SPERM INJECTION?

T. Barrett, S. McQuaid, D. Barton, R. Stallings, R. F. Harrison.

HARI Unit, Rotunda Hospital and Department of Cytogenetics and Molecular Genetics, Our Lady's Hospital for Sick Children, Crumlin.

Male infertility affects 5-7 per cent of men. Intracytoplasmic 
sperm injection (ICSI) is the optimal treatment for severe oligospermia. Furthermore testicular aspiration of sperm (TESA) allows males with congenital absence of the vas, deferens (CAVD) to undergo treatment with ICSI. Oligospermia and azoospermia are associated with cytogenetic abnormalities. CAVD is now known to be associated with mutations in the cystic fibrosis transmembrane conductance regulator (CFTR) gene.

Since July 1996, 138 male patients attending the Rotunda Hospital for treatment with ICSI have had chromosomal analysis. This included 8 men with CAVD who were screened for mutations in the CFTR gene.

Six patients (4.3 per cent) had an abnormal karyotype - 4 balanced Robertsonian translocations, 1 patient with a balanced reciprocal translocation and 1 patient with a sex chromosome aneuploidy. The incidence of Robertsonian and reciprocal translocation in the general population is 1 in 900 . Five (63 per cent) patients with CAVD have mutations in the CFTR gene.

Conclusion: Patients with oligospermia and azoospermia should have chromosomal analysis and genetic counselling prior to ICSI treatment.

Treating males with CAVD is increasing the incidence of CFTR mutations. Genetic screening and counselling is also essential for these patients.

\section{(111) RISK ASSESSMENT IN AN OBSTETRIC DAY CARE UNIT CORRELATION WITH OUTCOME}

\section{N. Collins, H. Higgins, P. Byrne.}

Department at Obstetrics and Gynaecology, Royal College of Surgeons in Ireland, Rotunda Hospital. Dublin 1.

The Rotunda Hospital day care unit was set up in 1993 as an alternative to hospital admission for pregnant women who develop non-proteinuric hypertension. Women are referred from the antenatal clinic if their diastolic blood pressure is between 90 and $100 \mathrm{mmHg}$ and there is no proteinuria. Following clinical assessment at the unit women are classified as either low or high risk. One thousand and eighteen women who attended the Rotunda Hospital daycare unit between September 1993 and August 1996 were evaluated.

The aim of the study was to correlate this risk with pregnancy outcome. High or low risk was correlated with the presence or absence of the outcome measures listed in the table.

$\begin{array}{lcccc} & \text { Sensitivity } & \text { Specificity } & \text { +ve. } & \text {-ve. } \\ \text { Gestational HT } & 34 & 72 & 24 & 81 \\ \text { Proteinuric HT } & 58 & 77 & 37 & 89 \\ \text { Diastolic >110 mm H g } & 60 & 78 & 37 & 90 \\ \text { CS/labour induced for HT } & 60 & 80 & 16 & 87\end{array}$

+ ve $=$ positive predictive value. $-v e=$ give predictive value $\mathrm{HT}=$ hypertension $. \mathrm{CS}=$ Caesarean section

The relatively low sensitivity values are a reflection of the progressive and unpredictable nature of pre-eclampsia. The high negative predictive values support our policy of avoiding hospital admission in low risk women.

\section{(112) INSTRUMENTAL DELIVERY AND PERINEAL} INJURY

M. Fynes, C. O'Herlihy, P. R. O Connell.

University College Dublin, National Maternity Hospital, Mater Misericordiae Hospital, Dublin.

Instrumental delivery (ID) is associated with significant postpartum maternal morbidity. The aims of the study were to determine the incidence of third degree perineal injury and impaired faecal continence following instrumental delivery. Prospective analysis of all patients who underwent instrumental delivery between June ' 96 - Jan ' 97 . $(n=560)$. All patients who sustained a third degree tear $(n=24)$, were assessed by symptom questionnaire. Parity was a significant factor with 20 per cent of primigravid versus 3 per cent of multigravid patients requiring instrumental delivery, $(\mathrm{P}<0.001)$. Twenty-one per cent had a failed ventouse forceps (FVF). Ninety-one per cent of instrumental deliveries required episiotomy ( $p<0.0001) ; 4$ per cent sustained a third degree tear of which 10 per cent complained of episodic frank faecal incontinence. The risk of third degree tear, ( 17 per cent) and impaired faecal continence (8.2 per cent), was greatest following FVF delivery $(\mathrm{P}<0.001)$.

Conclusion: The most significant risk factor for perineal injury and impaired faecal continence is FVF. When presented with failed ventouse this risk should be considered. Used alone forceps and ventouse have similar injury and incontinence rates.

\section{(113) OBSTETRIC ANAL SPHINCTER DISRUPTION AND THE OUTCOME OF PRIMARY REPAIR}

M. Fynes, A. Cahill, C. O'Herlihy, P. R. O'Connell. University College Dublin, National Maternity and Mater Misericordiae Hospitals, Dublin.

Anal sphincter disruption during childbirth is an important cause of postpartum maternal morbidity'.

The aim of our study was to determine prospectively the outcome of primary repair of recognised third degree tears in a large maternity unit.

Eighty-eight women ( 1 per cent) delivered at NMH over a 1 yr period to September 1996 underwent primary repair of a recognised third degree tear. All patients were reviewed 12-16 weeks postpartum with symptom questionnaire, anal manometry and anal endosonography.

Seventy-one per cent of patients reported altered faecal continence of whom 10 per cent had episodic frank faecal incontinence. Eighty-three per cent had a persistent defect on ultrasound and 96 per cent $(n=83)$ had abnormal manometry (squeeze $<20$ VSI $<0.75$ ).

Conclusion: Primary anal sphincter repair following vaginal delivery as currently practiced results in a high rate of persistent sphincter defects and postpartum alteration in faecal continence.

\section{Reference}

1. Sultan, A. H., Kamm, M. A., Hudson, C. N., Bartram, C.I. Third degree obstetric anal sphincter tears: risk factors and outcome of primary repair. BMJ. 94 Apr. 2; 308 (6933): 887.91.

\section{PAEDIATRICS/PERINATOLOGY}

(114) THE ROLE OF A NATIONAL REGISTER FOR SUDDEN UNEXPECTED DEATHS.

A. Cullen', M. Meehani' ${ }^{2}$, B. Kiberd², M. McDonald², T. Matthews'.

'Department of Paediatrics, University College Dublin, Temple Street, Dublin. ${ }^{2}$ National Sudden Infant Death Register, Temple Street, Dublin.

During the past 2 decades in Ireland, SIDS has received considerable public and medical attention. Yet it was not until 
1992, with the foundation of the National Sudden Infant Death Register, that comprehensive epidemiological data became available. With this information it has been possible to monitor the decline in SIDS and to look at possible changes in child care practices which could have impacted on this.

Detailed epidemiological data has been collected on all sudden unexpected deaths under the age of 2 since 1992.

The SIDS rate had dramatically declined from $1.9 / 1000$ to $0.7 / 1000$ in 1995 . The male predominance is still evident. There has been a loss in the seasonal variation of the time of death since 1993, a finding confirmed internationally. The majority of deaths still occur around 2 to 4 months of age ( 35 per cent). The socio-demographic profile of SIDS families demonstrates a marked predominance of families in the lower socio-economic groups, among the unemployed and in families with medical cards. The prevalence of the risk factors for SIDS in these families is also discussed.

Conclusion: The provision of accurate ongoing SIDS data is extremely valuable. Apart from providing information on the prevalence of risk factors, it also helps direct future research. A second noteworthy benefit is the provision of support services to bereaved families and professionals.

\section{(115) KAWASAKI DISEASE IN AN INFANT}

\section{N. Salim, R. Fitzsimons}

Department of Paediatrics, Tralee General Hospital.

Kawasaki disease (KD) is diagnosed by the presence of a number of clinical criteria (see below). Early treatment with intravenous immunoglobulins (IVIG) is said to prevent the development of coronary aneurysm. A 3 month infant presented with a history of irritability and chestiness. The GP had started Amoxil 3 days prior to admission. The day before admission he had a fever and a slight rash. On examination fever was $39.3^{\circ} \mathrm{C}$ and he had very red lips and loose stools.

$\begin{array}{lll}\text { Sign } & \text { KD Criteria } & \text { This Case } \\ \text { Fever Duration } & \text { 5D } & \text { 2D (?3D) } \\ \text { Muco- } & \text { Conjunctivitis } & \text { Absent } \\ \text { Cutaneous/ } & \text { Oral Mucosa } & \text { Red lips } \\ \text { Lymphnode } & \text { Periphery } & \text { Desquamation D15 } \\ \text { (4 out of 5) } & \text { Rash } & \text { mild truncal Dl } \\ & \text { Cervical } & \text { Absent }\end{array}$

The temperature was normal from D3-7. Platelet count rose to $1276 / \mathrm{cm} 3$ on D11. Coronary aneurysmal dilatation was noted on D16. It appears that young infants may not fulfill all the criteria for KD. This results in a delay in commencing IVIG, thereby increasing the likelihood of coronary aneurysms. This case suggests the need for a high index of suspicion together with a redefining of diagnostic criteria for the younger infant.

(116) NIROSCOPE MEASUREMENTS OF CEREBRAL HAEMOGLOBIN AND OXYGENATION CHANGES WITH SURFACTANT ADMINISTRATION

M. J. White, D. T. Tanaka, R. L. Auten, R. F. Goldstein, F. F. Jobsis, R. Goldberg.

Division of Neonatal Perinatal Medicine, Duke University Medical Center, Durham, North Carolina. 27710, USA.

Near infrared spectroscopy, a non-invasive method of monitoring cerebral oxygenation is based on the principle that near infrared absorption signals change with the relative oxygenation state of haemoglobin and cytochrome aa3. The study set out to explore whether changes in cerebral tHb (total haemoglobin), $\mathrm{HbO} 2$ (oxygenated haemoglobin), rHb (deoxygenated haemoglobin) and Cytaa 3 (oxygenated Cytochrome aa3) occur during surfactant administration.

Using the Niroscope Instrument (Van der Corp. Inc), we studied 5 surfactant administrations in 4 ventilated newborn infants aged 1-15 days, mean gestation 35.3 weeks (26-41 weeks), mean birth weight $2.8 \mathrm{~kg}(1.04-3.74 \mathrm{~kg}), 3$ studies on 2 patients with hyaline membrane disease and 2 studies on 2 patients with meconium aspiration syndrome. Transmitting and receiving optrodes fitted onto a holder were placed on the infant's forehead, whose eyes were shielded with opaque eyecovers and the infant's head covered by a dark sterile blanket to exclude light. Heart rate, pulse oximetry, respirations and blood pressure were monitored throughout the study period. Each surfactant dose was administered in 2-4 aliquots through the endotracheal tube via a measured feeding tube while the baby was monitored continuously by the Niroscope.

Following surfactant administration there were statistically significant increases in mean \pm SD $\mathrm{tHb}$ (Pre $-0.0076 \pm 0.0094$ vs Post $0.1310 \pm 0.0660 ; \mathrm{p}<0.002$ ) and mean \pm SD HbO2 (Pre $0.0053 \pm 0.0069$ vs Post $0.09992 \pm 0.0959 ; \mathrm{p}<0.05)$ using the Student's $t$ test. The respective pre and post values for mean \pm SD rHb $(-0.0022 \pm 0.0049$ vs $0.1481 \pm 0.3089)$ and mean \pm SD Cyt aa3 (-0.0011 \pm 0.0057 vs $0.0466 \pm 0.0773)$ failed to reach statistical significance.

These results suggest $\mathrm{tHb}$ and $\mathrm{HbO} 2$ increase following surfactant administration. The increase in the tHb together with no significant change in $\mathrm{rHb}$ are consistent with the notion that surfactant administration is associated with an increase in cerebral arterial blood flow rather than venous stasis. Such an increase may be damaging in infants $<1.5 \mathrm{~kg}$ with immature cerebral vascular autoregulation and may predispose to intraventricular haemorrhage.

(117) CARBONIC ANHYDRASE II DEFICIENCY, OSTEOPETROSIS AND ALLOGENEIC BONE MARROW TRANSPLANTATION

C. McMahon, O. P. Smith.

Department of Paediatric Haematology, National Children's Hospital, Harcourt Street, Dublin 2.

Autosomal Recessive Osteopetrosis is a rare disorder characterised by, abnormal bone remodelling, deficient haematopuiesis and neurological impairment. Onset is usually during infancy leading to death within the first decade of life. It is caused by a quantitative or qualitative defect in Osteoclass. Carbonic Anhydrase II (CAII) which plays a critical role in acid/ base homeostasis and osteoclast function, when deficient causes a variably severe syndrome of Osteopetrosis, Renal Tubular Acidosis (RTA) and cerebral calcification. It is reported mainly in Middle Eastern and Mediterranean families.

We report 2 related Irish families with clinically severe CAII deficiency. Both families have 2 homozygous children with nondetectable CAII levels. One family has 4 other children - 3 are unaffected hetrozygotes. A successful Bone Marrow Transplant (BMT) was performed in a 6 month old boy using his HLA compatible hetrozygous sister (CAII level 3.2 units/mg haemoglobun). DNA analysis now confirms a hetrozygous state 
with normal CAII levels $(8.3 \mathrm{u} / \mathrm{mg} \mathrm{Hb})$ There is resolution of his bone disease and impaired growth and development and his RTA shows improvement. We suggest BMT is a curative therapeutic modality for severe CAII deficiency, a condition hitherto felt to be poorly responsive to transplantation.

\section{RESPIRATORY}

\section{(118) PROTEASE CONTENT OF CIRCULATING} NEUTROPHILS FROM PATIENTS WITH CYSTIC FIBROSIS

\section{Costello, K. J. Russell, V. Keatings, S. Linnane,} M. X. FitzGerald, C. M. O'Connor.

Department of Medicine \& Therapeutics, University College Dublin \& St. Vincent's Hospital, Dublin.

It is recognised that in vivo 'priming' of neutrophils may contribute to their destructive potential in certain disease states including cystic fibrosis (CF). Several studies indicate that, during infection, inflammatory mediators can promote the production of more 'potent' neutrophils (containing higher quantities of elastase) during maturation in the bone marrow. The objective of this study was to assess the potency of circulating CF neutrophils with respect to levels of neutrophil elastase (NE), neutrophil collagenase (NC) and myeloperoxidase (MPO), $n=19$. CF patients with stable disease and $n=19$ age and sex matched non-CF controls were recruited to the study. Blood neutrophils were isolated and resuspended at a concentration of $3 \times 10^{6} \mathrm{PMN} / \mathrm{ml}$. Results (mean $\pm \mathrm{SEM}$ ) are shown in the following table:

$\begin{array}{llll}\text { Activity } & & \text { Controls } & \text { CF Patients } \\ \text { NE (mU) } & n=18 & 0.012 \pm 0.002 & 0.019 \pm 0.002 * \\ \text { NC }(\mathrm{U} / \mathrm{ml}) & \mathrm{n}=15 & 1.63 \pm 0.43 & 0.80 \pm 0.15 \\ \text { MPO }(\mathrm{mU}) & \mathrm{n}=19 & 0.015 \pm 0.003 & 0.008 \pm 0.002\end{array}$

Levels of active NE were significantly elevated in CF neutrophils compared to controls $\left({ }^{*} p=0.0325\right)$ whereas no significant difference was seen in either NC or MPO levels. This study suggests that CF neutrophils are primed in vivo to produce elevated levels of active NE but not of NC or MPO.

This work was funded by the Health Research Board.

\section{(119) CONSTITUTIVE ADHESION MOLECULE EXPRESSION ON PULMONARY VS UMBILICAL VEIN ENDOTHELIAL CELLS}

S. M. Davern, C. M. O'Connor, T. J. McDonnell. Department of Medicine \& Therapeutics, University College Dublin \& Department of Respiratory Medicine, St. Vincent's Hospital, Dublin.

Neutrophils adhere to endothelial cells (ECs) by interactions between the $\beta 2$ integrins on the neutrophil cell surface and cellular adhesion molecules expressed on the surface of the endothelial cell e.g. (intercellular adhesion molecule-1 (ICAM1)). Recent studies' suggest that that ICAM-1 expression on ECs from different organs may vary. The aim of this study is to examine constitutive ICAM- 1 expression on ECs from 3 different sources, human umbilical vein (HUVEC), human pulmonary artery (HPAEC), and human pulmonary microvascular (HPMVEC). All cell lines were labelled with fluorescent antibody to ICAM-1 and examined by FACS analysis. Results obtained are shown in the table:

$\begin{array}{lccc}\text { Cell Line } & \begin{array}{c}\text { Mean } \\ \text { \% ICAM-1 }\end{array} & \text { SEM } & \\ \text { HUVEC } & 4.06 & 3.16 & \mathrm{n}=3 \\ \text { HPAEC } & 12.75 & 1.93 & \mathrm{n}=3 \\ \text { HPMVEC } & 22.18 & 7.62 & \mathrm{n}=3\end{array}$

Results suggest that pulmonary ECs constitutively express more ICAM-1 than umbilical vein ECs. This would support the argument that endothelial cells from different sources differ in relation to their expression of ICAM-1.

\section{Reference}

1. Panes, J. et al. Regional differences in the constitutive and induced ICAM-1 expression in vivo. Am. J. Physiol. 269 (Heart Circ. Physiol. 38): H1955-H1964, 1995.

This work was sponsored by the Health Research Board Ireland.

\section{(120) AN IN VITRO MODEL OF NEUTROPHIL MIGRATION ACROSS HUMAN PULMONARY ENDOTHELIAL MONOLAYERS}

A. J. Mackarel, M. X. FitzGerald, C. M. O'Connor. Department of Medicine \& Therapeutics, University College Dublin \& St. Vincent's Hospital, Dublin.

To date in vitro studies of transendothelial neutrophil (PMN) migration have used the umbilical vein as a source of human endothelial cells (HUVEC). Evidence of variations in endothelial cell characteristics depending on vascular origin ${ }^{1}$ suggests that endothelial cells of pulmonary origin would be more representative than HUVEC in in vitro studies of pulmonary inflammation. The aim of this study was to establish a model of PMN migration across monolayers of pulmonary artery endothelial cells (HPAEC). HPAEC were grown to form a confluent monolayer on microporous membrane filter inserts coated with human type IV collagen. Migration of PMNs (isolated from human venous blood) across the monolayer in response to n-formylmethionylleucyl-phenylalanine (fMLP) was assessed following a $3 \mathrm{~h}$ incubation at $37^{\circ} \mathrm{C}$. Results (Table) indicated that, while $\sim 40$ per cent of PMN in control assays adhered to HPAEC monolayers, migration through the monolayer was minimal. On stimulation with flMLP, migration of up to 74 per cent of added PMN was observed at the optimal fMLP concentration of $10^{-8} \mathrm{M}$. The model described here provides an improved system for in vitro studies of pulmonary inflammation.

\begin{tabular}{lccc} 
& \multicolumn{3}{c}{ Number of PMN (\% of total) } \\
Non-adherent & Adherent & Migrated \\
Control & $57.49 \pm 8.14$ & $42.50 \pm 8.15$ & $0.05 \pm 0.10$ \\
flMLP $\left(10^{-8} \mathrm{M}\right)$ & $8.09 \pm 6.95^{*}$ & $18.06 \pm 10.35^{*}$ & $73.82 \pm 14.71^{*}$
\end{tabular}

\section{Reference}

1. Sage, H., Pritzl, P., Bomstein, P. Secretory phenotypes of endothelial cells in culture. Arteriosclerosis 1981; 1(6): p. 427-42.

This work was funded by the Health Research Board.

\section{(121) FARMERS LUNG IN IRELAND (1983-1994) REMAINS AT A CONSTANT LEVEL}

D. S. McGrath, J. Kiely, B. Cryan, C. P. Bredin.

Department of Respiratory Medicine and Medical Microbiology, Cork University Hospital, Cork, Ireland.

A current and prospective study was undertaken by the Department of Respiratory Medicine and the Medical 
Microbiology Department at the Cork University Hospital to investigate 1. the epidemiology of Farmers Lung (FL) in Ireland (pop. 3.5 million), with special reference to the South Western Region of this country (pop. 536,000) and 2. to assess any relationship between the prevalence/incidence of Farmers Lung with climatic factors (obtained from the National Meteorological Office) in South West Ireland between 1983 and 1994. Hospital discharges with a primary diagnosis of Farmers Lung, or a secondary diagnosis were used to assess incidence and prevalence respectively. Percent positive serological results per annum for Farmers Lung antibodies (ie Thermoactinamycetes Vulgaris and Micropolyspora Faeni) in the South West were also used as markers of prevalence. This was called the FL index. Farmers Lung incidence remained constant $(0.74$ cases per 100,000 pop. in $1983,0.55$ cases in 1994 , with a peak number of cases 3.73 in 1986) throughout the 11 years studied, in the South West region. There was a significantly similar relationship between the incidence $(p<0.0002)$ and prevalence $(p<0.005)$ of Farmers Lung in the South West region when compared with the whole of Ireland. The other epidemiological marker used (FL index) also remained constant at 21 per cent positive in 1983 to 22 per cent positive in 1994. A significant relationship was found between total rainfall (in millimetres) each summer (June-August inclusive) and Farmers Lung incidence and prevalence over the following year $(\mathrm{p}<0.005)$. No significant relationship, however, was found between hrs of sunshine during that same period and these indices. The persistence of Farmers Lung in Ireland at a constant level therefore suggests that the working environment and dairy farm practices have remained unchanged.

\section{(122) MATRIXMETALLOPROTEASES EXPRESSION BY ALVEOLAR MACROPHAGES IN EMPHYSEMA}

\section{R. O'Driscoll, G. A. Finlay, M. X. FitzGerald,}

C. M. O'Connor.

Department of Medicine \& Therapeutics, University College Dublin \& St. Vincent's Hospital, Dublin.

Release of matrixmetalloproteinases (MMPs) by alveolar macrophages (AMs) has been implicated in the pathogenesis of emphysema. To date, however, the identity of these MMPs and whether or not their expression is directly up-regulated in emphysema has not been examined. The aim of this study was to assess MMP gene expression in AMs from emphysema patients. AMs isolated from bronchoalveolar lavage (BAL) specimens of 10 male emphysema patients (4 smokers; 6 exsmokers) and 10 matched control subjects were analysed for interstitial collagenase, gelatinase $A$, gelatinase $B$ and macrophage metalloelastase (MME) gene expression using semiquantitative reverse transcriptase-polymerase chain reaction (RT-PCR). Interstitial collagenase was expressed by AMs from all 10 emphysema patients, but only 2 controls $(p<0.0005)$. Similarly, gelatinase B mRNA levels were elevated in AMs from the emphysema group compared to the controls $(\mathrm{p}<0.0005)$. In the case of gelatinase $A$ and MME, however, no significant difference in expression was noted between the patient and control groups. These results suggest that increased synthesis of interstitial collagenase and gelatinase $B$, but not gelatinase $A$ or MME, by AMs may contribute to the alveolar matrix degradation which characterises emphysema.

This work was funded by the Health Research Board.
(123) RESPONSIVENESS OF CIRCULATING NEUTROPHILS FROM CYSTIC FIBROSIS PATIENTS TO STIMULATION

K. J. Russell, J. McRedmond, N. Mukherji, V. Keatings, M. X. Fitzgerald, C. M. O'Connor.

Department of Medicine, University College Dublin and St. Vincent's Hospital, Dublin 4.

Neutrophil migration involves the sequential rolling of neutrophils (using L-selectin) and firm adhesion to the endothelium (mediated by Mac-1). Neutrophil stimulation triggers shedding of L-selectin and upregulation of the Mac-1 complex (CD18/CD11b). Recent studies suggest circulating neutrophils in patients with acute lung disease may be hyperresponsive to stimuli. The aim of this study was to investigate whether circulating neutrophils from acutely infected cystic fibrosis (CF) patients were similarly hyperresponsive when stimulated with neutrophil agonists. Blood samples $(n=13)$ from 11 acutely infected $C F$ patients $(6 \mathrm{~F}, 5 \mathrm{M}), 16$ stable $\mathrm{CF}$ patients $(8 \mathrm{~F}, 8 \mathrm{M})$ and 15 matched controls $(8 \mathrm{M}, 7 \mathrm{~F})$ were analysed for surface expression of L-selectin and Mac-1. While no significant difference in the basal levels of adhesion molecules was observed, upon stimulation with interleukin-8 (Il-8) and n-formylmethionylleucylphenylalanine (fMLP), acute CF patients shed significantly less L-selectin than both stable CF patients $(p<0.05)$ and controls $(p<0.01)$. Significantly less L-selectin was also shed by neutrophils from stable CF patients compared to controls $(\mathrm{p}<0.05)$. This difference in $\mathrm{L}$-selectin shedding indicates that circulating neutrophils in $\mathrm{CF}$ patients have a "dampened" response to stimulation with respect to $\mathrm{L}$ selectin, and are less likely to shed this adhesion molecule from their surface upon stimulation, especially during acute infection.

This work was funded by the Health Research Board of Ireland.

\section{(126) EFFICACY OF PULMONARY REHABILITATION IN PATIENTS WITH CHRONIC OBSTRUCTIVE PULMONARY DISEASE (COPD)}

D. V. Collins, M. F. O'Driscoll, M. Connor, D. Concannon, T. J. McDonnell.

Departments of Respiratory Medicine and Physiotherapy, St. Michael's Hospital, Dun Laoghaire and St. Vincent's Hospitals, Dublin.

The efficacy of pulmonary rehabilitation in end stage respiratory disease has been recently demonstrated in a series of controlled trials. However, pulmonary rehabilitation has not become established in the management of COPD in Ireland. We recently established and evaluated the initial benefits of a pulmonary rehabilitation programme.

Twenty-three patients with documented evidence of chronic airflow obstruction were recruited into a multi-disciplinary programme combining exercise and education. Baseline spirometry, diffusion, inspiratory muscle strength (PiMax), exercise tolerance as measured by the Shuttle [walking] and endurance [treadmill] tests were assessed on entry. Quality of life was evaluated by the Chronic Respiratory Disease Questionnaire (CRDQ) and Breathing Problems Questionnaire (BPQ) and dyspnoea was assessed by the Borg dyspnoea scale. Measurements were repeated at completion of the 8 week programme.

Ten patients to date have completed the programme and been 
reassessed. Significant improvement in dyspnoea scores, in the walking and endurance tests scores and quality of life was noted. Changes in pulmonary function (Pimax and FEV1) were not statistically significant. These results demonstrate that patients enrolled into a pulmonary rehabilitation programme demonstrate considerable improvement in functional capacity and increased quality of life.

\section{DERMATOLOGY}

\section{(127) LYMPHOMATOID PAPULOSIS - AN UNCOMMON PARADOXICAL ERUPTION}

P. Lenane, C. O Keane, D. O Sullivan, S. O Loughlin. Mater Misericordiae Hospital, Eccles Street, Dublin 7.

Labelled as "rhythmic paradoxical eruption" lymphomatoid papulosis is a chronic disorder of recurring crops of inflammatory haemorrhagic papules typically on trunk and limbs, progressing over 8 week period to necrosis. Clinically benign, histologically malignant, the self healing lesions resuit in scarring. Histology shows a dense dermal infiltrate of atypical cells, neutrophils and eosinophils. Immunochemistry confirms the former to be CD 4+, T helper CD30+ cells. We describe 6 patients who presented over a $10 \mathrm{yr}$ period with classical clinical and histological findings but with some atypical clinical features. Whether this condition is benign or malignant abinitio is debatable. Ten per cent progress to malignancy particularly mycosis fungoides, lymphoma. Treatments include low dose Methotrexate, PUVA. Detailed follow up is required.

Reference

Lynn Karp, D., Horn, T. Lymphomatoid papulosis JAAD Vol. 30 No. 3 March 1994 p. 379-395.

(128) SOLAR URTICARIA - CLINICAL FEATURES, DIAGNOSIS AND TREATMENT

D. B. McKenna, P. McCann, G. M. Murphy.

Departments of Dermatology and Photobiology, Beaumont and Mater Hospitals, Dublin.

Solar urticaria is a very uncommon idiopathic photodermatosis that may severely restrict outdoor activity and impair quality of life. It is an IgE mediated hypersensitivity reaction characterised by pruritus, erythema, wheals and rarely anaphylaxis that develops within minutes of exposure to ultraviolet or visible light radiation. We describe the clinical presentation, diagnosis and treatment of 8 patients, 6 female, 2 male, age 20-57 yr with a history of Solar Urticaria for 2-5 yr. The diagnosis was confirmed by Monochromator Light Testing to UVB, UVA and visible light wavelengths. Urticarial wheals developed immediately after the test exposure. The Minimal Urticarial Dose was defined for each patient at the wavelengths tested. Photosensitivity was restricted to UVB in 1/8, UVA+ visible in $1 / 8$, UVA+UVB in $1 / 8$ and throughout the range in $5 /$ 8 patients. Treatment with antihistamines alone failed. Desensitisation using ambient sunlight to induce tolerance partially improved symptoms in $5 / 7$ patients. All patients improved with repeated UVA exposure. Addition of Psoralen desensitised 3/4 patients. Two patients did not return for followup. Solar urticaria is frequently misdiagnosed. Diagnosis should be confirmed by phototesting. Identification of precipitating wavelengths may influence management. Treatment involves antihistamines, graded exposure to sunlight or phototherapy to induce tolerance. Plasma exchange may prove beneficial in severe cases.

\section{(129) CHEST SYNDROME ASSOCIATED WITH PRIMARY BILIARY CIRRHOSIS (PBC)}

\author{
R. Callan, M. Young.
}

Adelaide Hospital, Dublin.

A $72 \mathrm{yr}$ old female presented to a Cryotherapy clinic for treatment of hand warts. She was noted to have multiple telangiectasia on her hands. On direct questioning she gave a history of Raynauds phenomenon, a hard nodule on the right hand, dysphagia and tightening of the skin of the fingers. Anticentromers antibody was negative but antimitochondrial antibody was positive with a titre 1:160. Pyruvate dehydrogenase antibodies were also present in the serum which was suggestive of primary biliary cirrhosis. Serum alkaline phosphatase, gamma glutamyl transferase and aspartate transaminase were elevated and a liver biopsy confirmed stage 4 PBC.

The association of CREST syndrome and PBC was first reported in 1971. In a recent study of over 500 patients with PBC at the Mayo Clinic it was found that up to 4 per cent of patients with PBC had 1 or more features of CREST syndrome but less than one half of one per cent showed all of the features of CREST syndrome. The association of PBC with CREST syndrome is a poor prognostic factor.

\section{(130) BORRELIA BURGDORFERI AND MORPHOEA}

\author{
S. P. Lenane, C. O. Keane, F. Powell.
}

Regional Dermatology Centre, Mater Hospital, Dublin 7.

The spirochette causing lyme disease Borrelia Burgdorferi has been suggested as an aetiological agent of morphea.

Forty patients, (27 female) average age $39 \mathrm{yr}$ with clinical morphea, duration 3 months to $12 \mathrm{yr}$ were studied. Six patients had multiple lesions. Three had linear morphea, 2 coup de sabre and 2 atrophoderma. One patient had lesions consistent with erythema chronicum migrans.

Histology consistent with morphea was noted in 13 samples. Elisa tests for borrelia antibody titres ( 27 patients) were positive in 4 cases ( 15 per cent). This included 1 with erythema chronicum migrans, 1 with atrophoderma and 2 having classical morphea lesions. These results indicate a possible relation between morphea and borrelia burgdorferi infection. PCR which detects and amplifies borrelia. DNA would be a more specific and sensitive test. We anticipate further studies relating to this. Reference

Stanislan, A. B., Rufli, T. Localized scleroderma associated with Borrelia Burgdorferi infection. JAAD Vol. 29 N2 P1 P190-196.

\section{GENETICS}

(131) NO ASSOCIATION BETWEEN 5HT2A/Hpa II POLYMORPHISM AND IRISH FAMILIAL SCHIZOPHRENICS

Z. Hawi, R. Straub', K. Kendler ${ }^{1}$, D. Walsh ${ }^{2}$, M. Gill. Department of Psychiatry and Genetics, Trinity College

Dublin. 'Department of Psychiatry, University of Virginia, Richmond. ${ }^{2}$ Health Research Board, Dublin.

Serotonin receptor and transporter genes are potential candidate genes for mental disorders such as depression, anxiety, 
and schizophrenia. Drugs, such as Clozapine, which block $5 \mathrm{HT}_{2 \mathrm{~A}}$ receptors are effective in the treatment of schizophrenia. Recently, genetic association studies have demonstrated a higher frequency in schizophrenics of allele 2 of a HpalI polymorphism within the $5 \mathrm{HT}_{2 \mathrm{~A}}$ gene. This has also been demonstrated in a European multi-center study consisting of 571 cases and 631 controls. However, there are conflicting findings from American and British samples. In the present study we examine 247 familial schizophrenic cases and 249 general population controls. In contrast to the published findings, a non-significant decrease in the frequency of the genotype 2-2 was observed in the patient population ( 35.2 per cent $v$ controls 38.9 per cent) which was accompanied by a similar increase in the genotype 1-2 (patients 51 per cent $v$ controls 45.5 per cent). Allele frequencies similarly do not differ between patient and control populations. In conclusion, the Hpa II polymorphism at the $5 \mathrm{HT}_{2 \mathrm{~A}}$ receptor is not associated with schizophrenia in the Irish population. It is possible that the reported association were false. In particular the size of the studied Japanese population was small $(n=62)$ and the significance was weak. In addition the European multi-center samples were ethnically heterogeneous.

\section{(132) A PROTECTIVE EFFECT OF APOLIPOPROTEIN E e2 ALLELE ON DEMENTIA IN DOWNS SYNDROME}

J. Tyrrell, M. Cosgrave, J. McPherson, Z. Hawi, B. Lawlor, M. Gill.

Departments of Psychiatry and Genetics, Trinity College, Dublin.

The classical neuropathological features of Alzheimer's Disease (AD) are present in all Down's Syndrome (DS) over the age of 35. Possession of an extra copy of chromosome 21 leading to over expression of the amyloid precursor protein is believed to be responsible. Possession of the ApoE e4 allele confers increased risk of $A D$ whereas the ApoE e2 allele is protective. In normal centenarians the frequency of the ApoE e4 allele is reduced, suggesting an effect of ApoE on longevity. We previously reported a similar finding in an elderly DS population. (e4 frequency in DS and controls was 11.5 per cent $-v 19.2$ per cent, Chi square $8.33, p=0.004$ ). In this study we compare the frequency of ApoE alleles in a group of 31 DS individuals with dementia to 60 age matched DS individuals without dementia. ApoE e2 frequencies were significantly lower in the demented group ( 0 per cent $-\mathrm{v}-8.3$ per cent, Fisher exact 1-tailed $P=007)$ and ApoE e4 frequencies were higher (17.7 per cent $-\mathrm{v}-10.8$ per cent) although this did not reach statistical significance. In summary, ApoE e 2 is protective against the development of dementia in Down's Syndrome.

\section{HAEMATOLOGY}

(133) DEVELOPMENT OF A CD44 ELISA METHOD - A MOLECULE IMPLICATED IN THE DISSEMINATION OF NON-HODGKIN'S LYMPHOMA

C. Hurley', S: Fanning ${ }^{1}$, H. O'Shea', M. Madden'2.

'Medical Sciences Section, Regional Technical College, Cork. ${ }^{2}$ Department of Haematology, Mercy Hospital, Cork.

The process of lymphocyte extravasation takes place in specialised postcapillary High Endothelial Venules.
Lymphocytes adhere to endothelium in order to exit the circulation, this mechanism is facilitated by lymphocyte adhesion molecules, in particular the adhesion molecule CD44. CD44 is an integral membrane glycoprotein expressed on several cells, including lymphocytes (B\&T), epithelial tissue \& mesenchymal tissue amongst others.

The objective of this study was to develop an Enzyme Linked Immunosorbent Assay (ELISA) which could rapidly \& reliably measure serum CD44 levels. Initially, a commercially available ELISA kit (Bender Med Systems, Austria) was used to measure CD44 levels in a wide variety of patients with lymphoma, leukaemia and other haematological disorders $(n=54)$. However, the precision data and the percentage recovery of the controls demonstrated the unreliability of the kit in measuring serum CD44 (S.D. $=0.26 \mu \mathrm{g} / \mathrm{ml}$, C.V. $=20$ per cent). Therefore, to facilitate the development of a standard CD44 assay, it was necessary to provide a source of standard protein. This was done by subcloning and expressing the CD44 gene.

Complete CD44 cDNA was amplified by the Polymerase Chain Reaction (PCR), using modified primers. The amplified cDNA was then subcloned into the expression vector pCal-c. This construct was then transformed into Escherichia coli BL21(DE3)pLys cells from which CD44 was produced. This provided a reliable and accurate source of CD44. Using this protein as a standard, the previous assay was replicated and the results compared:

\section{IMMUNOLOGY}

\section{(134) IN VITRO TECHNIQUE FOR QUANTITATION OF SALMONELLA ADHERENCE TO INTESTINAL EPITHELIAL CELLS}

A. Alwan, L. Malone, T. Deignan, J. Kelly*, C. O'Farrelly. Education and Research Centre, St. Vincent's Hospital,

Dublin \& *Dublin Institute of Technology, Kevin Street, Dublin.

Salmonella spp are responsible for a spectrum of gastrointestinal infections in animals as well as humans. Adhesion of bacteria to intestinal epithelial cells is an important initial pathogenic step.

In this study, two novel in vitro techniques were developed to examine the adherence of $S$. typhimunum to epithelial cells

Technique I (Cytospin): Epithelial cells were incubated in suspension with $S$. typhimurium $\left(1 \times 10^{3}\right.$ bacteria per cell) and centrifuged Adherent bacteria per cell were counted microscopically. The average number of bacteria attached to a single epithelial cell was 17.

Technique 2 (ELISA): mouse intestinal epithelial cells ( $1 \mathrm{x}$ $10^{5}$ cells per well) were immobilised onto microtiter plates. $S$. typhimurium $\left(1 \times 10^{8}\right.$ bacteria per well were overlaid. Specific anti Salmonella antibody was added followed by substrate. The results were expressed as optical density (Table I). The adhesion of varying bacterial concentrations $\left(1 \times 10^{5}-1 \times 10^{10}\right)$ was studied and the experiment was repeated 3 times.

Bacterial number per $\mathrm{ml}$ added to epithelial cell

$\begin{array}{llllll} & 0 & 1 \times 10^{5} & 1 \times 10^{7} & 1 \times 10^{9} & 1 \times 10^{11} \\ \text { OD } & & & & & \\ \text { Mean } & 235.5 & 299.1 & 572.6 & 1152.1 & 1302.88 \\ \text { SD } & 79.6 & 56.4 & 130.9 & 386.7 & 286.4\end{array}$

The results of these studies indicate that Salmonella adherence to intestinal epithelial cell can be visualised using cytospin technology and quantitated using ELISA based system. 
(135) HEN EGG YOLK PREVENTS ADHERENCE OF SALMONELLA TO INTESTINAL EPITHELIAL CELLS IN VITRO

A. Alwan, T. Deignan, J. Kelly, C. O'Farrelly.

Education and Research Centre, St. Vincent's Hospital, Dublin \& Dublin Institute of Technology, Kevin Street, Dublin.

Salmonella infection in cattle has significant economic and public health implications. Bacterial adherence to small intestinal epithelial cells is an essential first step in the infection and may provide a useful therapeutic target

In vivo studies have shown that hen egg yolk with high titre of anti-Salmonella antibodies (prepared by repeat immunisation of hens against Salmonella) may prevent Salmonellosis. It is thought that egg yolk inhibits bacterial adherence to epithelial cells in the gut.

The aim of this study was to evaluate the ability or hen egg yolk to prevent the attachment of Salmonella to intestinal epithelial cells using enzyme linked immunosorbent assays (ELISA) and cytospin centrifugation techniques.

Bacteria were incubated with egg yolk from control and immunised hens. Adherence to intestinal epithelial cells was determined using ELISA and cytocentrifugation. Results, presented as mean and SD of 3 experiments are shown in Table I.

$\begin{array}{lccc} & \text { no egg yolk } & \begin{array}{c}\text { Bacterial adherence } \\ \text { Control } \\ \text { egg yolk }\end{array} & \begin{array}{c}\text { Immunised } \\ \text { egg yolk }\end{array} \\ \text { Cytospin } & 17.4 \pm 2.78 & <3 & <3 \\ \text { ELISA } & 825 \pm 15.8 & 267 \pm 21 & 335 \pm 24\end{array}$

These results indicate that hen egg yolk significantly inhibits adherence of Salmonella to intestinal epithelia cells. Immune and control eggs were equally efficacious suggesting that the mechanism or inhibition is not immunoglobulin related.

\section{(136) TRAUMA IN MOUSE SPLEEN T-LYMPHOCYTES IS ASSOCIATED WITH AN INCREASED EXPRESSION OF CD28}

D. J. Beddy, S. E. Calvano, M. D. McCarter, J. M. Daly. Department of Surgery, New York Hospital-Cornell Medical Centre, 525 East 68th Street, New York, NY 10021.

Trauma causes a change in T-lymphocyte cell populations. Serious injury in mice reduces production of IL-2, IFN-G and IL-12 with an associated shift to the T-helper-2 lymphocyte phenotype (Th2). There is increased production of IL-4 and IL10 which inhibit the T-helper-l lymphocyte phenotype (Thl) ${ }^{1}$. We examined the effects of femur fracture with haemorrhage on spleen T-lymphocyte surface receptors at 1 and 7 days post injury.

Seven days post trauma there was a reduction in the percentage (mean \pm SEM) of trauma splenocytes $(n=5)$ compared to control $(\mathrm{n}=5)$ staining for $\mathrm{CD} 3(40.54 \pm 0.69$ per cent trauma, 46.18 \pm 1.04 per cent control, $P<0.01, t$ test), CD4 (23.87 \pm 0.65 per cent, trauma, $26.37 \pm 0.42$ per cent control, $P<0.05)$ and CD8 (13.38 \pm 0.42 per cent trauma, $17.02 \pm 0.96$ per cent control, $P<0.01$ ). In contrast the percentage of splenocytes positive for CD28 was increased by trauma $(59.21 \pm 2.84$ per cent trauma, $47.98 \pm 2.91$ per cent control, $\mathrm{P}<0.05$ ). One day post trauma there were no significant differences between trauma $(n=5)$ and control $(n=5)$ splenocytes.
CD28 costimulation is necessary for the development of the Th2 cell. In the absence of CD28 costimulation T-cells default to the Thl subset ${ }^{2}$. We demonstrate reduction of splenic Tlymphocytes 7 days post trauma associated with increased expression of CD28.

\section{References}

1. O'Sullivan, S., Lederer, J., Horgan, A., Chin, D., Mannick, J., Rodrick M. Annals of Surgery 1995; 222: 482-492.

2. Webb, L, Feldmann, M. Blood 1995; 86: 3479-3486.

\section{(137) DOUBLE NEGATIVE T LYMPHOCYTES IN ACUTE CELLULAR REJECTION FOLLOWING LIVER TRANSPLANTATION}

O. Crosbie, P. Costello, J. Hegarty, C. O'Farrelly.

The Liver Unit and Education and Research Centre, St. Vincent's Hospital, Elm Park, Dublin 4.

Conventional $\mathrm{T}$ lymphocytes include $\mathrm{T}$ helper and cytotoxic populations which express CD4 or CD8 molecules respectively. Recently a novel population of $T$ cells which lack expression of these surface markers has been described (CD3+, CD4-, CD8-) and termed Double Negative T cells (DN). DN cells have been shown to have cytolytic activity and hence may have an important functional role in transplant rejection. The aim of this study was to quantitatively assess changes in peripheral blood DN lymphocytes following liver transplantation and to monitor the change in this population during episodes of acute cellular rejection (ACR). Ten patients had serial measurements (total of 115) performed from the time of liver transplant and over 8 consecutive weeks, during which time 12 episodes of biopsy proven ACR occurred in 8 patients. DNs were analysed using 3 colour flow cytometric analysis with CD3-PERCP, CD4-FITC and CD8-PE and calculated as a percentage of the total CD3+ lymphocyte count.

The mean baseline DN count for the 10 patients was 2.4 , range $0.22-3.7$. There was a significant increase $(p=0.04)$ in DNs to 9.1 , range $3.35-26.0$ in association with $11 / 12$ episodes of ACR. No significant changes occurred in the CD4+ and CD8+ populations during periods of ACR.

Conclusion: Murine studies have suggested that DNs may arise from extrathymic sites including the liver. The expansion of the $\mathrm{DN}$ population in association with $\mathrm{ACR}$ provides evidence for local and specific immunological responses occurring during acute cellular rejection.

\section{(138) EFFECT OF ORGAN PRESERVATIVE AND DISRUPTIONS ENZYMES ON LYMPHOCYTE VIABILITY AND SURFACE MARKERS}

M. Curry*, S. Norris*, D. Doherty*, J. E. Hegarty, C. O. Farrelly*.

Education and Research Centre* and Liver Unit, St. Vincent's Hospital, Dublin.

Recent interest in human hepatic lymphocytes has resulted in the need for enzymatic disruption for the isolation of these cells. Moreover, the normal human liver tissue is obtained from adult donor liver which is preserved in University of Wisconsin fluid ( $U$ of $W$ ) prior to transplantation. The possible effects of these solutions on cell surface glycoproteins could have important implications for functional and phenotypic studies.

The aim of the study was to examine the effect of organ 
preservative and proteolytic enzymes on lymphocyte viability and expression of surface molecules.

Lymphocytes $\left(1 \times 10^{6} / \mathrm{ml}\right)$ were incubated at $4^{\circ} \mathrm{C}$ in $\mathrm{U}$ of $\mathrm{W}$ and RPMI for 2,6 and $24 \mathrm{~h}$ and at $38^{\circ} \mathrm{C}$ in a cocktail of proteolytic enzymes (Collagenase and DNase) for 20 minutes. Viability studies and flow cytometric analysis was carried out following incubation.

Lymphocyte viability remained unchanged (100 per cent) following incubation in RPMI or U of $W$ over $24 \mathrm{~h}$ or in proteolytic enzyme solution for 20 minutes. Relative percentages of lymphocyte subpopulations (CD3, CD4, CD8) also remained unchanged. However, both treatments did diminish the intensity of surface marker expression as determined by the Median fluorescence intensity $(p<0.01)$.

Conclusion: These results indicate that commonly used methods for preserving liver tissue prior to transplantation and for isolating hepatic lymphocytes do not affect cell viability. Changes in intensity of surface marker expression do not affect phenotypic analysis but may have subtle implications for functional studies.

\section{(139) CHARACTERISATION OF UTERINE LYMPHOCYTE SUBPOPULATIONS INDICATES A UNIQUE IMMUNOLOGICAL ENVIRONMENT}

L. Flynn, J. Carton, B. Byrne, *P. Kelehan, **C. O'Herlihy, C. O'Farrelly.

Education \& Research Centre, St. Vincent's Hospital, Dublin.

Department of Pathology, National Maternity Hospital,

Dublin. **Department Obstetrics \& Gynaecology, UCD.

Lymphocytic populations of the female reproductive tract are of particular interest as specific tolerance of the semiallogenic fetus is required for successful pregnancy. The initial aim of this study is to investigate the mononuclear subpopulation in normal non-pregnant endometrium. Endometrial tissue was obtained by sharp curettage from 4 women with regular menstrual cycles, and single cell suspensions suitable for flow cytometry were prepared using chelating and reducing agents. Cell suspensions were then labelled with monoclonal antibodies specific for CD3, CD4, CD8, CD56+16. HLA-DR and TCR $\gamma \delta$

Cell yields ranged from $0.8-3.60 \times 10^{6} \mathrm{cells} / \mathrm{ml}$, (mean 2.11 $\mathrm{x} 10^{6}$ cells $/ \mathrm{ml}$ ). In a lymphocyte gate drawn using FSC/SSC, several populations were identified and expressed as a percentage of the gate:

\begin{tabular}{|c|c|c|}
\hline CELL TYPE & MEAN & RANGE \\
\hline $\begin{array}{l}\text { NK-Cells CD56+ and/or CD16 } \\
\text { B-Cells CD } 19^{+}\end{array}$ & $\begin{array}{l}21 \% \\
0.95 \%\end{array}$ & $\begin{array}{l}12.06-38.53 \% \\
0.15-3.15 \%\end{array}$ \\
\hline T-Cells CD3 ${ }^{+}$ & $18.83 \%$ & $16.36-22.83 \%$ \\
\hline
\end{tabular}

The T-cell (CD3+) population was further analysed demonstrating the following subpopulations. Results are expressed as a percentage of $\mathrm{CD} 3+$ cells:

\begin{tabular}{|c|c|c|}
\hline CELL TYPE & MEAN & RANGE \\
\hline $\mathrm{CD}_{3}{ }^{+} \mathrm{CD} 4{ }^{+}$ & $35.16 \%$ & $26.29-49.5 \%$ \\
\hline $\mathrm{CD}^{+}{ }^{\mathrm{CD}} 8^{+}$ & $75.59 \%$ & $56.39-90.86 \%$ \\
\hline $\mathrm{CD} 3+\mathrm{TCR} \gamma \delta^{+}$ & $2.60 \%$ & $0.74-3.82 \%$ \\
\hline $\mathrm{CD}^{+}{ }^{+} \mathrm{CD} 56^{+}$and/or CD $16^{+}$ & $6.43 \%$ & $5.2-7.12 \%$ \\
\hline $\mathrm{CD}^{+}{ }^{+} \mathrm{HLA}-\mathrm{DR}^{+}$ & $30.37 \%$ & $22.62-41.32 \%$ \\
\hline
\end{tabular}

This pilot study demonstrates a unique uterine lymphocyte profile, suggestive of a specific local immune system. Significant populations of classical NK cells, T-cells expressing NK markers and activated T-cells in the endometrium are suggestive of specific immunosurveillant and immunoregulatory functions.

\section{INFECTIOUS DISEASE/GU MEDICINE}

\section{(142) AIDS TO COMPLIANCE IN HIV POSITIVE PATIENTS}

S. Clarke', C. Merry', A. O'Leary², M. Ryan², F. Mulcahy'. ${ }^{1}$ Department of G.U. Medicine, St. James's Hospital,

Dublin 8. '2Department of Clinical Pharmacy, St. James's Hospital, Dublin.

We previously reported a compliance rate of 61 per cent ( 89 per cent in homosexual males and 24 per cent in IVDU) in HIV positive patients attending St. James's Hospital, Dublin. Poor patient understanding of the prescribed therapy was found to significantly affect compliance. We prospectively studied the effect of introducing aids to compliance in these patients from 1 st January to 30th June 1996. All patients attending the service were counselled by the doctor and pharmacist as to the indication for and potential side effects of the medication. This was reiterated at every subsequent visit. Patients were given medication charts, patient information leaflets and dosettes. To determine the compliance rate, we documented medication prescribed and dispensed to each patient. Patients were interviewed to determine adherence to, ability to recognize and understand the prescribed medication. We report an overall compliance rate of 72 per cent ( 91 per cent in homosexual males and 35 per cent in IVDU). We suggest that spending time counselling patients and introducing aids to compliance may significantly increase compliance rates particularly in certain patient groups.

\section{(143) HEPATITIS C VIRUS GENOTYPES - A THREE YEAR STUDY}

A. Conroy, G. Kaminski, A. Higgins.

Virus Reference Laboratory, University College Dublin, Dublin 4.

Hepatitis $\mathrm{C}$ virus is now classified into 6 major genotypes, with further subtypes within these. While there is no agreed nomenclature of these variants, we refer to types 1-6 as suggested by Simmonds et al ${ }^{1}$. There is increasing evidence that infecting genotypes may influence clinical outcome and response to therapy.

The aim of this study was to determine which Hepatitis $\mathrm{C}$ genotypes and subtypes are prevalent in an Irish population.

Genotypes were identified using restriction fragment length polymorphism (RFLP) analysis of a 251 base pair polymerase chain reaction (PCR) product. This allowed identification of the 6 genotypes based on size and migration of the resulting fragments on a 5 per cent Metaphor ${ }^{\mathrm{TM}}$ agarose gel. These genotypes were subtyped by further restriction enzyme analysis as described by Smith et $a^{2}$. Subtypes $1 a / 1 b, 2 a / 2 b$ and $3 a / 3 b$ can be distinguished using this method. In this study 1200 samples were analysed over a $3 \mathrm{yr}$ period to determine their hepatitis $\mathrm{C}$ genotype.

Five genotypes (1-5) were shown to be present in the Irish population Genotype 1 was the most prevalent ( 64 per cent) followed by Type 3 (31 per cent) Type 2 ( 4 per cent). There were 6 Type 4 and 1 Type 5 infections detected. Of a total of 125 Type $1 \mathrm{~b}$ specimens 47 ( 38 per cent) were subtype $1 \mathrm{a}$ and 78 (62 per cent) were subtype $1 \mathrm{~b}$. Of a total of 21 Type 3 specimens 20 ( 95 per cent) were subtype $3 \mathrm{a}$ and 1 was subtype $3 \mathrm{~b}$.

This study has shown that Hepatitis C genotypes 1,2,3,4 and 
5 and subtypes $1 a / 1 b$ and $3 a / 3 b$ are present in Ireland, with genotype 1 and subtype $1 \mathrm{~b}$ being the most common.

\section{References}

1. Simmonds P. et al. J. Gen. Virol. 1993, 74: 2391-2399.

2. Smith, D. et al. J. Gen. Virol. 1995, 76: 1749-1761.

\section{(144) GCSF AS ADJUNCTIVE THERAPY IN HIV} DISEASE

L. Cormican', M. Ryan², C. Merry'1, F. Mulcahy'. 'Department. of G.U. Medicine, St. James's Hospital, Dublin 8. ${ }^{2}$ Department of Clinical Pharmacy, St. James's Hospital, Dublin.

GCSF is commonly used in the management of disease or drug induced neutropaenia. The aim of the study was to examine the effectiveness, safety and tolerability of GCSF in HIV infected patients. We retrospectively reviewed the medical charts of 24 HIV infected patients who received GCSF over an 18 month period from January 1995 to June 1996. Of the 24 patients, 4 had HIV associated neutropaneia, 3 had neutropaenia related to opportunistic infection, 17 had drug induced neutropaenia. All patients achieved a satisfactory response within 3-5 days i.e. neutrophils $>1.0$. Withdrawal of myelosuppressive therapy was not required in any patient. Eight episodes of bacteraemia and 1 episode of fungaemia were documented in a total of 6 patients on concurrent therapy with GCSF. Twenty-one of 24 patients reported flu like symptoms not warranting discontinuation of GCSF. Of the 12 patients on GCSF maintenance 9 successfully self administered the agent, 1 had poor technique despite adequate training, I declined training and 1 was unable to self administer due to poor vision. The cost of GCSF during the period analyzed was $£ 200,000$.

\section{(145) HIV VIRAL LOAD TESTING FOR MONITORING} THERAPY

M. Crean, A. Conroy, F. Mulcahy*, G. Sheehan**, G. Kaminski.

Virus Reference Laboratory, University College Dublin, Dublin 4.

*Department of Genito-Urinary Medicine, St. James's Hospital, Dublin 8.

**Departments of Infectious Diseases, Beaumont and Mater Hospitals, Dublin.

Recent developments in molecular virology have permitted the development of a new technique to detect and quantify circulating HIV. The quantitation of HIV RNA in plasma (viral load) directly reflects the number of virus particles present and has been shown to be an important prognostic marker of HIV disease progression, and a measure of the response of infection to therapy.

The aim of this presentation is to review our experience of viral load testing in the Virus Reference Laboratory between July 1996 and January 1997. Plasma specimens (896) from HIVinfected patients have been tested using the Roche Amplicor HIV I Monitor assay. This is a reverse transcriptase PCR assay for the quantitation of HIV viral RNA.

Our results show that in many, but not all, patients viral RNA levels decrease after anti-retroviral therapy but this response may not be sustained.
In conclusion viral load testing is an effective way of monitoring the effects of therapy and is a good predictor of the long term prognosis of HIV infection.

(146) HEPATITIS A OUTBREAK MANAGEMENT: A COMBINED PUBLIC HEALTH AND VIRUS REFERENCE LABORATORY APPROACH

D. De La Harpe*, G. Sayers. Eastern Health Board (*now at Midland Health Board)

J. Connell, S. Dooley, M. Curley.

Virus Reference Laboratory, University College Dublin, Belfield, Dublin 4.

Traditionally the management of outbreaks of Hepatitis A has been based on the administration of immune-globulin and attention to basic hygiene (enteric precautions). More recently, studies indicate that the use of vaccine may be an effective way to limit outbreaks.

Because of the perceived risk of parenteral transmission of viruses there is growing reluctance to receive immune-globulin. Prior to the administration of vaccine it is considered cost effective to identify those immune or susceptible to Hepatitis A. The logistics, expense and acceptability of drawing blood restricts this type of study.

The investigation of hepatitis $A$ outbreaks using samples collected noninvasively, such as saliva, has been well documented. Such studies usually depended upon a radioimmunoassay (RIA) technique which is restricted to laboratories with the necessary containment facilities. This presentation describes the public health practitioner led management of an outbreak of Hepatitis A in a family and a local institution attended by a family member. Salivary samples, collected using a simple foam swab, were tested by classl specific enzyme immunoassays (EIAs) developed at the Virus Reference Laboratory.

This collection and testing strategy was shown to be a valuable technique to identify immune subjects and to monitor the antibody status of susceptible individuals. The close collaboration between public health officials and the VRL enabled advice to be given expeditiously regarding the requirement tor specific preventive interventions.

\section{(147) A STUDY OF HEPATITIS G VIRUS PREVALENCE IN SELECTED POPULATIONS}

G. Kaminski, J. Connell, C. Keating, A. Conroy, S. Dooley Virus Reference Laboratory, University College Dublin, Dublin 4.

A significant number of cases of infectious hepatitis have unknown aetiology despite the availability of reliable diagnostic tests for Hepatitis A, B, C, D and E. A newly discovered Flavivirus, termed Hepatitis $\mathrm{G}$ or GBV-C agent, has recently been isolated and has been found to infect humans.

This study investigates the prevalence of this virus in selected populations to determine the clinical significance of HGV infection.

In the absence of a commercially available antibody test, we have developed a polymerase chain reaction (PCR) method to detect HGV viral RNA in serum. After amplification the PCR product is detected using a chemiluminescent method. 
Specimens from 226 individuals including intravenous drug abusers, organ transplant recipients and patients with clinical evidence of hepatitis were tested for HGV infection.

Results show that HGV RNA was detected in 39 (17 per cent) subjects. The incidence of HGV infection was significantly higher amongst intravenous drug users compared to transplant recipients. There was no evidence of $\mathrm{HGV}$ infection in those patients with clinical history of hepatitis.

This study has established the presence of Hepatitis G Virus in Ireland. No HGV was detected in patients with clinical symptoms of hepatitis and this may be attributable to either poor specimen quality, clearance of the virus or that morbidity was due to some other factor.

\section{(148) EVALUATION OF PCR BASED ASSAYS FOR THE DETECTION OF M. TUBERCULOSIS IN CLINICAL SPECIMENS}

T. Smith', M. Maher ${ }^{1}$, M. Glennon', M. Dawson ${ }^{1}$, G. Martinzzo2, E. Turchetti², S Marcolini², Ú Ní Rian³, M. Cormican ${ }^{3}$, J. Flynn ${ }^{3}$, A. Kearns ${ }^{4}$.

'The National Diagnostics Centre, BioResearch Ireland, Galway, Ireland. ${ }^{2}$ Raggio Italgene S.r.l. Pomezia, Rome, Italy.

${ }^{3}$ University College Hospital Galway, Galway, Ireland.

${ }^{4}$ Public Health Laboratory, Newcastle upon Tyne, United Kingdom.

Human tuberculosis remains a leading infectious disease worldwide resulting in 3 million deaths annually. Because of the limitations of the current laboratory based diagnostic methodologies there is a requirement for a rapid assay for the diagnosis of tuberculosis. We describe a PCR based assay (B/ RI C-TRAK ${ }^{\mathrm{TM}}$ MTB) that targets the amplification of the 16S/ 23S rRNA intergenic spacer from members of the $M$. tuberculosis complex in clinical samples. The assay incorporates an internal standard control to monitor the level of PCR inhibition in each specimen. We report on a 2 centre comparative evaluation of B/RI C-TRAK ${ }^{\mathrm{TM}}$ MTB assay and the AMPLICOR $^{\mathrm{TM}}$ MTB (Roche) assay system. A total of 142 samples were tested, which included a range of clinical specimens (e.g. sputum, BAL, CSF). These results, together with those results obtained by culture and acid fast staining of the specimens will be presented. While the results obtained with the 2 PCR assay systems were comparable, culture remains the most sensitive method for detecting $M$. tuberculosis in clinical specimens. PCR may represent a more rapid detection method in certain clinical situations and optimisation of sample preparation and amplicon detection will improve the assay sensitivity.

\section{(149) COMBINATION THERAPY WITH SAQUINAVIR- RITONAVIR FOR HIV INFECTION}

C. Merry', M. Ryan', D. Back ${ }^{3}$, M. Barry ${ }^{3}$, F. Mulcahy'. 'Department of G.U. Medicine, St. James's Hospital, Dublin 8. ${ }^{2}$ Department of Clinical Pharmacy, St. James's Hospital, Dublin. ${ }^{3}$ Department of Pharmacology \& Therapeutics, University of Liverpool.

Combination anti-retroviral therapy has been shown to be superior to monotherapy in treatment of HIV. The Protease Inhibitors (PIs) are a new class of anti-retroviral agents which act by inhibiting the post translational processing of gag and gag pol polyprotein precursors. This results in the production of non infectious virions. All PIs to date (i.e. Ritonavir, Saquinavir and Indinavir) are both metabolised by, and potent inhibitors of Cytochrome p450 3A4. Therefore therapy with multiple PIs may elevate drug levels and cause toxicity. However PI combinations would be particularly beneficial in those patients with advanced HIV disease who are already heavily anti-retroviral experienced. We performed pharmacokinetic studies on 7 patients; initially on triple therapy including Saquinavir, then on quadruple therapy including Saquinavir and Ritonavir. We found a 30 fold variation in Saquinavir levels in patients on triple therapy. There was also a 20 fold increase in Saquinavir levels in the presence of Ritonavir. Based on this we created a modified dosing regimen of Saquinavir $200 \mathrm{mg}$ od and ritonavir $600 \mathrm{mg}$ bd. We are currently following a cohort of patients on this regimen. All patients have had significant improvement in disease markers without significant toxicity.

\section{MICROBIOLOGY}

(151) PULSED-FIELD GEL ELECTROPHORESIS INVESTIGATION OF AN OUTBREAK OF SALMONELLA TYPHIMURIUM

G. Corbett-Feeney, U. Ni Riain.

Department of Medical Microbiology, University College Hospital, Galway.

Studies were carried out for epidemiological purpose on isolates of Salmonella typhimurium from 31 patients involved in an institutional outbreak.

Methods employed included antibiograms, phage typing and pulsed-field gel electrophoresis (PFGE).

Phage typing has been the method of choice in epidemiological studies of outbreaks of Salmonella typhimurium. In this study the additional use of PFGE established a link between strains which may have been missed if phage typing alone had been employed.

\section{(152) EFFECT OF INOCULUM ON ANTIBIOTIC} SENSITIVITY TESTING BY THE STOKES METHOD

M. Cormican, D. Hughes, U. Ni Riain, G. Corbett-Feeney. Department of Bacteriology, University College Galway.

Antibiotic sensitivity testing is an important function of clinical microbiology laboratories. The modified Stokes comparative disk diffusion method is widely used in Ireland and Great Britain. The method permits categorisation of a clinical isolate as sensitive (S), intermediate (I), or resistant (R). Categorisation is based on comparison of the zone of inhibition of growth of the test strain and the zone of inhibition of growth of a control strain around an antibiotic disk. We have conducted a pilot study of the effect of variation in the inoculum used in testing on the size of the zone of inhibition and on the categorisation as S, I or R. Bacterial strains were clinical and type strains of E.coli. Testing was performed in triplicate on Diagnostic Sensitivity Test agar. Antibiotic disks were ampicillin (10ug), co-amoxyclav (30ug), cephradine (30ug), cefotaxime (30ug), ciprofloxacin (5ug) and gentamicin (10ug). The radius of zone diameter was measured to the nearest $\mathrm{mm}$. For all 6 antimicrobials the mean radius of the zone of inhibition of the 
control strain 10418 increased by $2-3 \mathrm{~mm}$ as the inoculum density decreased. A similar trend was noted in the test strains. For some strains categorisation varied between $S$ and I with variation in inoculum density.

\section{(153) IN VITRO ADHERENCE OF CLOSTRIDIUM DIFFICILE TO INTESTINAL EPITHELIAL CELLS}

D. Drudy, A. Alwan, L. Fenelon, C. O'Farrelly. Education and Research Centre, St. Vincent's Hospital, Dublin 4.

Clostridium difficile is recognised as a causative pathogen of antibiotic associated diarrhoea and pseudomembranous colitis in humans. Little is known about adherence of this organism to intestinal epithelial cells, the initial step in pathogenesis. In this study we examined adherence of $C$. diffcile to cells of mouse duodenum, small intestine and colon. Adherence to human colonocytes was also studied. Intestinal epithelial cells were isolated using EDTA, incubated with $C$. difficile, washed and centrifuged onto slides using a Shandon cytospin. Slides were fixed and stained by Gram's stain and examined microscopically for adherence of bacteria to epithelial cells. Cells from 3 mice and 2 humans were studied. Results were expressed as the number of adhering bacteria/cell $\pm S D$

C. diffcile bound to mouse intestinal epithelial cells with maximum adherence to colonocytes. The organism also adheres consistently to human colonocytes (table I).

\section{Table I}

Bacterial Adherence Duodenal E.C. Small Intestinal Colonic E.C. to

Mouse E.C. $( \pm S D)$

$3.3 \pm 3.4$

$2.2 \pm 13$

E.C.

$2.0 \pm 2.1$

$3.2 \pm 1.5$
$0.4 \pm 0.5$

$5.0 \pm 1.9$

$3.3 \pm 2.2$

$4.2 \pm 1.5$

Human E.C. $( \pm S D)$

ND

ND

$3.2 \pm 1.0$

$4.2 \pm 1.5$

Adherence of $C$ diffcile to intestinal epithelial cells prior to colonization and infection is therefore likely and a potential target for preventative therapy.

\section{(154) THE INCIDENCE OF METHICILLIN RESISTANT STAPHYLOCOCCUS AUREUS CARRIAGE AMONGST RESIDENTS IN LONG-STAY CARE FACILITIES AND IN AN ORTHOPAEDIC REHABILITATION HOSPITAL}

C. McDonagh, A. McGeary, B. Boyle, A. Murray, R. Hone. Department of Microbiology, Mater Misericordiae Hospital, Dublin 7.

Methicillin resistant Staphylococcus aureus (MRSA) has become a significant pathogen in Irish hospitals since the 1970's. The incidence of carriage in community facilities in Ireland is unknown. This study assessed the incidence of MRSA colonisation and infection in residents of 2 long-stay care facilities (LSCF) for the mentally handicapped, and of patients in an orthopaedic rehabilitation hospital (ORH).

Two hundred and twelve residents from LSCF and 85 patients from ORH had swabs taken from the following sites: anterior nares, throat, axilla, groin, perineum, wounds and abrasions. These were cultured for MRSA by conventional and enrichment techniques. All isolates were bacteriophage typed.

Three ( 1 per cent) residents of the LSCF were MRSA carriers, whilst 15 (10.5 per cent) patients in ORH were colonized and 6
(7 per cent) had infected wounds or abrasions. There was no evidence of cross infection.

Patients in ORH are transferred from acute general hospitals throughout the country following treatment for serious trauma. The incidence of MRSA carriage in these patients is likely to reflect the prevalence of MRSA in these hospitals. Identification and treatment of carrier sites amongst these patients would minimise the pool of MRSA carriers discharged into the community.

Although, in this study, MRSA carriage amongst residents was low, high standards of hygiene are required in all LSCF to prevent MRSA spread.

\section{(155) DETECTION OF E. COLI O157 IN WATER SUPPLIES}

F. O Cochlain, M. Cormican, J. Flynn.

Department of Bacteriology, University College Galway.

E.coli strains which produce a cytotoxin active against cultured Vero cells (Verocytotxoic E.coli) are important human pathogens. Most such strains express a specific lipopolysaccharide $\mathrm{O}$ antigen, $\mathrm{O} 157$. These strains are associated with gastroenteritis, haemorrhagic colitis and haemolytic uraemic syndrome. The most commonly recognised source of infection is meat, in particular minced beef products. It has recently been suggested that water supplies may also be a source of infection. Water samples from group water schemes and private water supplies in Counties Galway, Mayo and Roscommon were examined for the presence of Escherichia coli 0157. Three local water sources (Galway public water supply, Galway canal, and the Barna coastal amenity area) were also monitored over a 6 week period. A variety of culture methods for selective culture and detection of sorbitol non-fermenting E.coli strains were used. Sorbitol non-fermenting strains were confirmed as E.coli by API $20 \mathrm{E}$ and the O157 antigen detected by latex agglutination. E coli $\mathrm{O} 157$ was detected on one occasion in samples from 3 separate public water supplies in rural areas. These findings suggest that domestic water supplies may be a source of infection with E.coli $\mathrm{O} 157$ in rural areas.

\section{(156) STUDIES OF LIPOPOLYSACCHARIDE FROM CAMPYLOBACTER JEJUNI 0:41 STRAINS FOLLOWING AN OUTBREAK OF GUILLAIN-BARRÉ SYNDROME IN SOUTH AFRICA.}

M. Prendergast, A. Lastovica*, A. Moran. Department of Microbiology, University College, Galway and *Department of Medical Microbiology, Red Cross Children's Hospital, Capetown, South Africa.

Anti-ganglioside antibodies are induced in some patients upon Campylobacter jejuni infection and may contribute to the development of the neurodegenerative disease, Guillain-Barre syndrome (GBS). The core oligosaccharide of lipopolysaccharide (LPS), an outer membrane surface molecule of certain $C$. jejuni strains $(0: 2,0: 4,0: 19)$ have been found to mimic gangliosides. We investigated antibody and ligand crossreactivities between gangliosides and LPS extracted from $3 C$. jejuni 0:41 strains from individuals who developed GBS in a South African outbreak and a $C$. jejuni isolate from a patient with enteritis alone. Rabbit antisera raised against the GBS 
strains reacted with all the 0:41 LPS and with $C$. jejuni $0: 2$ and 0:19 LPS but not with 0:4 LPS. These antisera also reacted with gangliosides GM 1 and A-GM 1. Anti-GM 1 and anti-asialo GM 1 antibodies cross reacted with all 0:41 LPS, including LPS from the enteritis patient and with $0: 2$ and $0: 19$ LPS but not with $0: 4$ LPS. The ligands (cholera-toxin, a GM 1 ligand and peanut agglutinin, a GalB 1-3GalNac ligand) bound to all 0:41 LPS and also to 0:2 LPS. In addition, cholera-toxin bound $0: 19$ and $0: 4$ LPS. Immunoabsorption results confirmed GM 1 relatedness. Since the 0:41 LPS shares cross reactive epitopes with GM 1 including LPS of the enteritis patient, molecular mimicry and the presence of identical epitopes in LPS and gangliosides is not alone sufficient to explain the pathogenesis of GBS. Other factors e.g. host and/or bacterial factors also maybe involved in the development of the disease.

\section{ONCOLOGY}

\section{(157) INDIVIDUAL VARIATION IN RESPONSE OF HUMAN UROTHELIUM TO RADIATION \\ C. Mothersill, K. O'Malley, J. Harney, D. Murphy, C. Seymour. \\ Dublin Institute of Technology, and Beaumont Hospital, Ireland, Manchester Royal Infirmary, U.K.}

Uroepithelium was cultured from the normal ureters or bladders of 250 normal individuals and 25 cancer bearing individuals to assess individual variation in response to a carcinogen. The cultures were exposed to radiation and left to grow for 14 days, then fixed and stained for growth control. proteins. Extent of growth and of necrosis or apoptosis was also recorded. Three different response sub-types were identified. For each type the low radiation dose response was similar and acute but the groups varied considerably in their ability to induce a survival response to doses above $0.5 \mathrm{~Gy}$. Type I was resistant to radiation, induced anti-apoptosis proteins and showed low levels of necrosis. This type accounted for more than 60 per cent of the normal patient, all the smokers and all the tumour bearing individuals. Types 2 and 3 had a sensitive response with high induction of apoptosis and high levels of necrosis at all radiation doses, It is likely that these different response are genetically determined but the sectoring of smokers to type I suggests that environmental factors may be involved in determining response possibly through deregulation of apoptosis control pathways.

\section{(158) DETERMINATION OF THE ONCOGENIC POTENTIAL OF HUMAN PAPILLOMA VIRUSES ISOLATED FROM SKIN LESIONS}

D. P. O'Connor, E. W. Kay, M. Leader, G. M. Murphy. Molecular Oncology Laboratory, Beaumont Hospital, Dublin 9.

Human papillomaviruses (HPV) are the causative agents of the ubiquitous benign tumours known commonly as warts. Cervical "high-risk" types, e.g, HPV16/18 have long been associated with malignant conversion. The association is founded upon the frequent detection of HPV DNA in cancerous lesions, and the ability of oncogenes from "high-risk" types to transform cells in culture. Although HPV are the most common virus to infect human skin, they have largely been overlooked as aetiological agents of skin cancer Recent evidence suggests that, in the case of skin cancers, exceptional circumstances such as a genetic predisposition or allograft transplantation (particularly renal or cardiac), may allow viral infection to result in malignancy. The aim of this study is to elucidate the various viral types present in a variety of skin lesions and to correlate viral type with lesion type. Total DNA was extracted from warts and squamous cell carcinomas. Degenerate Polymerase Chain Reaction (PCR) was used to amplify a $45 \mathrm{CI}$ base pair region of the viral $\mathrm{Ll}$ gene, which was subsequently cloned and sequenced. A homology search of a HPV database revealed that all of the warts were positive for HPV(HPV2/10/and 57 predominantly and one case of HPV 17). Of the tumours analysed, all but one demonstrated HPV specific bands after PCR, and the viral types found all belonged to a group generally associated with an inherited genetic disorder (epidermodysplasia verruciformis (EV)) and previously shown to be involved in malignant conversion. One novel viral type was discovered which was also related to $\mathrm{EV}$-associated $\mathrm{HPV}$.

\section{(159) THYROID STATUS AS A PROTECTIVE FACTOR IN BREAST CANCER OUTCOME}

P. P. A. Smyth, S. G. Shering, M. T. Kilbane, D. F. Smith, E. W. M. McDermott, N. J. O'Higgins.

Endocrine Laboratory, Department of Medicine \&

Therapeutics and Department of Surgery (St. Vincent's Hospital), University College, Dublin.

Alterations in thyroid volume and thyroid peroxidase autoantibody (TPO.Ab) positivity have been demonstrated in breast cancer. The purpose of this study was to investigate if these observations contributed to outcome in breast cancer. Thyroid volume was measured by ultrasound and TPO.Ab by a highly sensitive radioimmunoassay using $0.3 \mathrm{U} / \mathrm{ml} \mathrm{MRC}$ Standard $65 / 93$ as the upper limit of the reference range. TPO.Ab positivity had a significant protective effect in 145 breast cancer patients available for follow up (median 3.45 years), both in terms of disease-free (56 per cent compared to 73 per cent at 5 yr, relative risk $R R=1.91, p=0.032)$ and overall $(80$ per cent compared to 91 per cent at $5 \mathrm{yr}, \mathrm{RR}=3.42, \mathrm{p}=0.009$ ) survival. This enhanced survival was not additive to that previously recorded when thyroid volumes were $<9.4 \mathrm{ml}$ or $>18.8 \mathrm{ml}$.

In contrast, a highly significant protective effect was observed when TPO.Ab were $\geq 0.3 \mathrm{U} / \mathrm{ml}$ in patients with intermediate $(9.4-18.8 \mathrm{ml})$ thyroid volumes (disease-free survival 36 per cent compared to 65 per cent at five $y r ; R R=9.12$, $\mathrm{p}=0.001$ ) and overall survival ( 54 per cent compared to 93 per cent at 5 yr $(R R=2.51, p=0.004)$. Thus underlying thyroid autoimmunity appears to contribute to improved outcome in breast cancer. 


\section{PATHOLOGY/CYTOLOGY}

(160) SEMINAL $\alpha$-GLUCOSIDASE DISCRIMINATES BETWEEN NORMAL AND ABNORMAL EPIDIDYMAL FUNCTION

D. Cannon, D. Powell.

Department of Endocrinology, Mater hospital, Dublin.

Measurement of seminal proteins that originate in the accessory sex glands may give an index of testicular function. One protein, $\alpha-1,4$-glucosidase (E.C.3.2.1.20) originates in the epididymis and its measurement may help in the investigation of epididymal dysfunction.

Our purpose was to determine if $\alpha$-glucosidase could be used to: (a) diagnose the etiology of azoospermia and (b) test for epididymal dysfunction in men in infertile relationships

$\alpha$-glucosidase was measured (EPISCREEN, MICROM U.K.) in sperm free seminal plasma and recorded as $\mathrm{mU} / \mathrm{ml}$.

In semen post vasectomy, enzyme levels were very low (12$14 \mathrm{mU} / \mathrm{ml}$ ). Azoospermic semen ranged from $12-35 \mathrm{mU} / \mathrm{ml}$ and 59 per cent of samples had similar levels to the vasectomised group. These patients were diagnosed with blocked ducts, undescended testes and past radiation therapy. The remaining 41 per cent ( 8 patients) had higher levels, 5 of whom had exposure to chemotherapy. In samples from men in infertile relationships, enzyme activities ranged from $13-70 \mathrm{mU} / \mathrm{ml}$. Ten per cent of specimens had enzyme activities in the vasectomised range.

We found no relationship between sperm counts and $\alpha$-glucosidase activity.

In conclusion, low $\alpha$-glucosidase indicates epididymal pathology with possible fertility implications. Low levels in association with azoospermia indicates blocked ducts or permanent epididymal damage. In addition, we propose a lower discriminatory level for $\alpha$-glucosidase for the detection of epididymal dysfunction than that indicated by the manufacturer of the reagents.
(161) A COMPARATIVE STUDY OF LIVER DISEASE

ACTIVITY IN ANTI-D AND BLOOD TRANSFUSION

RECIPIENTS INFECTED WITH CHRONIC HEPATITIS C VIRUS INFECTION

M. Sheehan*, J. Hogan*, M. Whelton, E. Kenny-Walsh, C. T. Doyle.

Department of Histopathology* and Gastroenterology/

Hepatology, Cork University Hospital, Wilton, Cork.

The aim of this study was to compare disease activity in 2 patient groups with chronic hepatitis $\mathrm{C}$ virus ( $\mathrm{HCV}$ ) liver disease. The study population included 15 patients infected with HCV via contaminated anti-D immunoglobulin received in 1977 and 15 patients believed to have acquired HCV infection via blood transfusion. Patients were age matched.

Tru-cut biopsy of liver was obtained from each patient using a Menghini needle. Liver tissue was formalin fixed, stained with H\&E, Pcrls, PAS \pm diastase, Massons trichrome and reticulin. Liver disease activity was assessed histologically using the International scoring system ${ }^{1}$ which separately assesses and scores necroinflammatory disease activity (grade) and architecture (stage) i.e. semi-quantitative. Accordingly the 2 patient groups were compared for the following parameters: piecemeal necrosis, confluent necrosis, spotty necrosis/ apoptosis, portal inflammation and architecture. Statistical analysis using the non-parametric paired t-test showed a statistically significant difference between the 2 groups for piecemeal necrosis $(p=0.006)$ and stage $(p=0.001)$. Although the study population is small, our findings indicate that there is a significant difference in necroinflammatory disease activity and architectural changes between the 2 groups, with greater histological abnormality seen in blood transfusion recipients. We suggest this may be due to differences in viral load at the time of infection, or infection with different viral subtypes in the 2 patient populations.

\section{Reference}

1. Ishak et al. Histological grading and staging of chronic hepatitis. J. Hepatology 1995; 22: 696-699. 